LA-14030

Approved for public release;

distribution is unlimited.

MCNPX Model/Table Comparison

Ideas That Change the World 
Edited by Lisa Rothrock, Group IM-1

Prepared by Tamara Hallman, Plus Group

Los Alamos National Laboratory, an affirmative action/equal opportunity employer, is operated by the University of California for the United States Department of Energy under contract W-7405-ENG-36.

This report was prepared as an account of work sponsored by an agency of the United States Government. Neither the Regents of the University of California, the United States Government nor any agency thereof, nor any of their employees make any warranty, express or implied, or assume any legal liability or responsibility for the accuracy, completeness, or usefulness of any information, apparatus, product, or process disclosed, or represent that its use would not infringe privately owned rights. Reference herein to any specific commercial product, process, or service by trade name, trademark, manufacturer, or otherwise does not necessarily constitute or imply its endorsement, recommendation, or favoring by the Regents of the University of California, the United States Government, or any agency thereof. The views and opinions of authors expressed herein do not necessarily state or reflect those of the Regents of the University of California, the United States Government, or any agency thereof. Los Alamos National Laboratory strongly supports academic freedom and a researcher's right to publish; as an institution, however, the Laboratory does not endorse the viewpoint of a publication or guarantee its technical correctness. 
LA-14030

Issued: March 2003

\section{MCNPX Model/Table Comparison}

John S. Hendricks

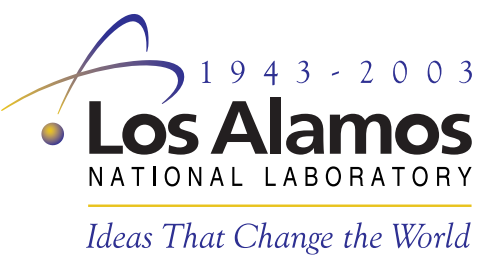





\section{CONTENTS}

Page

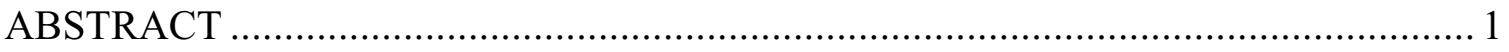

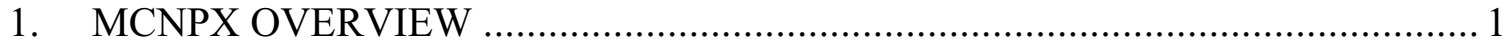

1.1. MCNPX 2.3.0 Features Not Found in MCNP4C3 ........................................ 2

1.2. MCNP4C3 Features Not Found in Earlier MCNPX Versions ........................... 3

1.3. MCNPX Capabilities Provided after the MCNP4C/MCNPX Merger ............... 3

1.4. MCNPX Mix-and-Match Capability ……................................................. 4

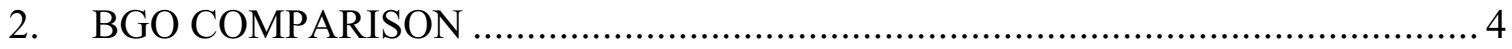

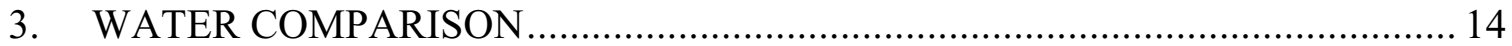

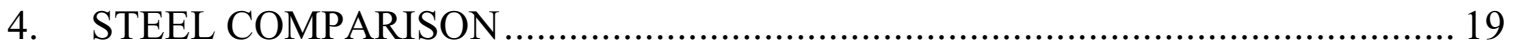

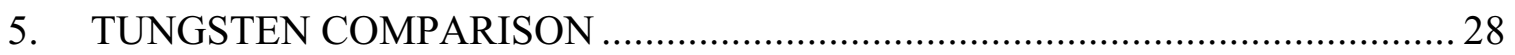

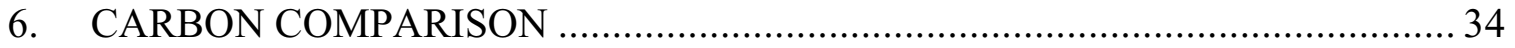

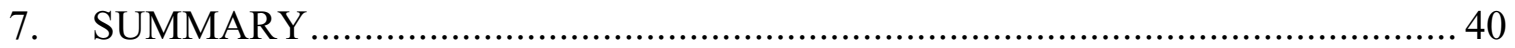

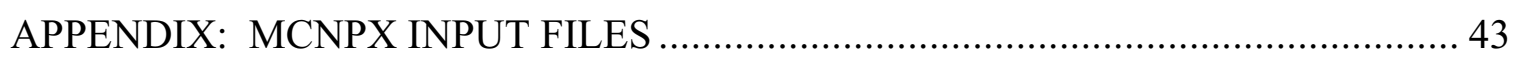

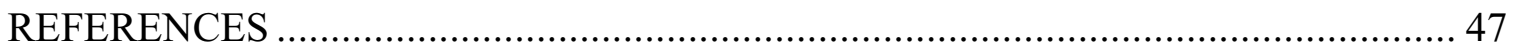




\title{
MCNPX MODEL/TABLE COMPARISON
}

by

John S. Hendricks

\begin{abstract}

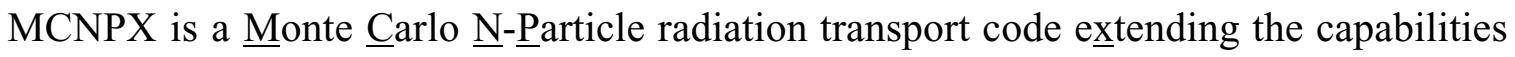
of MCNP4C. As with MCNP, MCNPX uses nuclear data tables to transport neutrons, photons, and electrons. Unlike MCNP, MCNPX also uses (1) nuclear data tables to transport protons; (2) physics models to transport 30 additional particle types (deuterons, tritons, alphas, pions, muons, etc.); and (3) physics models to transport neutrons and protons when no tabular data are available or when the data are above the energy range (20 to $150 \mathrm{MeV}$ ) where the data tables end. MCNPX can mix and match data tables and physics models throughout a problem. For example, MCNPX can model neutron transport in a bismuth germinate (BGO) particle detector by using data tables for bismuth and oxygen and using physics models for germanium. Also, MCNPX can model neutron transport in $\mathrm{UO}_{2}$, making the best use of physics models and data tables: below $20 \mathrm{MeV}$, data tables are used; above $150 \mathrm{MeV}$, physics models are used; between 20 and $150 \mathrm{MeV}$, data tables are used for oxygen and models are used for uranium.
\end{abstract}

The mix-and-match capability became available with MCNPX2.5.b (November 2002). For the first time, we present here comparisons that calculate radiation transport in materials with various combinations of data charts and model physics. The physics models are poor at low energies $(<150 \mathrm{MeV})$; thus, data tables should be used when available. Our comparisons demonstrate the importance of the mix-and-match capability and indicate how well physics models work in the absence of data tables.

\section{MCNPX OVERVIEW}

MCNPX $^{1}$ is a Monte $\underline{\text { Carlo }} \underline{\mathrm{N}}$ - $\underline{\text { Particle radiation transport code extending the capabilities }}$ of MCNP4C. ${ }^{2}$

As with MCNP, MCNPX uses nuclear data tables to transport neutrons, photons, and electrons. Unlike MCNP, MCNPX also uses (1) nuclear data tables to transport protons; (2) physics models to transport 30 additional particle types (deuterons, tritons, alphas, pions, muons, etc.); and (3) physics models to transport neutrons and protons when no tabular data are available or when the data are above the energy range (20 to $150 \mathrm{MeV})$ where the data tables end. The energy range of MCNPX particles is illustrated in Fig. 1. 


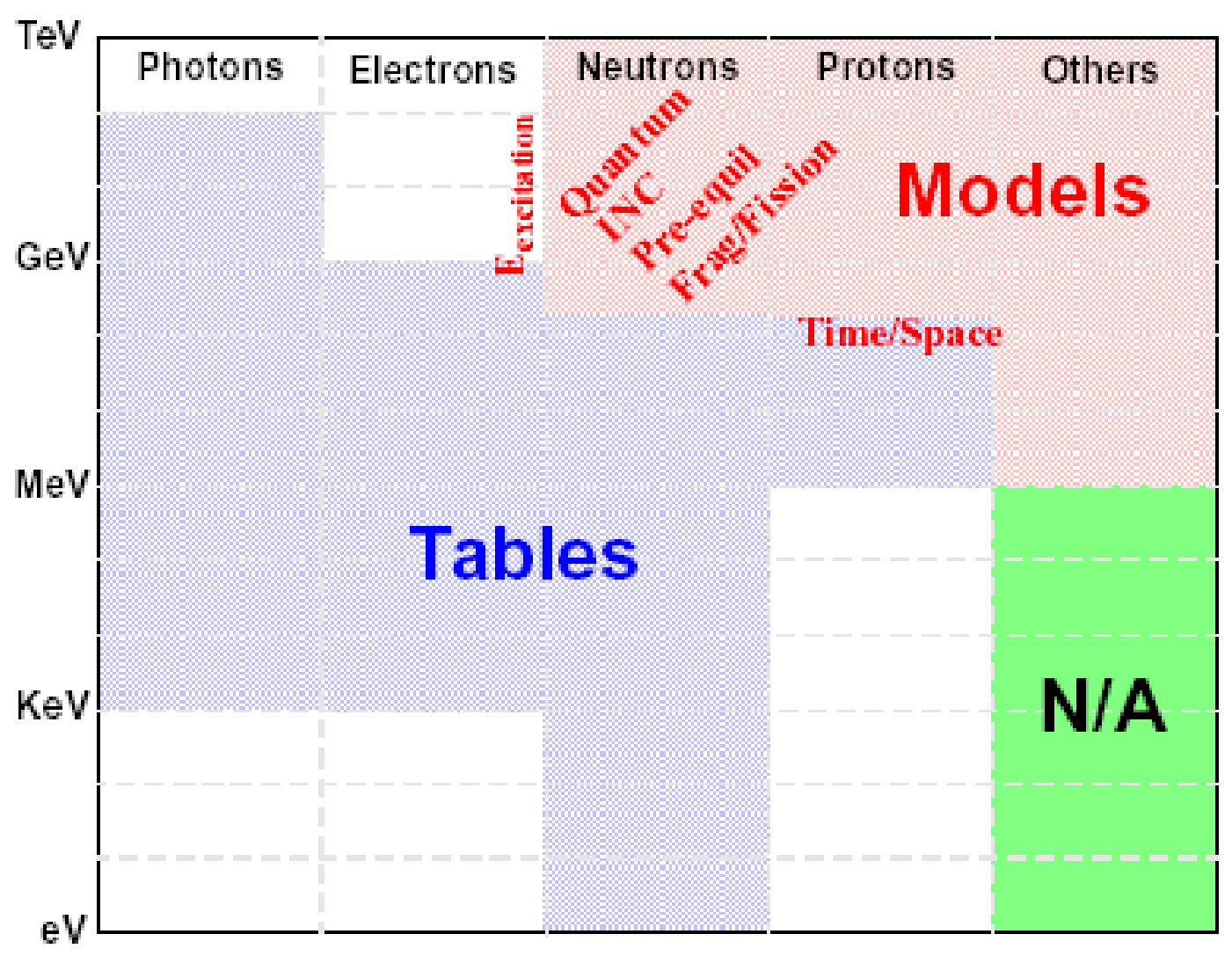

Fig. 1. MCNPX particles and energies.

\subsection{MCNPX 2.3.0 Features Not Found in MCNP4C3}

MCNPX includes all of the features and capabilities of MCNPX 2.3.0 (based on MCNP4B), which was released recently to the Radiation Safety Information Computational Center (RSICC). The RSICC ${ }^{4}$ is located in Oak Ridge, Tennessee, and is the principal distributor of MCNP, MCNPX, and other Department of Energy (DOE) computer codes. The following features are not found in MCNP4C3:

- physics for 34 particle types;

- high-energy physics above the tabular data range;

- photonuclear physics; ${ }^{5}$

- neutron, proton, and photonuclear $150-\mathrm{MeV}$ libraries and utilization;

- mesh tallies (tally fluxes, heating, sources, etc., in a superimposed mesh);

- radiography tallies;

- secondary-particle production biasing; and

- autoconfiguration build system for compilation.

In particular, the mesh tallies enable users to plot source particle locations, fluxes, energy deposition, particle tracks, DXTRAN contributions, and other useful quantities on a superimposed tally grid. The mesh tally capability is useful for all transport problems, not just high-energy problems. 


\subsection{MCNP4C3 Features Not Found in Earlier MCNPX Versions}

MCNPX includes all of the features and capabilities of MCNP4C3. Until MCNPX2.4.0 (August 2002), MCNPX was based on MCNP4B (March 1997). ${ }^{6}$ MCNPX now has all the capabilities of MCNP4C ${ }^{7,8}$ (March 2000), MCNP4C29 (January 2001), and MCNP4C ${ }^{10}$ (April 2001). The initials of principal developers are shown in parentheses.* The new features previously unavailable in MCNPX are

- PC enhancements: MCNPX is fully Linux and Windows capable (LLC/ GWM);

- easier geometry specification with macrobodies (LLC);

- interactive geometry plotting (JSH);

- improved variance reduction with the superimposed mesh weight window generator (TJE/JAF/JSH);

- superimposed mesh plotting (JSH);

- delayed neutrons (CJW);

- unresolved resonance range probability tables (LLC/RCL);

- perturbations for material-dependent tallies (GWM/LLC/JSH);

- ENDF/B-VI extensions (MCW);

- electron physics enhancements (upgrade to ITS3.. $\left.0^{11}\right)(\mathrm{KJA} / \mathrm{HGH})$;

- weight window enhancements (JSH/JAF); and

- distributed memory multiprocessing (GWM).

\subsection{MCNPX Capabilities Provided after the MCNP4C/MCNPX Merger}

MCNPX has many new capabilities not found in either MCNP4C or MCNPX 2.3.0. ${ }^{12}$ The following features became available with MCNPX2.4.0, ${ }^{13,14}$ which was released to the RSICC on August 1, 2002:

- FORTRAN 90 modularity and dynamic memory allocation (GWM);

- distributed memory multiprocessing for the entire energy range of all particles (GWM);

- repeated structures source path improvement (LLC/JSH);

- default dose functions (LSW/JSH);

- light-ion recoil (JSH);

- enhanced color geometry plots (GWM/JSH);

- photonuclear cross-section plots (JSH);

- proton cross-section plots (JSH);

- proton reaction multipliers with FM cards (JSH);

- photonuclear reaction multipliers with FM cards (JSH/GWM);

* Gregg W. McKinney (GWM), John S. Hendricks (JSH), Laurie S. Waters (LSW), Leland L. Carter (LLC), Franz X. Gallmeier (FXG), H. Grady Hughes (HGH), Richard E. Prael (REP), Stepan G. Mashnik (SGM), Arnold J. Sierk (AJS), Thomas J. Evans (TJE), Jeffrey A. Favorite (JAF), Christopher J. Werner (CJW), Robert C. Little (RCL), Morgan C. White (MCW), and Kenneth J. Adams (KJA). 
- some speedups (GWM/JSH);

- logarithmic interpolation on input cards (JSH);

- cosine bins that may be specified in degrees (JSH);

- cosine bins that may be specified for F2 flux tallies (JSH);

- source particles that may be specified by descriptors (JSH);

- pause command for tally and cross-section plots (JSH); and

- correction of all known MCNPX and MCNP4C bugs/problems (REP/GWM/ FXG/HGH/JSH).

The following additional features became available in MCNPX2.5.b (November 2002): ${ }^{15}$

- CEM2k physics ${ }^{16,17}$ (SGM/AJS/FXG);

- mix and match (JSH);

- positron sources $(\mathrm{HGH})$; and

- spontaneous fission (JSH).

\subsection{MCNPX Mix-and-Match Capability}

MCNPX can mix and match data tables and physics models throughout a problem. For example, MCNPX can model neutron transport in a bismuth germinate (BGO) particle detector by using data tables for bismuth and oxygen and using physics models for germanium. Also, MCNPX can model neutron transport in $\mathrm{UO}_{2}$, making the best use of physics models and data tables: below $20 \mathrm{MeV}$, data tables are used; above $150 \mathrm{MeV}$, physics models are used; between 20 and $150 \mathrm{MeV}$, data tables are used for oxygen and models are used for uranium.

This report provides comparisons that calculate radiation transport in materials with various combinations of data tables and model physics. The physics models are poor at low energies $(<150 \mathrm{MeV})$; thus, data tables should be used when available. Our comparisons demonstrate the importance of the mix-and-match capability and indicate how well physics models work in the absence of data tables.

\section{BGO COMPARISON}

The first example of the mix-and-match capability is a BGO detector crystal. An unambiguous description of this example problem is the MCNPX input file provided in the appendix. The crystal is $8.433 \mathrm{~cm}$ long and $3.932 \mathrm{~cm}$ in radius with a density of $7.13 \mathrm{~g} / \mathrm{cm}^{3}$. A monodirectional $100-\mathrm{MeV}$ beam of neutrons impinges on the base of the BGO can, and we tally and plot the neutron and photon leakage, flux, and heating.

The BGO consists of $21 \%$ bismuth, $16 \%$ germanium, and $63 \%$ oxygen. Currently, no germanium nuclear data table is available for either MCNP or MCNPX. With mix and match, the $150-\mathrm{MeV}$ data tables may be used for bismuth and oxygen and a physics model can be used for germanium. Before the mix-and-match capability, the only way to model the BGO detector was to substitute some other nuclide for germanium, such as 
arsenic. The available arsenic nuclear data table goes up to $20 \mathrm{MeV}$, leaving users with two poor choices:

1. use models for all neutron nuclides above $20 \mathrm{MeV}$, neglecting the 20- to $150-\mathrm{MeV}$ data for bismuth and oxygen; or

2. use models using $>150 \mathrm{MeV}$ to take advantage of the $150-\mathrm{MeV}$ bismuth and oxygen data tables but then use the $20-\mathrm{MeV}$ values of the arsenic cross sections in the 20 - to $150-\mathrm{MeV}$ range.

In either case, the model for arsenic would have to be used instead of germanium above the arsenic data table energy range. In all cases, data tables are used for the photons.

Figures 2 through 7 show the BGO leakage (penetration through the top of the crystal), flux, and heating for neutrons and photons. In each case, the following are plotted:

- mix/match: data tables are used for bismuth and oxygen, and a physics model is used for germanium.

- with arsenic at $20 \mathrm{MeV}$ (W/As @20): data tables up to $20 \mathrm{MeV}$ are used for bismuth, oxygen, and arsenic (substitute for germanium); above $20 \mathrm{MeV}$, physics models are used for bismuth, arsenic, and oxygen.

- with arsenic at $150 \mathrm{MeV}$ (W/As @150): data tables are used for bismuth and oxygen up to $20 \mathrm{MeV}$ (above the problem energy range). The arsenic data table is used up to $20 \mathrm{MeV}$. The $20-\mathrm{MeV}$ arsenic cross section is used above $20 \mathrm{MeV}$.

These figures illustrate the difference between the new mix-and-match capability in which a model for germanium can be used and the capability before mix and match where Table 1 data had to be either extended or ignored in the mix-and-match energy range.

It is evident that significant differences can be found in the answers, depending on whether a germanium model or arsenic table data below $20 \mathrm{MeV}$ are used and depending on the treatment of arsenic above $20 \mathrm{MeV}$ (either using the model or table extension with $20-\mathrm{MeV}$ values).

The physics models are not as good as evaluated data. Below $20 \mathrm{MeV}$, they become unreliable. At $\sim 1 \mathrm{MeV}$, where they are cut off, these models are highly questionable. In particular, the CEM2k physics model is poor below $7 \mathrm{MeV}$. Whether using a physics model for germanium is better or worse than substituting an arsenic data table will not be known until there is a good data table for germanium. Certainly, extrapolating the $20-\mathrm{MeV}$ data above $20 \mathrm{MeV}$ for arsenic is a very poor approximation. 


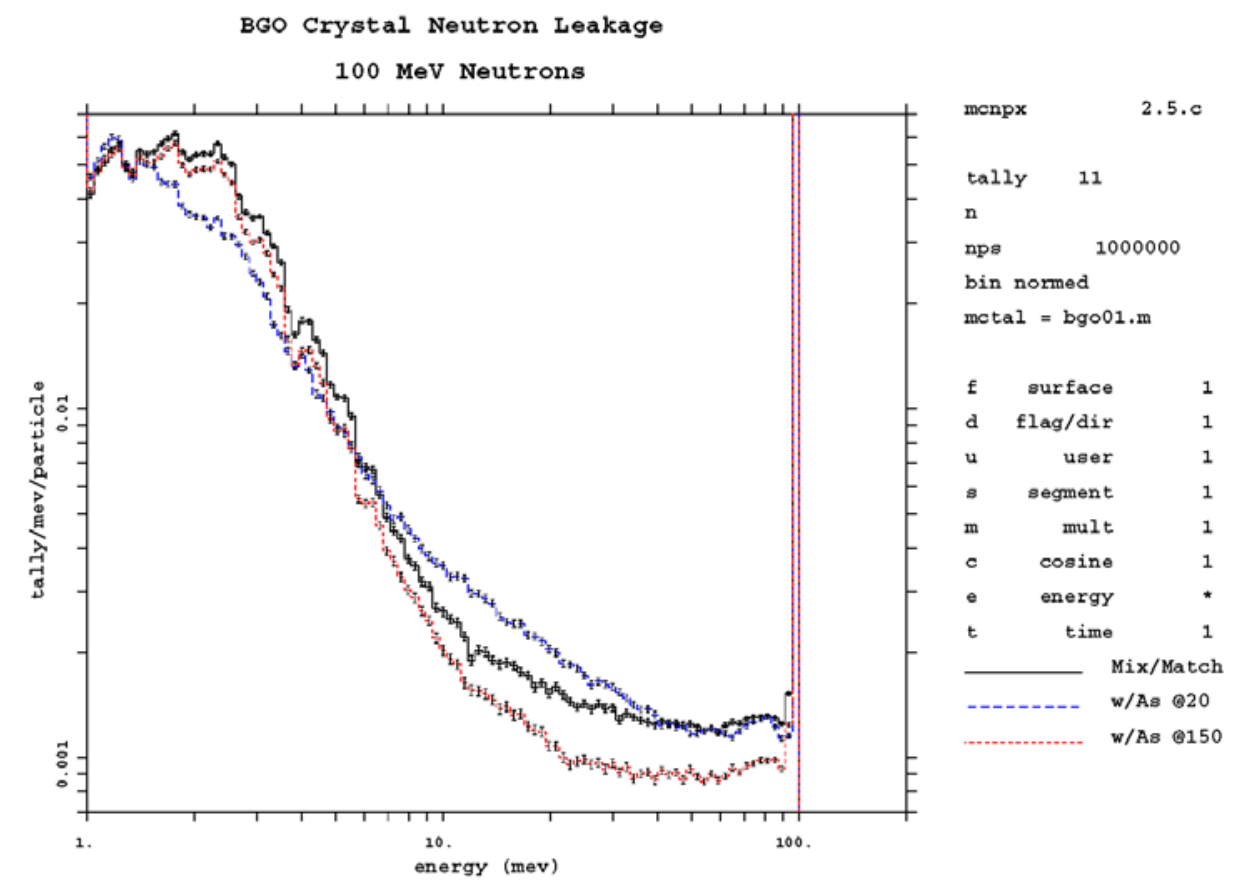

Fig. 2. BGO neutron leakage, new vs old capability.

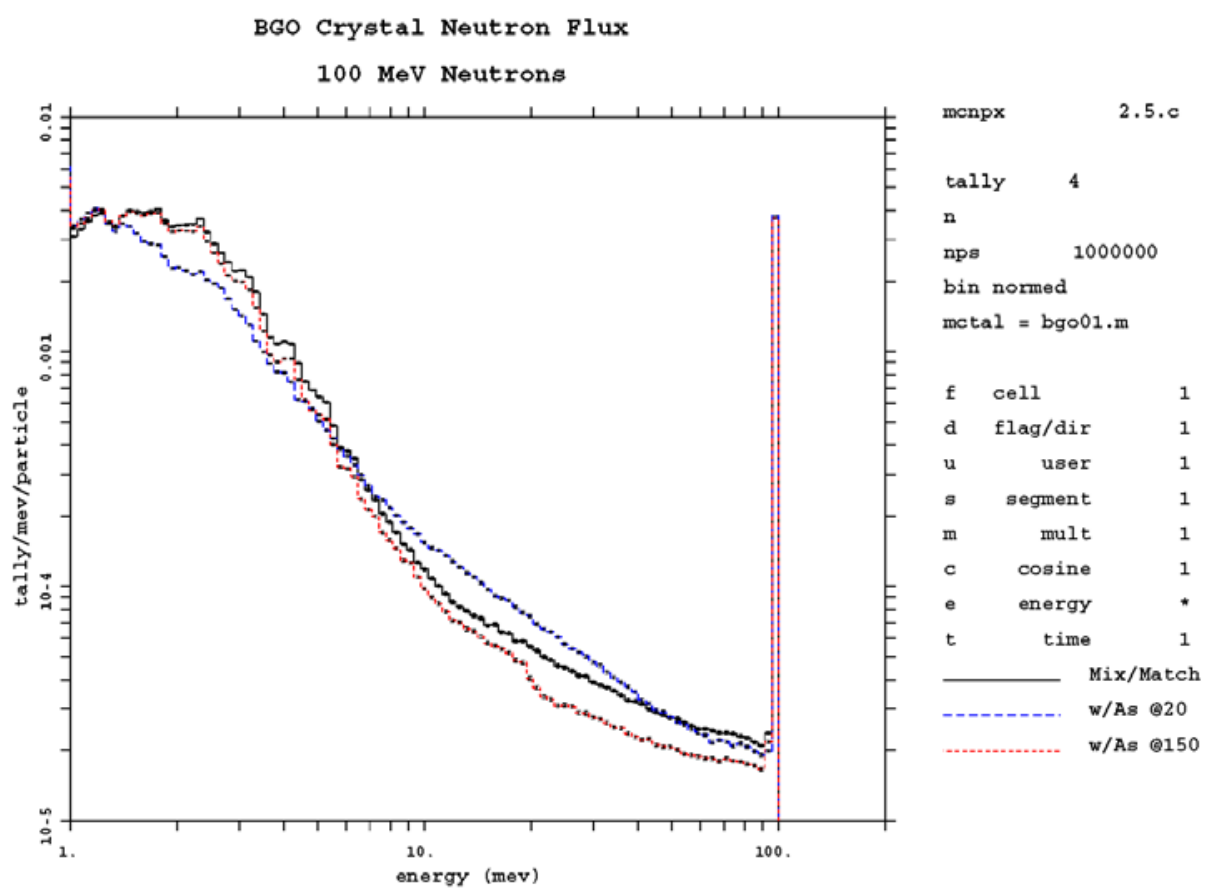

Fig. 3. BGO neutron flux, new vs old capability. 


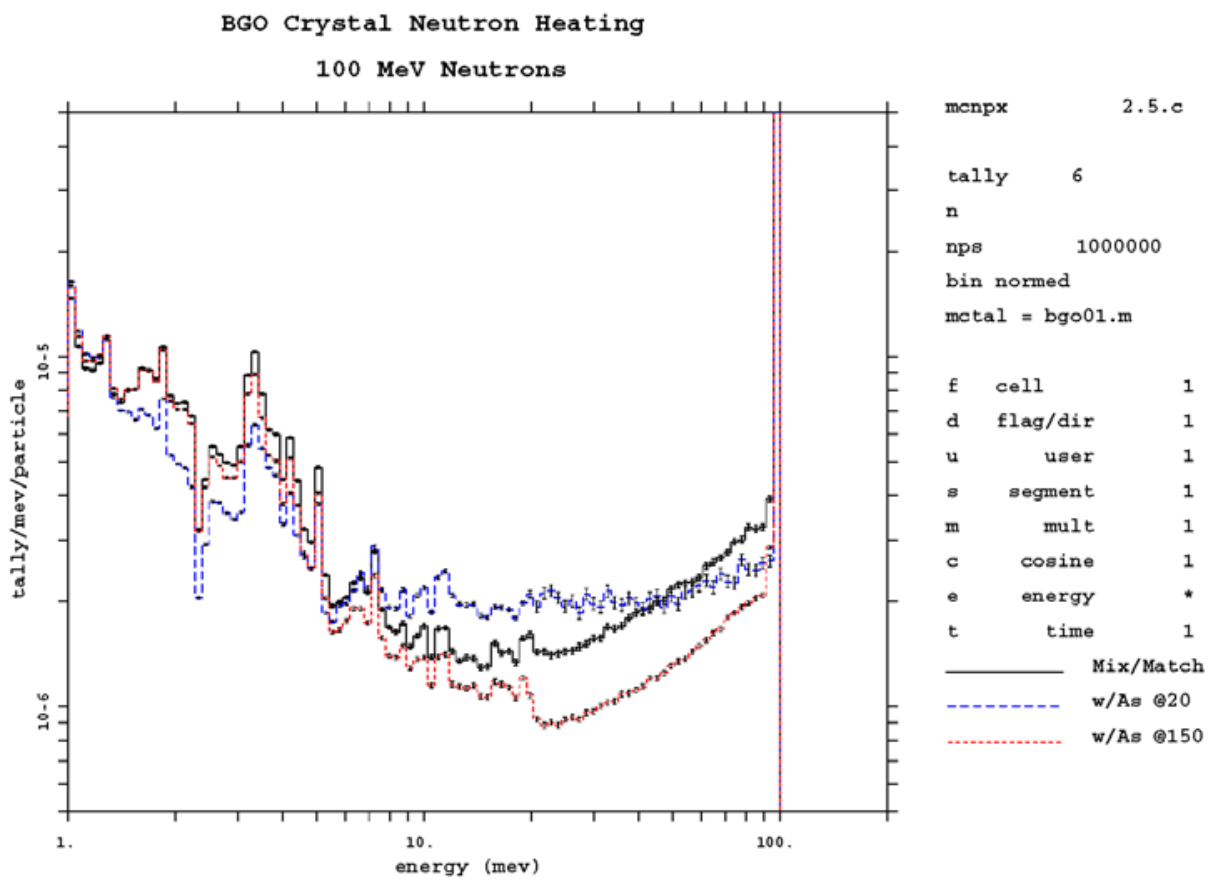

Fig. 4. BGO neutron heating, new vs old capability.

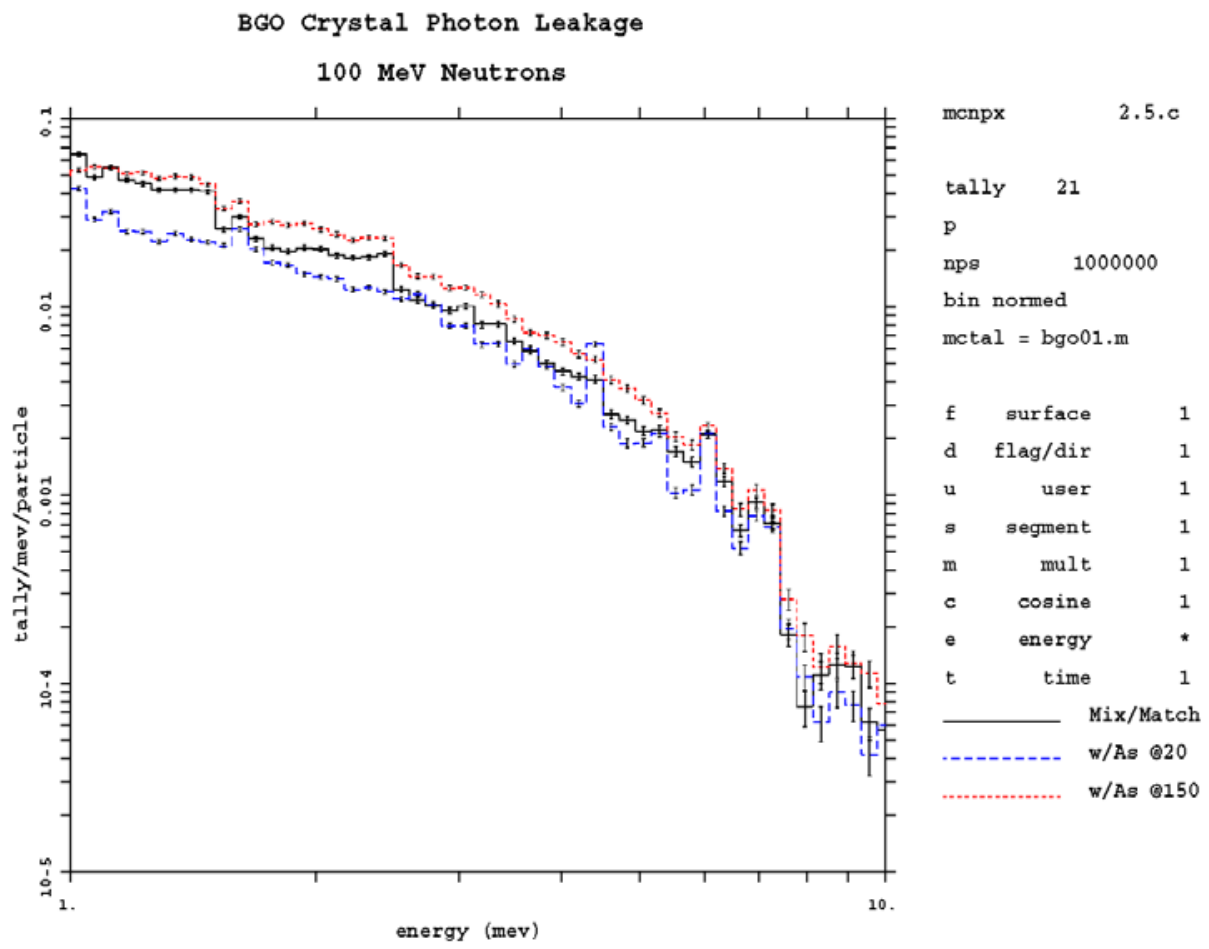

Fig. 5. BGO photon leakage, new vs old capability. 


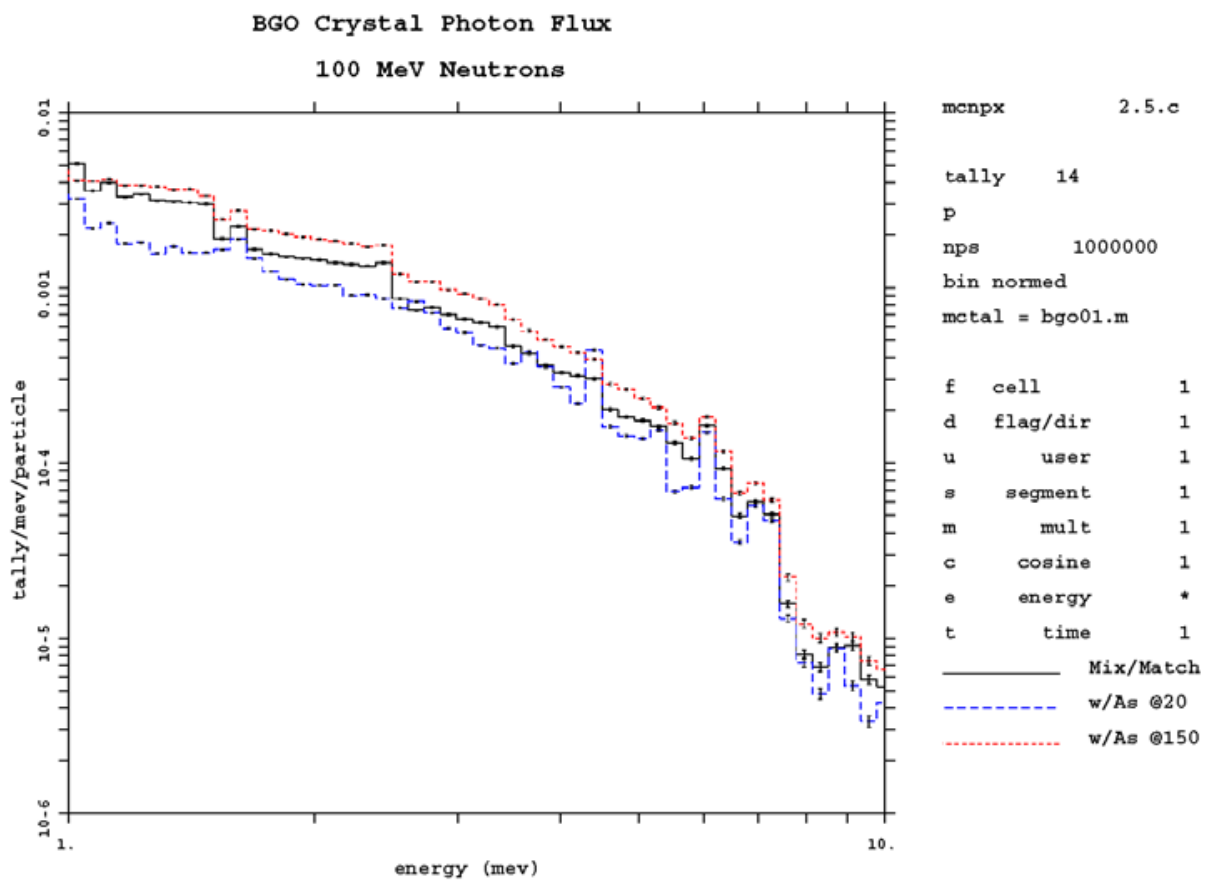

Fig. 6. BGO photon flux, new vs old capability.

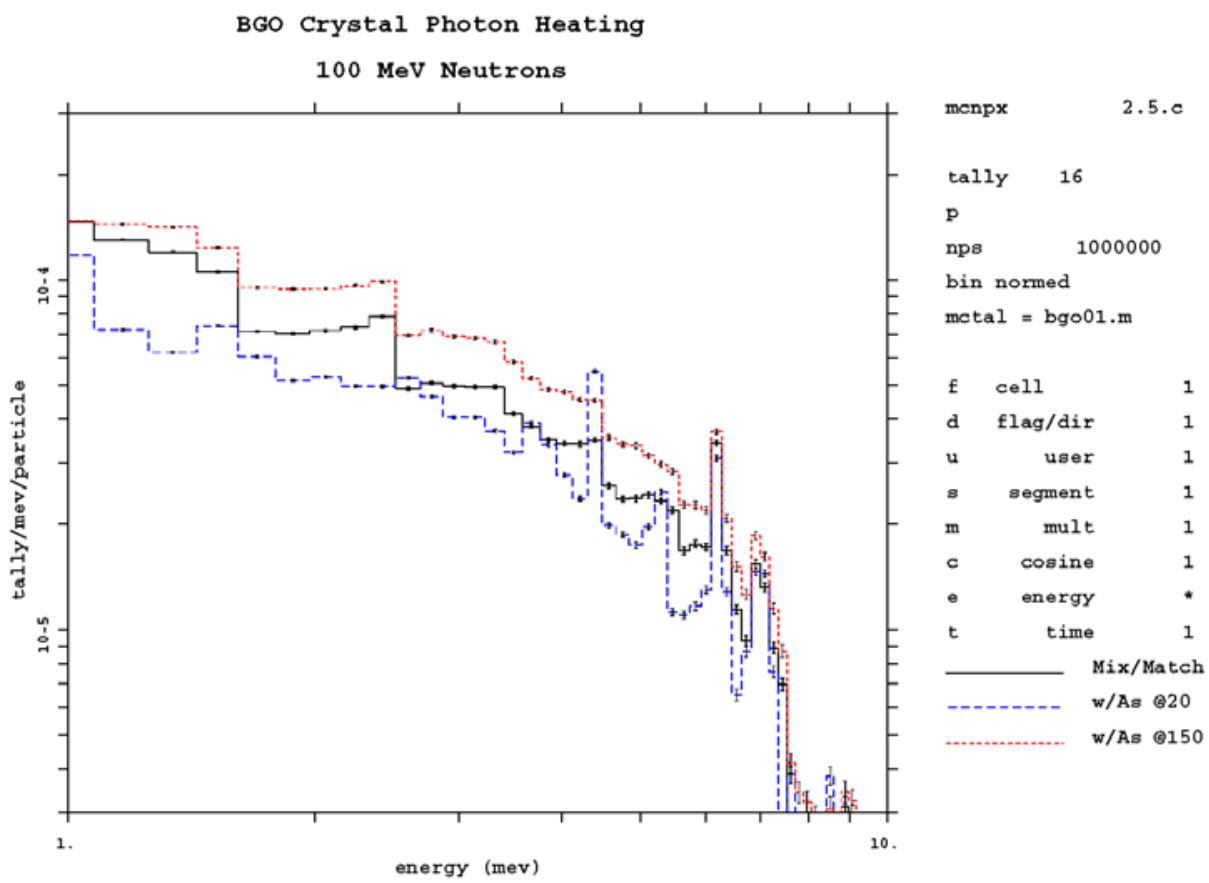

Fig. 7. BGO photon heating, new vs old capability. 


\section{Table 1}

BGO Crystal Integral Quantities

\begin{tabular}{lccc}
\multicolumn{1}{c}{ Quantity } & Mix/Match & $\begin{array}{c}\text { W/As } \\
\mathbf{2 0 ~ M e V}\end{array}$ & $\begin{array}{c}\text { W/As } \\
\mathbf{a 1 5 0 ~ M e V}\end{array}$ \\
Neutron Leakage & $9.9287 \mathrm{E}-01$ & $9.8895 \mathrm{E}-01$ & $9.0710 \mathrm{E}-01$ \\
Neutron Flux & $3.5566 \mathrm{E}-02$ & $3.4562 \mathrm{E}-02$ & $3.3783 \mathrm{E}-02$ \\
Neutron Heating & $3.1818 \mathrm{E}-03$ & $2.8093 \mathrm{E}-03$ & $2.5052 \mathrm{E}-03$ \\
Photon Leakage & $1.1231 \mathrm{E}-01$ & $8.7039 \mathrm{E}-02$ & $1.2856 \mathrm{E}-01$ \\
Photon Flux & $8.9828 \mathrm{E}-03$ & $6.9487 \mathrm{E}-03$ & $1.0474 \mathrm{E}-02$ \\
Photon Heating & $4.6665 \mathrm{E}-04$ & $3.7081 \mathrm{E}-04$ & $5.5945 \mathrm{E}-04$
\end{tabular}

Using an arsenic model instead of germanium is a crude approximation. Using arsenic photon table data rather than germanium whenever arsenic is substituted for the neutron table is also a poor approximation.

An indication of how poor the neutron physics model is at low energies can be found by comparing the default model, CEM $2 \mathrm{k}$ model, and data table for arsenic. Figures 8 through 13 show the arsenic leakage, flux, and heating for neutrons and photons for a $20-\mathrm{MeV}$ neutron source. The crystal density and dimensions are unchanged.

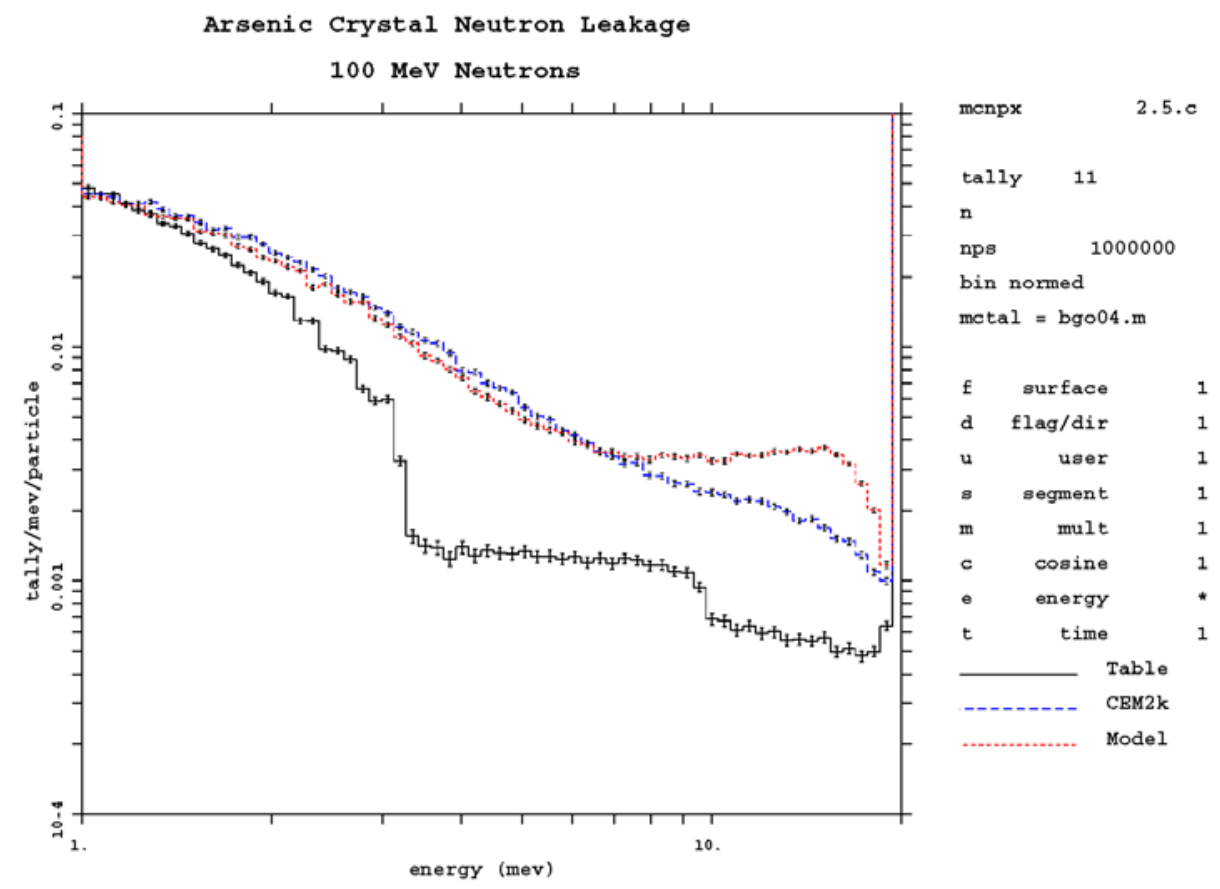

Fig. 8. Arsenic neutron leakage, table vs model. 


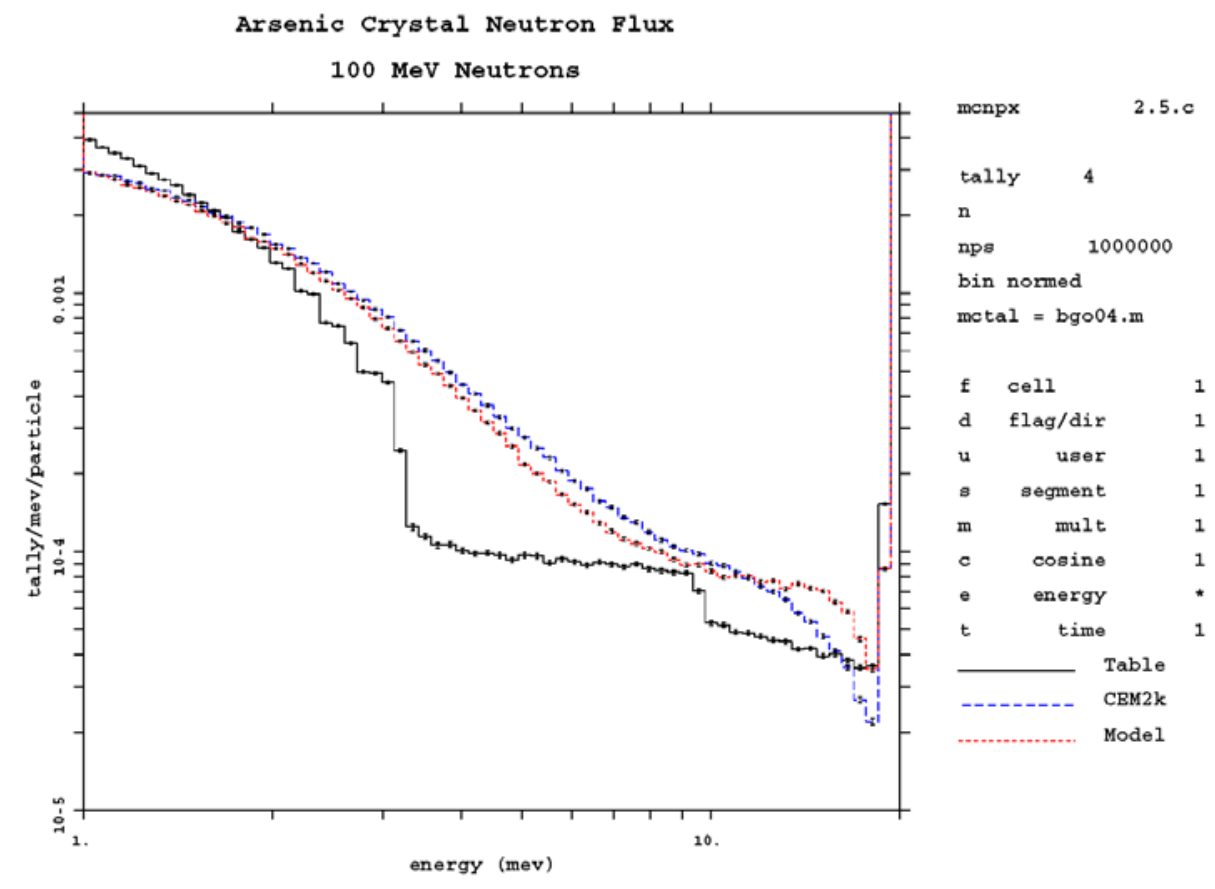

Fig. 9. Arsenic neutron flux, table vs model.

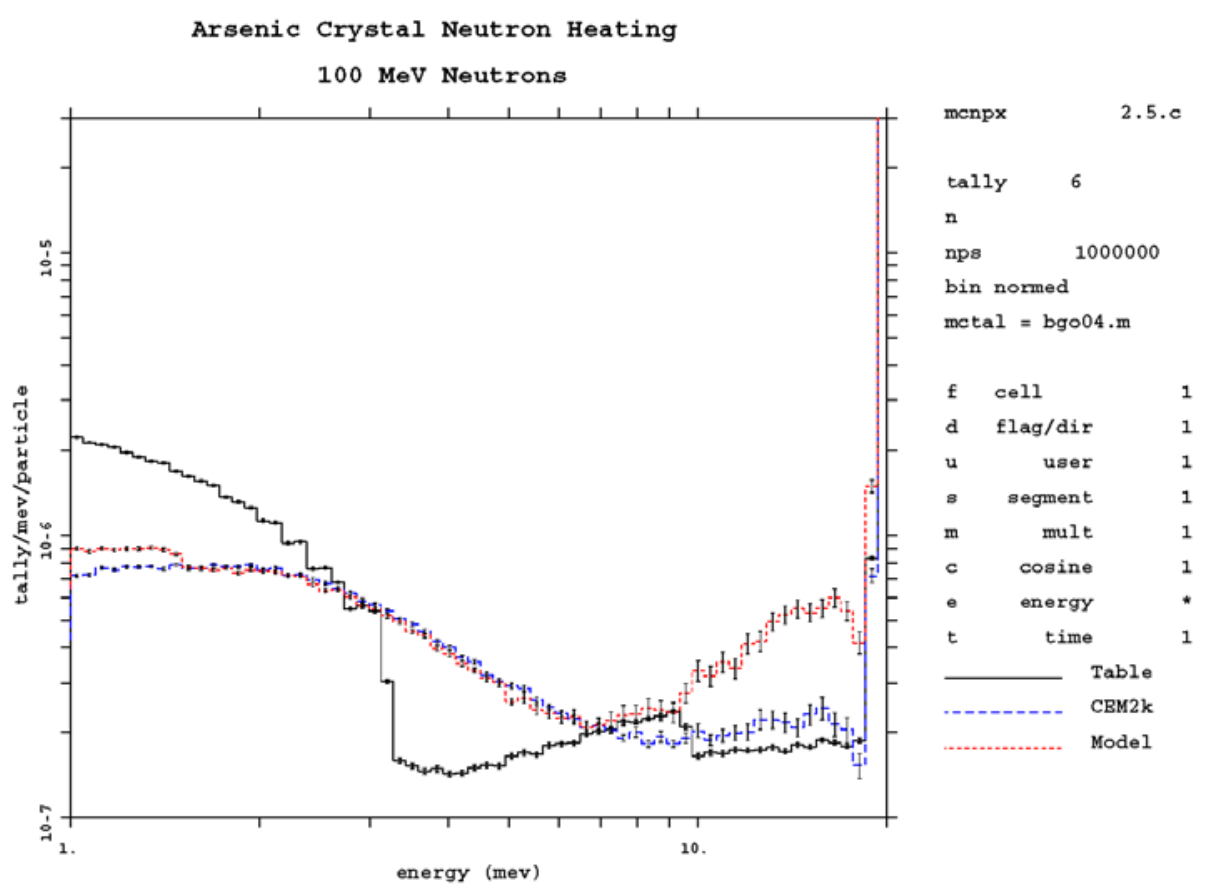

Fig. 10. Arsenic neutron heating, table vs model. 


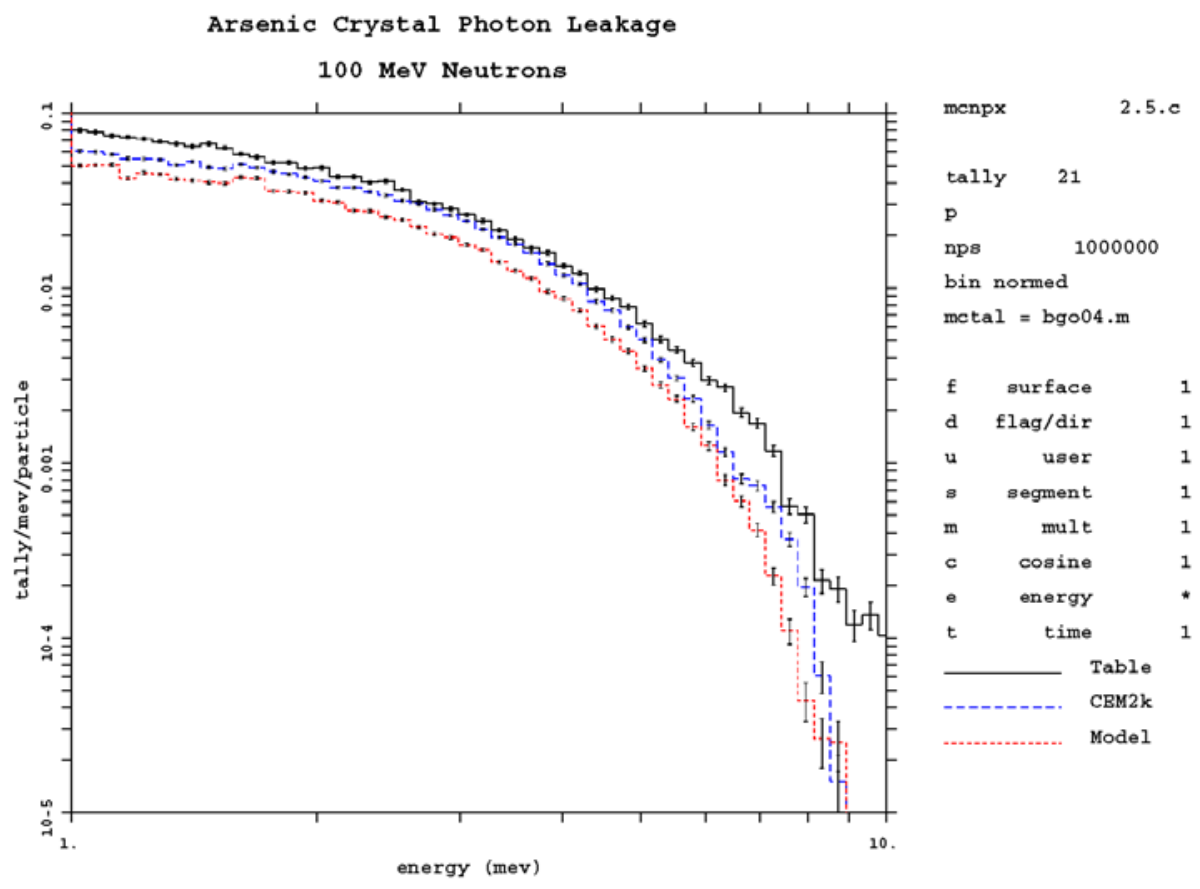

Fig. 11. Arsenic photon leakage, table vs model.

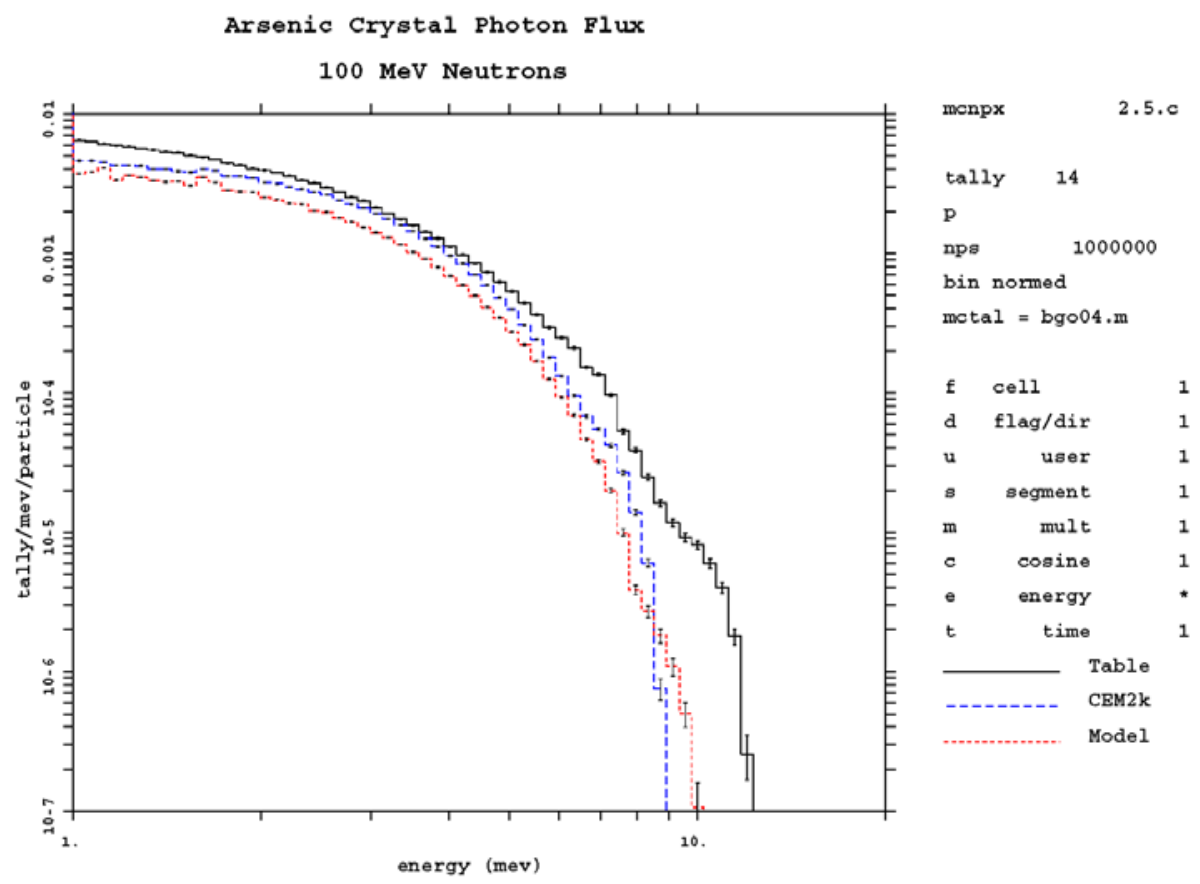

Fig. 12. Arsenic photon flux, table vs model. 


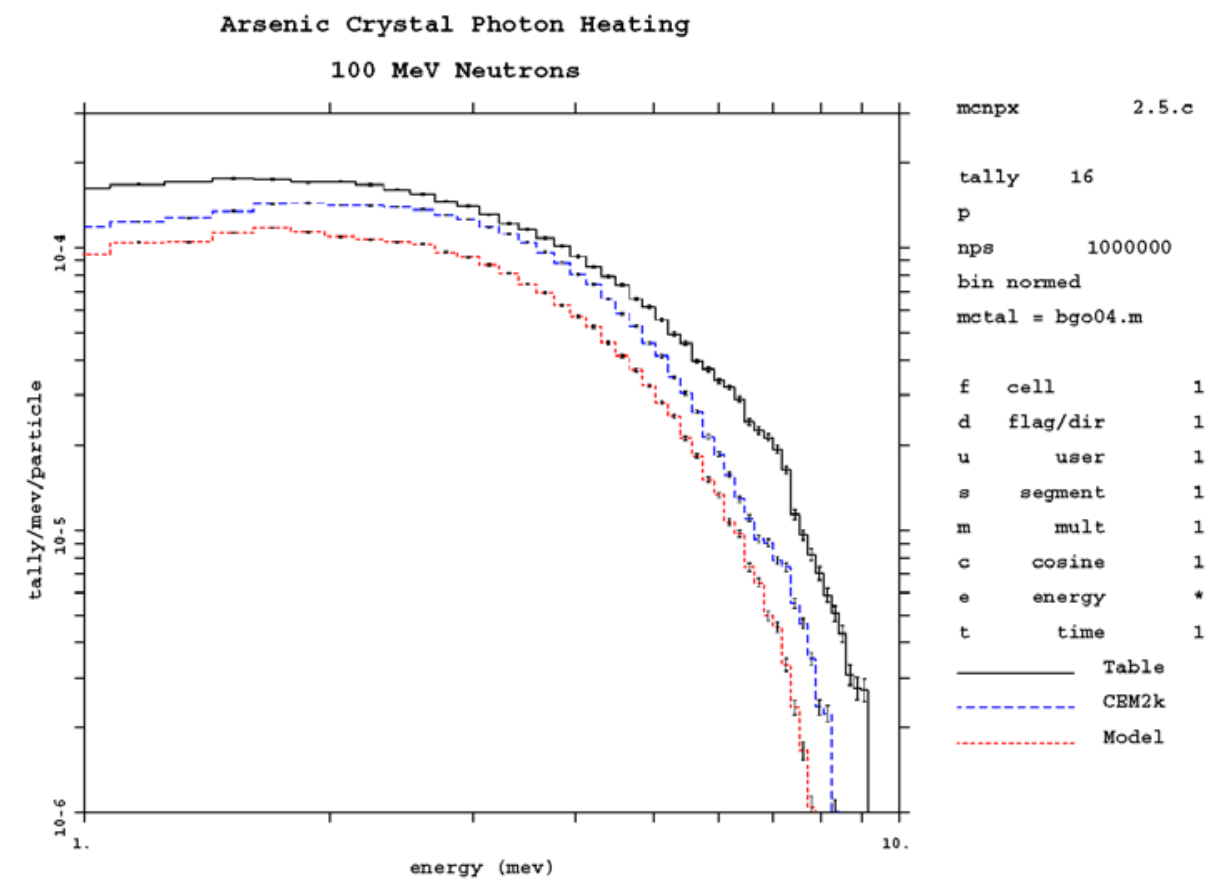

Fig. 13. Arsenic photon heating, table vs model.

The arsenic crystal comparison plots illustrate the serious deficiencies of models at low energies. All neutron heating is dumped at $20 \mathrm{MeV}$ with the physics models. The neutron flux and leakage are an order of magnitude higher for the models than for the arsenic data table below $20 \mathrm{MeV}$. Apparently, the LAHET portion of the MCNPX model physics has built-in assumptions that neutron cross sections will not be used below $20 \mathrm{MeV}$, and in some, or perhaps all cases, the cross section is set to zero.

For photons, the same photoatomic data table is used in all three cases: neutron table, neutron CEM2k, and neutron default model. The differences between the various photon plots are caused by scaling due to the neutron production of photons. Evidently, the models produce about an order-of-magnitude fewer photons.

Although the arsenic crystal plots make the models look poor, the difference between the data table and physics models is much smaller in an integral sense. Table 2 shows the arsenic crystal data integrated over energy.

How much of the difference between the data table and the models is due to a bad arsenic data table? Although arsenic is probably not as well characterized as more important nuclides, the quality of the arsenic table data is suggested by its cross-section plot in Figs. 14 and 15, which show the total $(\mathrm{mt}=-1)$, absorption $(\mathrm{mt}=-2)$, and elastic $(\mathrm{mt}=-3)$ table cross section over the entire energy range and over the 1 - to $20-\mathrm{MeV}$ energy range of the arsenic crystal problem. 


\section{Table 2}

Arsenic Crystal Integral Quantities, 20-MeV Source

\begin{tabular}{lccc}
\multicolumn{1}{c}{ Quantity } & Data Table & CEM2k & Model \\
Neutron Leakage & $5.7065 \mathrm{E}-01$ & $6.0530 \mathrm{E}-01$ & $6.4494 \mathrm{E}-01$ \\
Neutron Flux & $2.5913 \mathrm{E}-02$ & $2.3656 \mathrm{E}-02$ & $2.5626 \mathrm{E}-02$ \\
Neutron Heating & $9.0549 \mathrm{E}-05$ & $1.5594 \mathrm{E}-04$ & $2.5703 \mathrm{E}-04$ \\
Photon Leakage & $2.7146 \mathrm{E}-01$ & $2.4545 \mathrm{E}-01$ & $2.0415 \mathrm{E}-01$ \\
Photon Flux & $2.4901 \mathrm{E}-02$ & $2.2346 \mathrm{E}-02$ & $1.8625 \mathrm{E}-02$ \\
Photon Heating & $8.3046 \mathrm{E}-04$ & $7.0777 \mathrm{E}-04$ & $5.5700 \mathrm{E}-04$
\end{tabular}

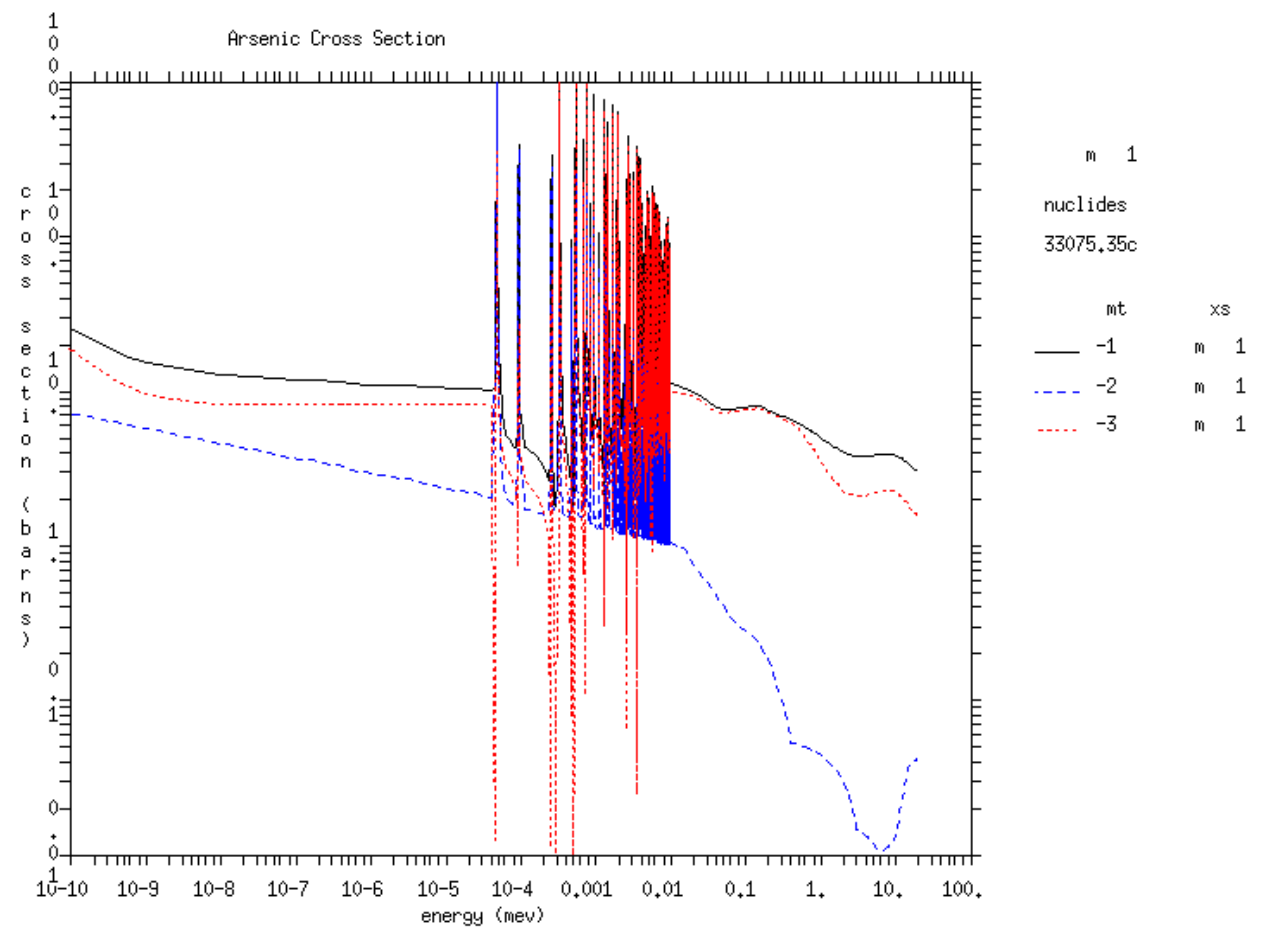

Fig. 14. Arsenic cross section, 0 to $20 \mathrm{MeV}$. 


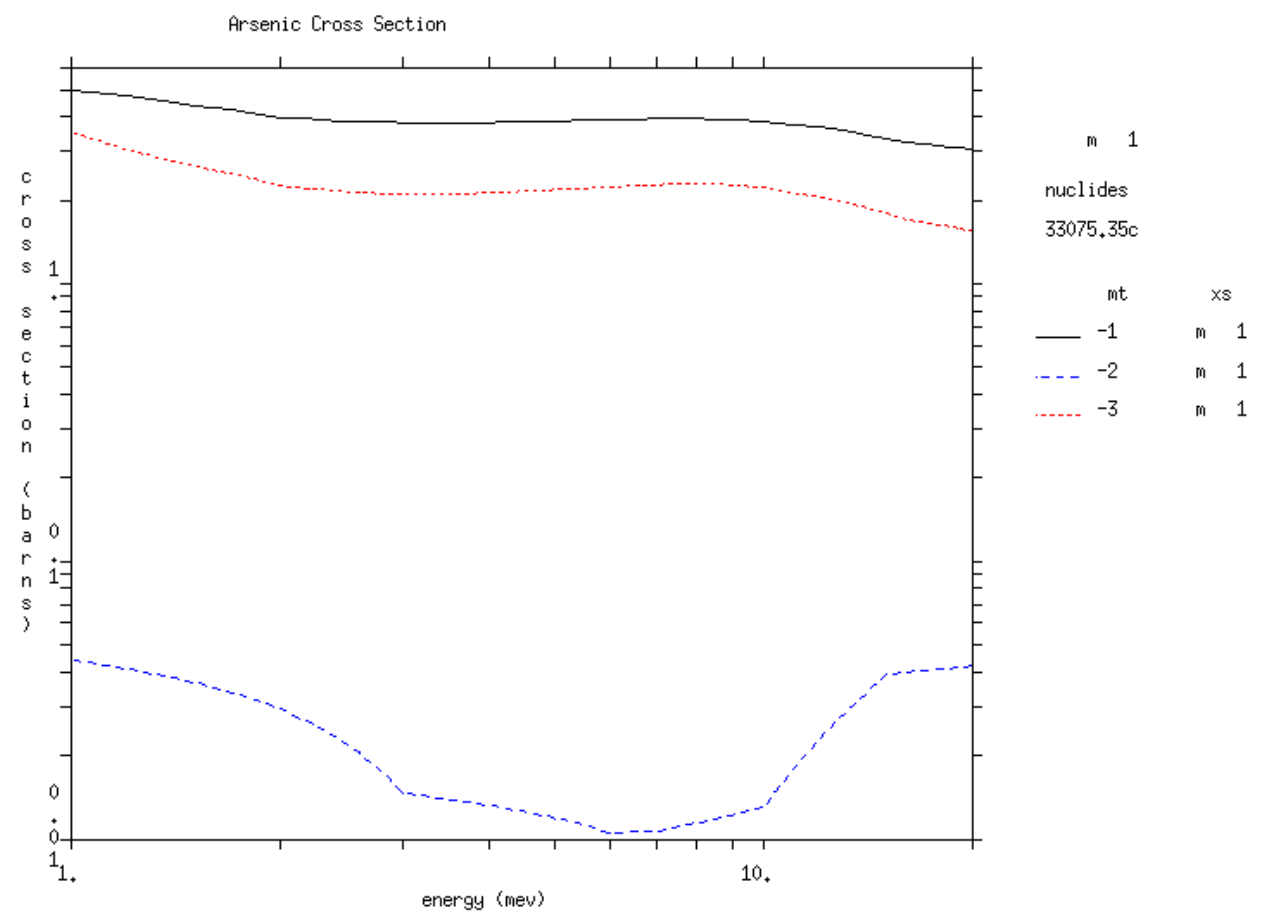

*Where the reaction MT numbers $-1,-2$, and -3 shown in the right margin are the total, absorption, and elastic cross sections, respectively.

Fig. 15. Arsenic cross section, 1 to $20 \mathrm{MeV}$ **

The BGO results demonstrate that the MCNPX mix-and-match capability enables the use of physics models where no data tables are available. Fortunately, neutron data tables are available for most nuclides. Photon and electron data tables are available for all elements and thus for all nuclides.

\section{WATER COMPARISON}

The worst-case scenario for models is light nuclei at low energy. Water is a very important material composed of light nuclei. The water comparison considers neutron table data and physics models for a 20 -cm-radius sphere of water. Leakage, flux, and heating are calculated for both a $150-\mathrm{MeV}$ neutron source and a $2-\mathrm{MeV}$ neutron source. These results are presented in Figs. 16 to 21 and Tables 3 and 4.

The $150-\mathrm{MeV}$ neutron source in the center of the 20 -cm-radius water sphere shows fairly decent agreement between using data tables and physics models. Note that the neutron heating jumps when the data tables are used. The $150-\mathrm{MeV}$ neutron data tables were constructed by adding 20 - to $150-\mathrm{MeV}$ data to the $20 \mathrm{-MeV}$ data tables without correcting for discontinuities at $20 \mathrm{MeV}$. 


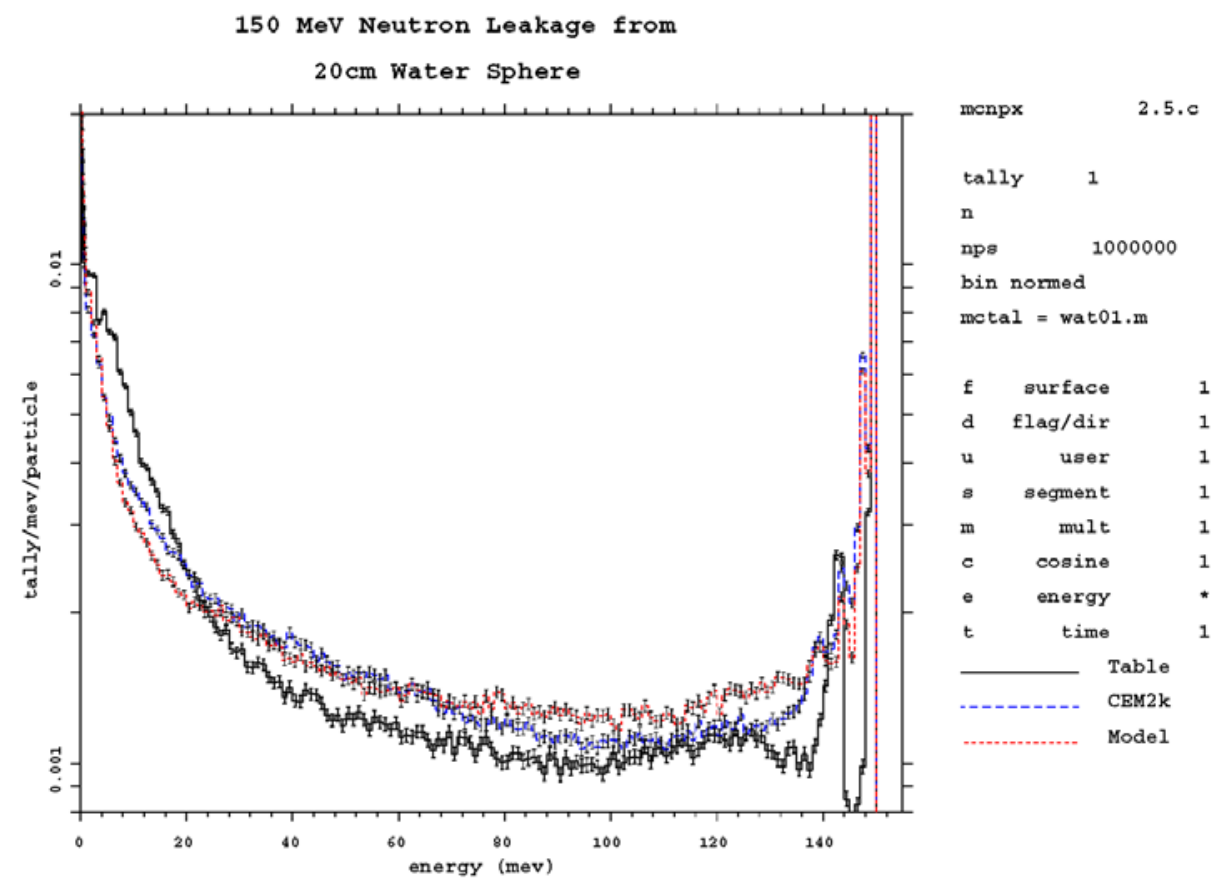

Fig. 16. The 150-MeV neutron water leakage, table vs model.

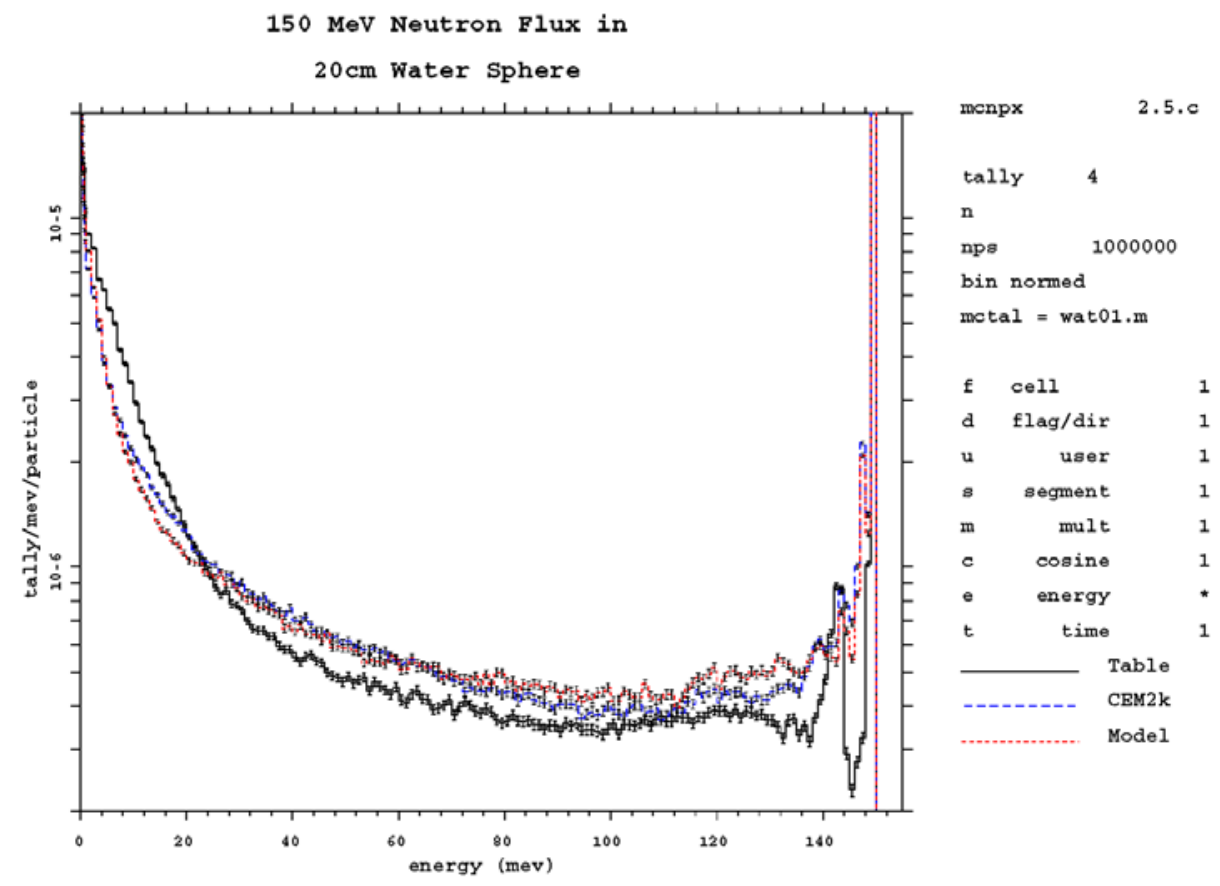

Fig. 17. The $150-\mathrm{MeV}$ neutron water flux, table vs model. 


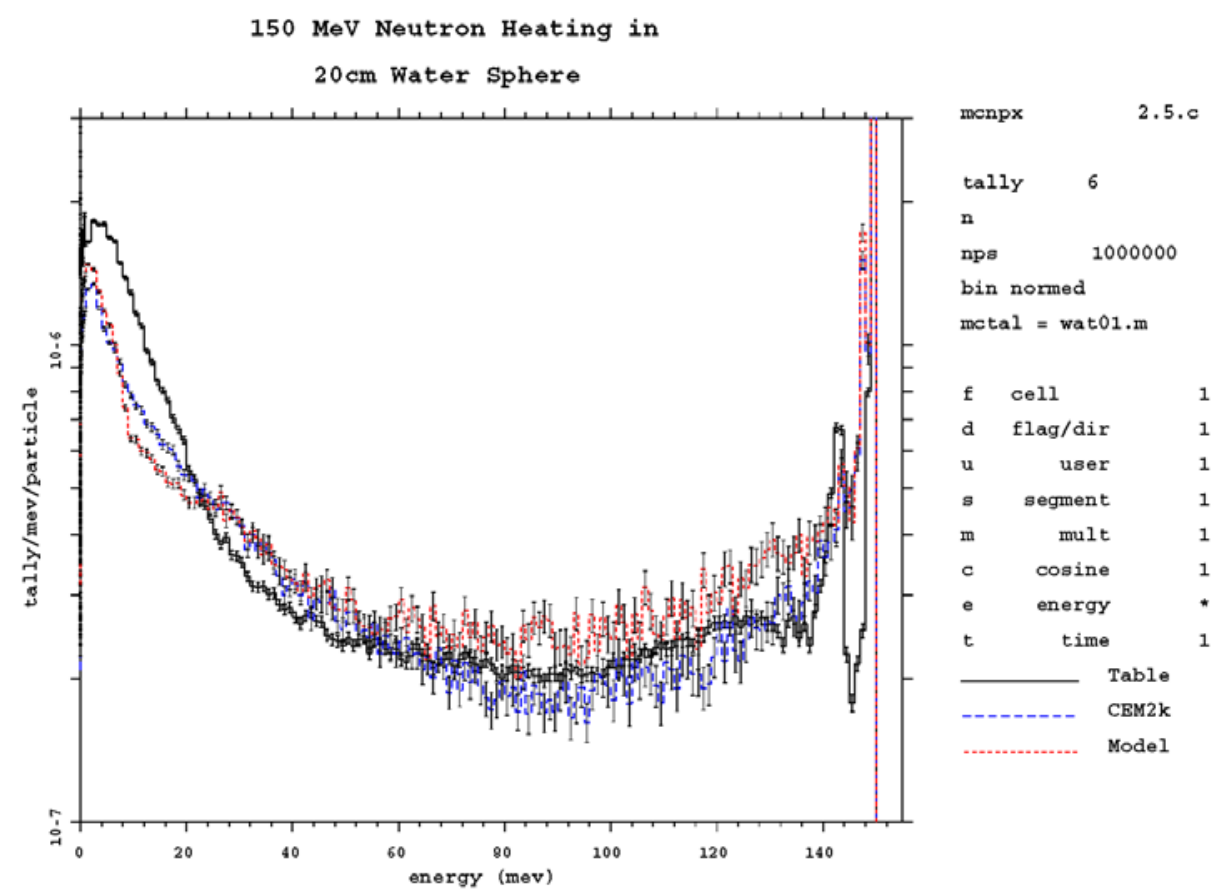

Fig. 18. The 150-MeV neutron water heating, table vs model.

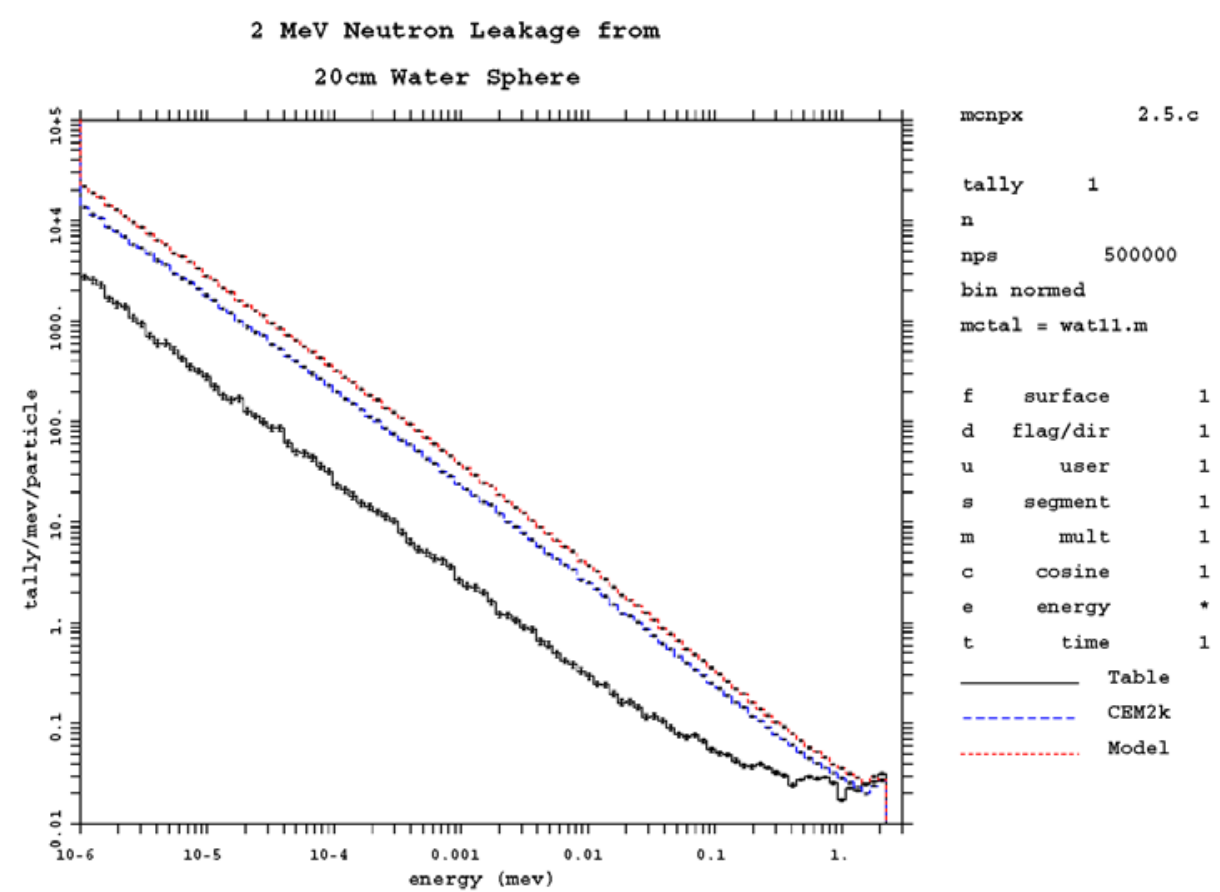

Fig. 19. The 2-MeV neutron water leakage, table vs model. 


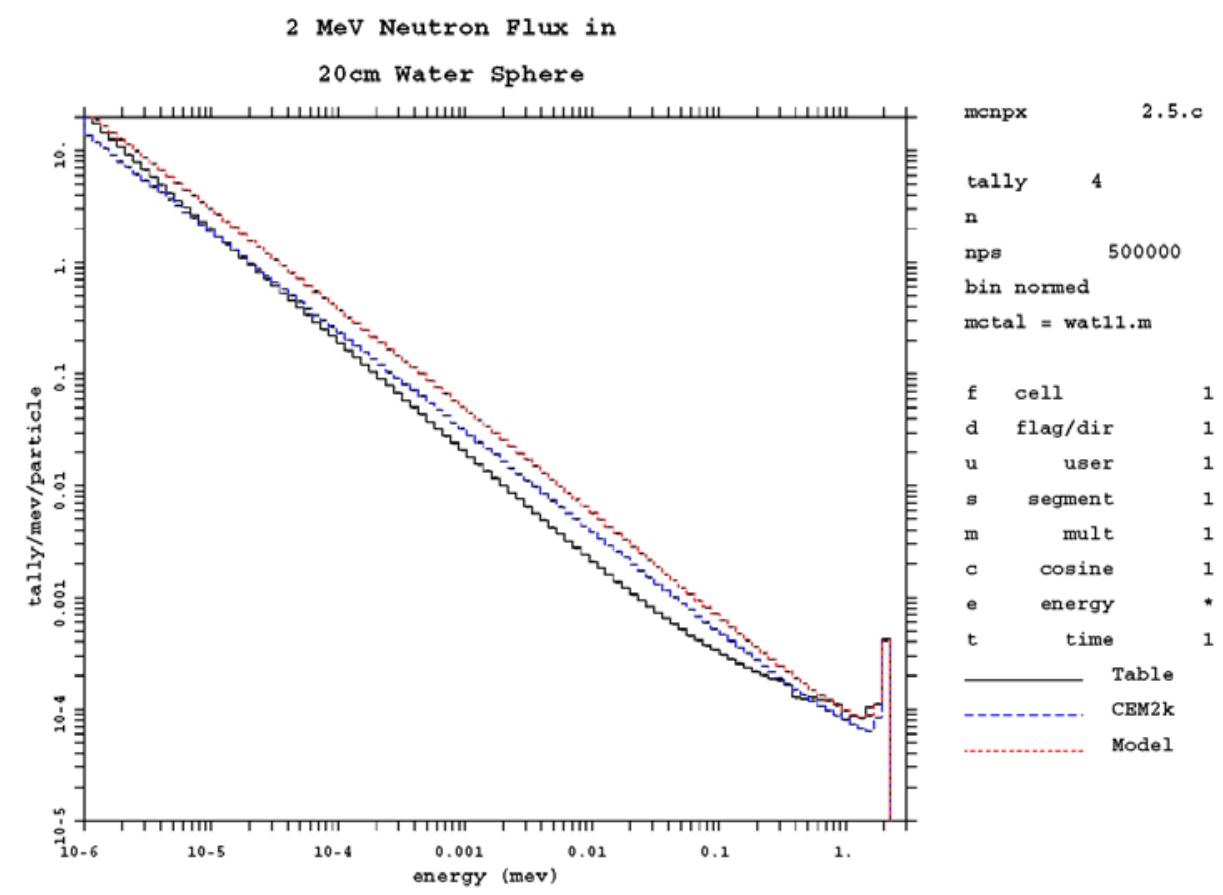

Fig. 20. The 2-MeV neutron water flux, table vs model.

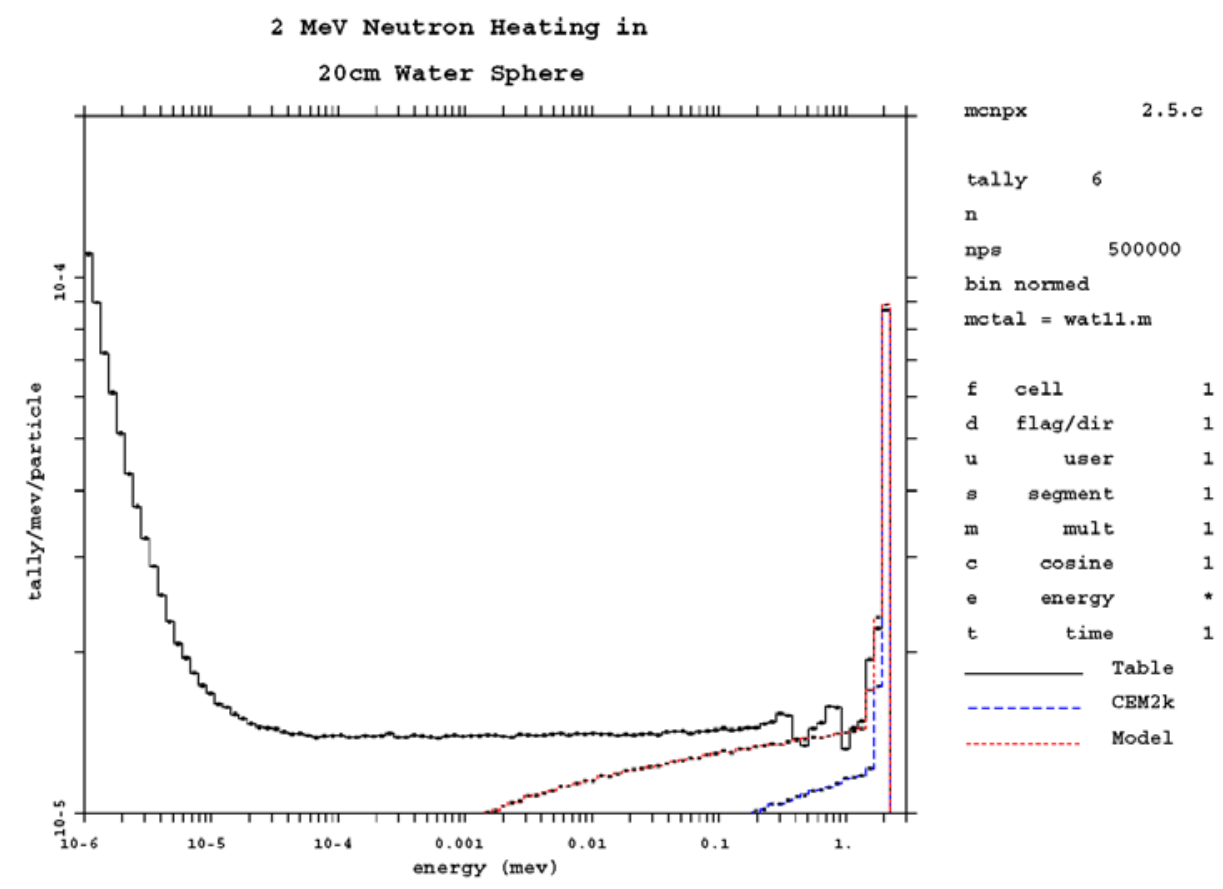

Fig. 21. The 2-MeV neutron water heating, table vs model. 
Table 3

150-MeV Neutrons in the 20-cm-Radius Water Sphere

\begin{tabular}{lccc}
\multicolumn{1}{c}{ Quantity } & Data Table & CEM2k & Model \\
Neutron Leakage & $1.0662 \mathrm{E}+00$ & $1.0781 \mathrm{E}+00$ & $1.0968 \mathrm{E}+00$ \\
Neutron Flux & $8.1373 \mathrm{E}-04$ & $6.9696 \mathrm{E}-04$ & $7.1651 \mathrm{E}-04$ \\
Neutron Heating & $4.7144 \mathrm{E}-04$ & $4.0048 \mathrm{E}-04$ & $4.6065 \mathrm{E}-04$
\end{tabular}

Table 4

2-MeV Neutrons in the 20-cm-Radius Water Sphere

0 to $2 \mathrm{MeV}$

\begin{tabular}{lccc}
\multicolumn{1}{c}{ Quantity } & Data Table & CEM2k & Model \\
Neutron Leakage & $1.7597 \mathrm{E}-01$ & $4.4548 \mathrm{E}-01$ & $6.7341 \mathrm{E}-01$ \\
Neutron Flux & $1.8921 \mathrm{E}-03$ & $7.7193 \mathrm{E}-04$ & $1.0697 \mathrm{E}-03$ \\
Neutron Heating & $5.7769 \mathrm{E}-05$ & $4.9643 \mathrm{E}-05$ & $5.7015 \mathrm{E}-05$
\end{tabular}

$1 \mathrm{eV}$ to $2 \mathrm{MeV}$

Quantity

Neutron Leakage

Neutron Flux

Neutron Heating
Data Table

9.2692E-02

$5.9237 \mathrm{E}-04$

$5.7717 \mathrm{E}-05$
CEM2k

3.3109E-01

6.6370E-04

4.9643E-05
Model

4.8552E-01

8.9802E-04

5.7015E-05

The integral results for the $20-\mathrm{MeV}$ neutron source in the 20 -cm-radius water sphere are shown in Table 3 . The physics models differ from the data tables by $10 \%$ to $20 \%$ in the range of 20 to $150 \mathrm{MeV}$.

Integral results for the $2-\mathrm{MeV}$ neutron source in the 20 -cm-radius water sphere are given in Table 4. Results are presented for the ranges of both $0 \mathrm{MeV}$ to $20 \mathrm{MeV}$ and $1 \mathrm{eV}$ to $20 \mathrm{MeV}$. It is evident that the low-energy results strongly affect the comparison. Certainly, physics models are known to be very poor at low energies, and the agreement between the tables and models in this worst-case scenario is impressive: energy deposition agrees to $15 \%$, fluxes above $1 \mathrm{eV}$ agree to within $50 \%$, and leakage is off by only a factor of 5 .

Light nuclei at low energies is the worst-case scenario for substituting neutron physics models for data tables. The $150-\mathrm{MeV}$ neutron source in the 20 -cm-radius sphere of water showed $10 \%$ to $20 \%$ differences between data tables and physics models. The $2-\mathrm{MeV}$ source showed a factor of 5 difference for leakage, $50 \%$ difference for flux, and only $15 \%$ difference for heating. 


\section{STEEL COMPARISON}

Stainless steel is another critical material. Our first stainless-steel problem consists of a $200-\mathrm{MeV}$ monodirectional neutron beam impinging on 10 - $\mathrm{cm}$-thick steel. The second problem is a $20-\mathrm{MeV}$ monodirectional neutron beam impinging on $1-\mathrm{cm}$-thick steel. The $8-\mathrm{g} / \mathrm{cm}^{3}$ steel isotopic composition is presented in the MCNPX input deck in the appendix. Calculated quantities include penetration, backscatter, flux, and heating.

Note that ${ }^{15} \mathrm{~N},{ }^{32} \mathrm{~S},{ }^{55} \mathrm{Mn}$, and ${ }^{58} \mathrm{Fe}$ do not have neutron data tables for $150 \mathrm{MeV}$. The mixand-match capability makes it possible to use physics models for these nuclides above $20 \mathrm{MeV}$. In Figs. 22 to 25, the mix-and-match results are compared with results using (1) a $20-\mathrm{MeV}$ cutoff between table and model regions; and (2) a $150-\mathrm{MeV}$ cutoff between table and model regions, which was required before mix and match. The $20-\mathrm{MeV}$ cutoff ignores the table data for most of the stainless-steel nuclides above $20 \mathrm{MeV}$. The $150-\mathrm{MeV}$ cutoff is better, but for the trace elements listed above, the $20-\mathrm{MeV}$ cross section is used in the $20-$ to $150-\mathrm{MeV}$ energy range. In all cases, physics models are used above $150 \mathrm{MeV}$.

The differences between the mix-and-match capability and having a $150-\mathrm{MeV}$ boundary between data tables and physics models is tiny because only the few trace elements previously mentioned use the $20-\mathrm{MeV}$ data in the range of 20 to $100 \mathrm{MeV}$. Using a $20-\mathrm{MeV}$ boundary between data tables and physics models makes a small but noticeable difference for the neutron heating.

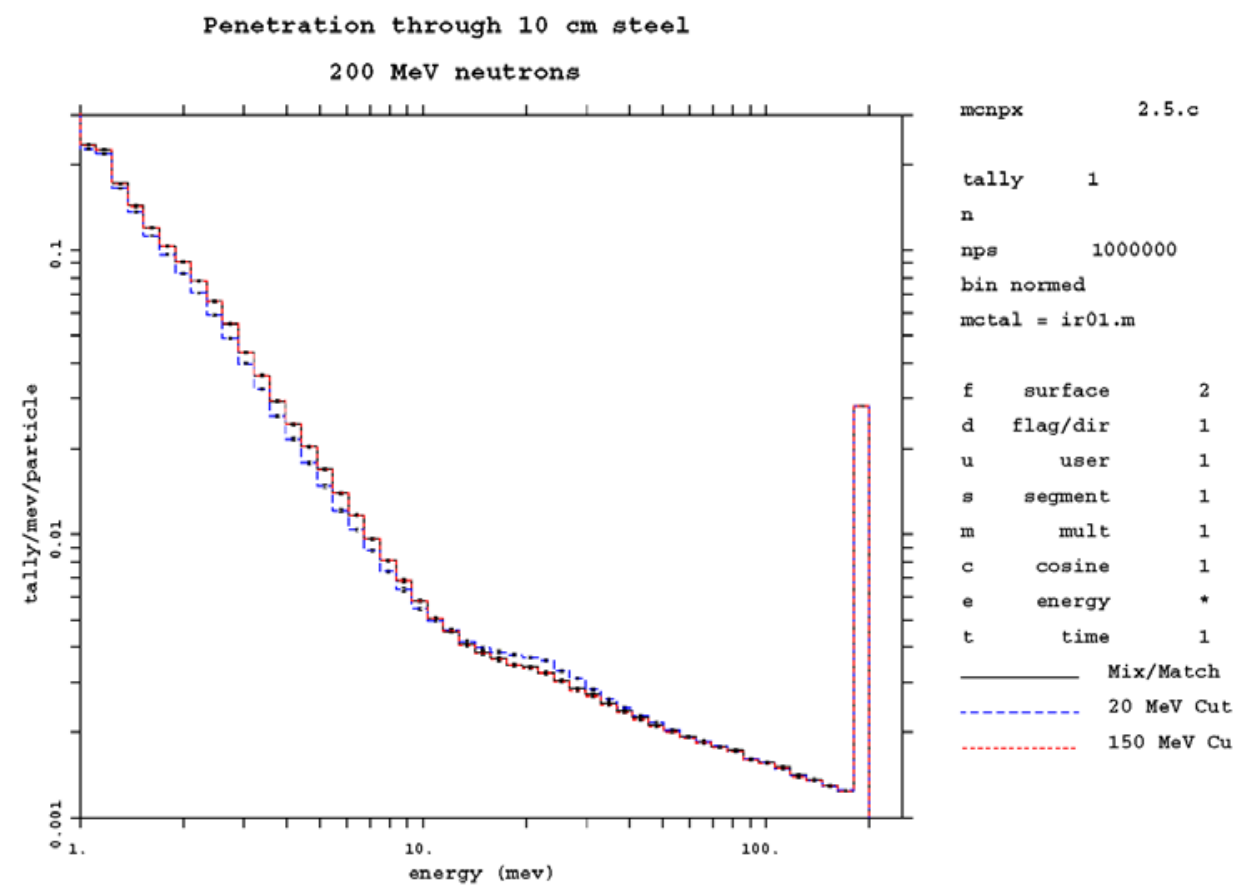

Fig. 22. The 200-MeV neutron steel penetration, new vs old. 


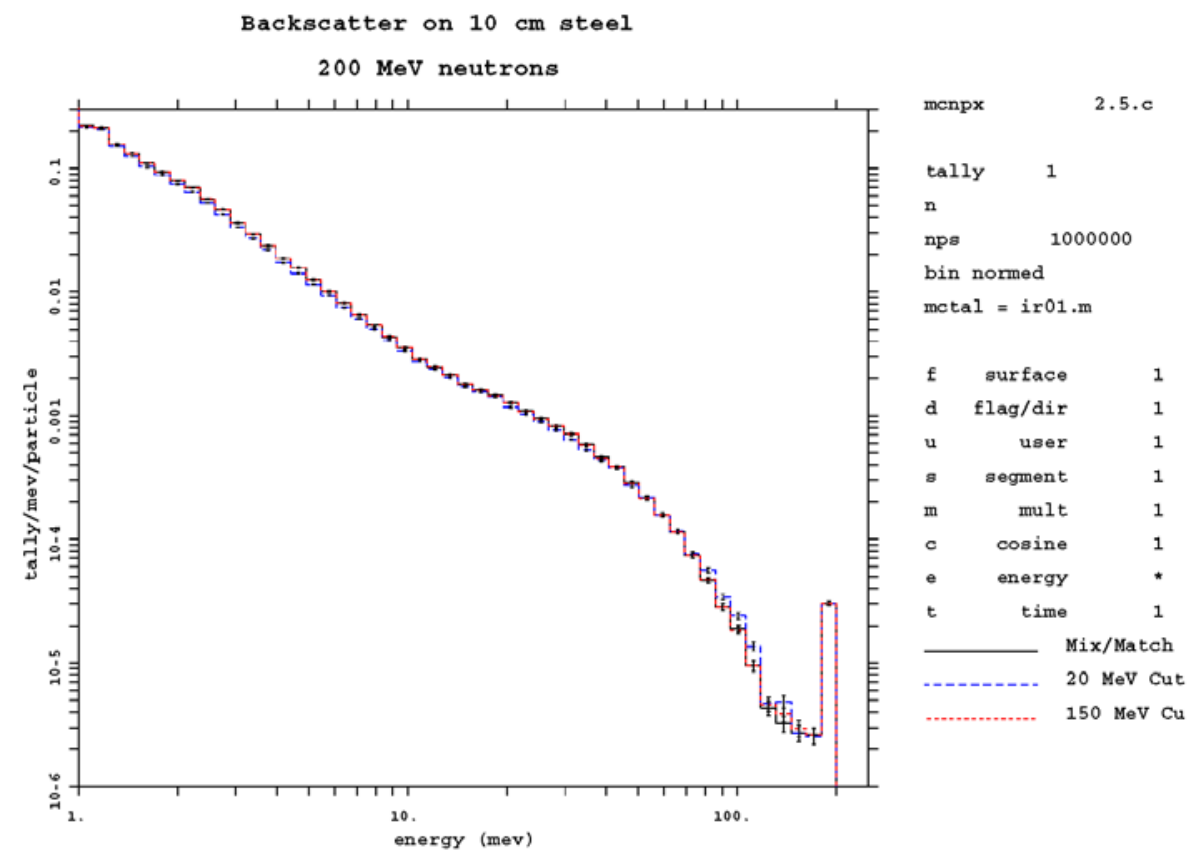

Fig. 23. The 200-MeV neutron steel backscatter, new vs old.

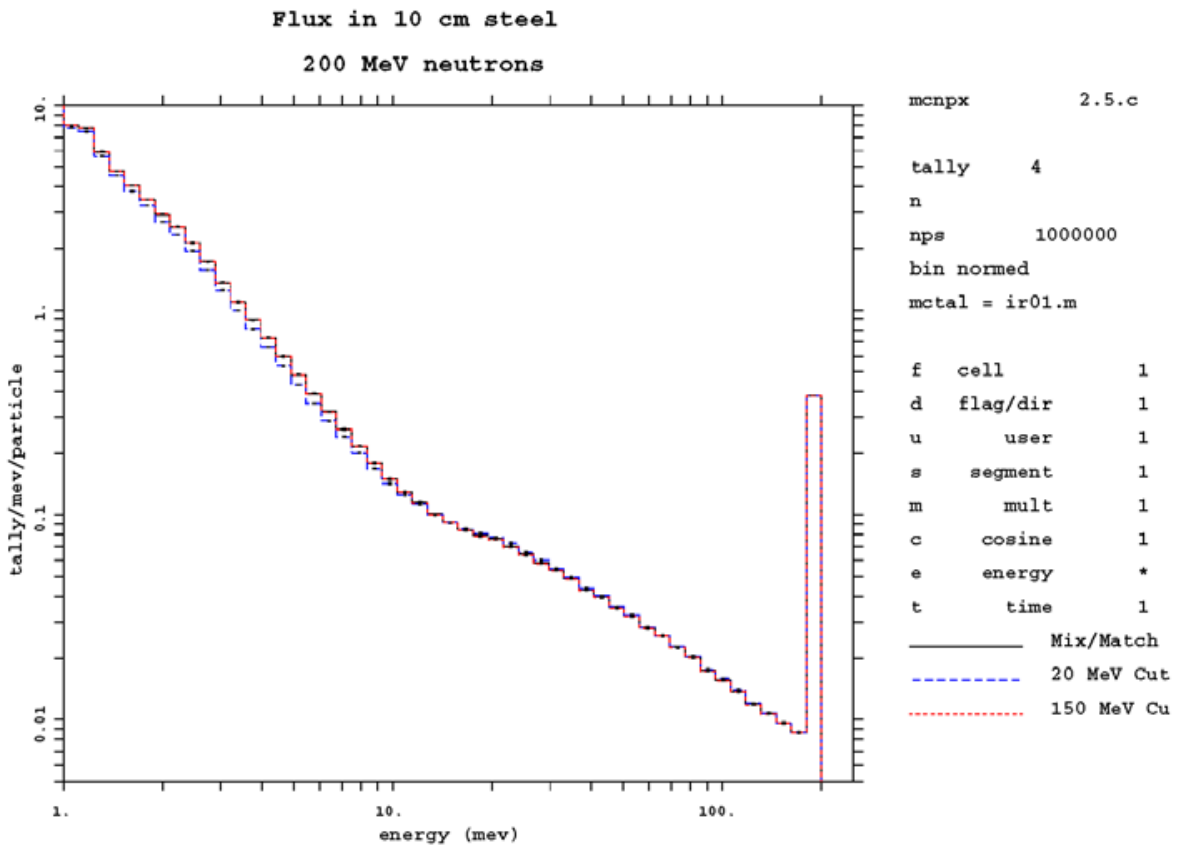

Fig. 24. The 200-MeV neutron steel flux, new vs old. 


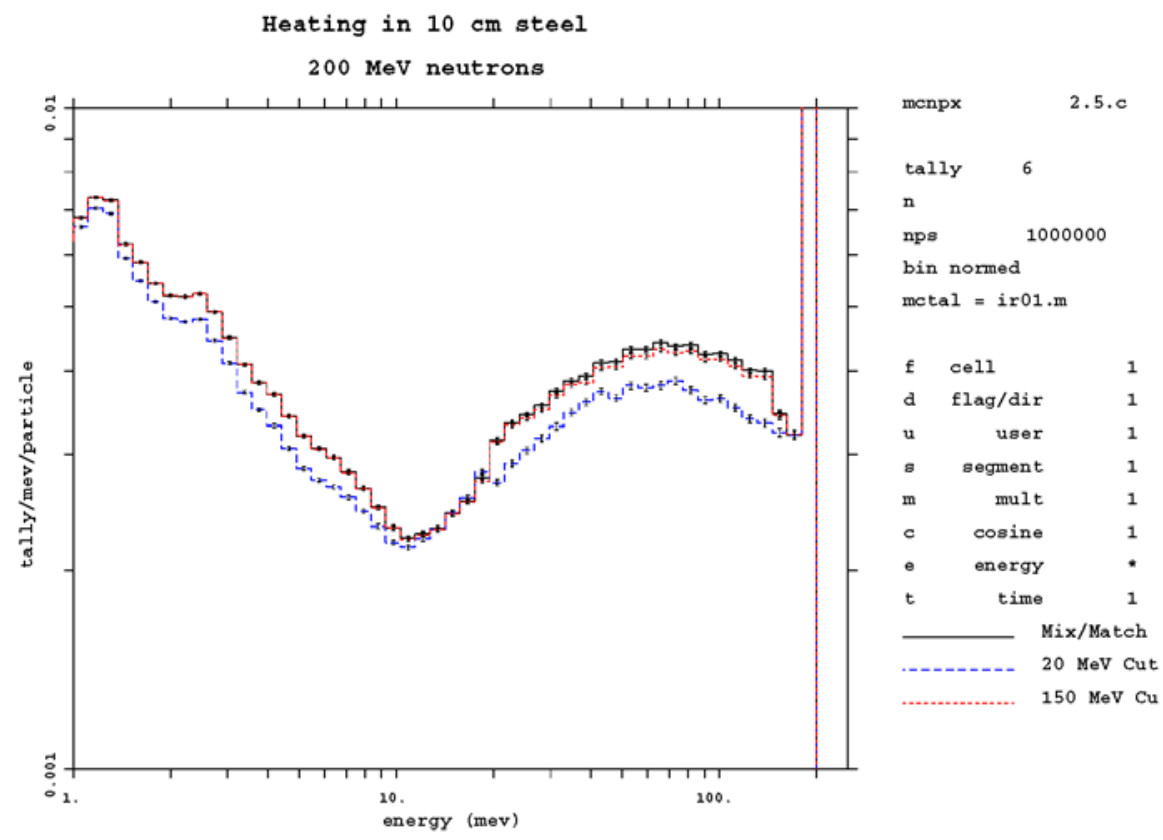

Fig. 25. The 200-MeV neutron steel heating, new vs old.

Figures 26 through 29 show the differences between using the mix-and-match tables for stainless steel and using strictly models instead.

The integral results over all energies are tabulated in Table 5. The neutron data tables and default physics model agree excellently. The CEM2k results are not as good.

When the CEM2k and default model calculations are rerun using a "zoo" of additional particles, the integral results change, as illustrated in Table 6. The "zoo" of particles added is

mode $\mathrm{n} \mathrm{h} / \mathrm{zpd} \mathrm{ta}$

Thus, in addition to neutrons, there are protons, positive pions, neutral pions, photons, deuterons, tritons, and alphas.

Note that the neutron heating in the neutron-only data table problem correctly includes the heating from all daughter particles, which is presumed to be deposited without further transport. The two model physics calculations, CEM2k and the default model, now agree better with the data table total heating calculation because the heating from all particles is included in all cases.

The total heating (for all particles) is illustrated in Fig. 30. As shown in Table 6, the integral results agree well; however, as shown in Fig. 30, the neutron-only (data table) calculation deposits most of the energy in the $180-$ to $200-\mathrm{MeV}$ energy bin. The model physics calculations with all of the progeny particles deposit the energy along the progeny particle tracks. 


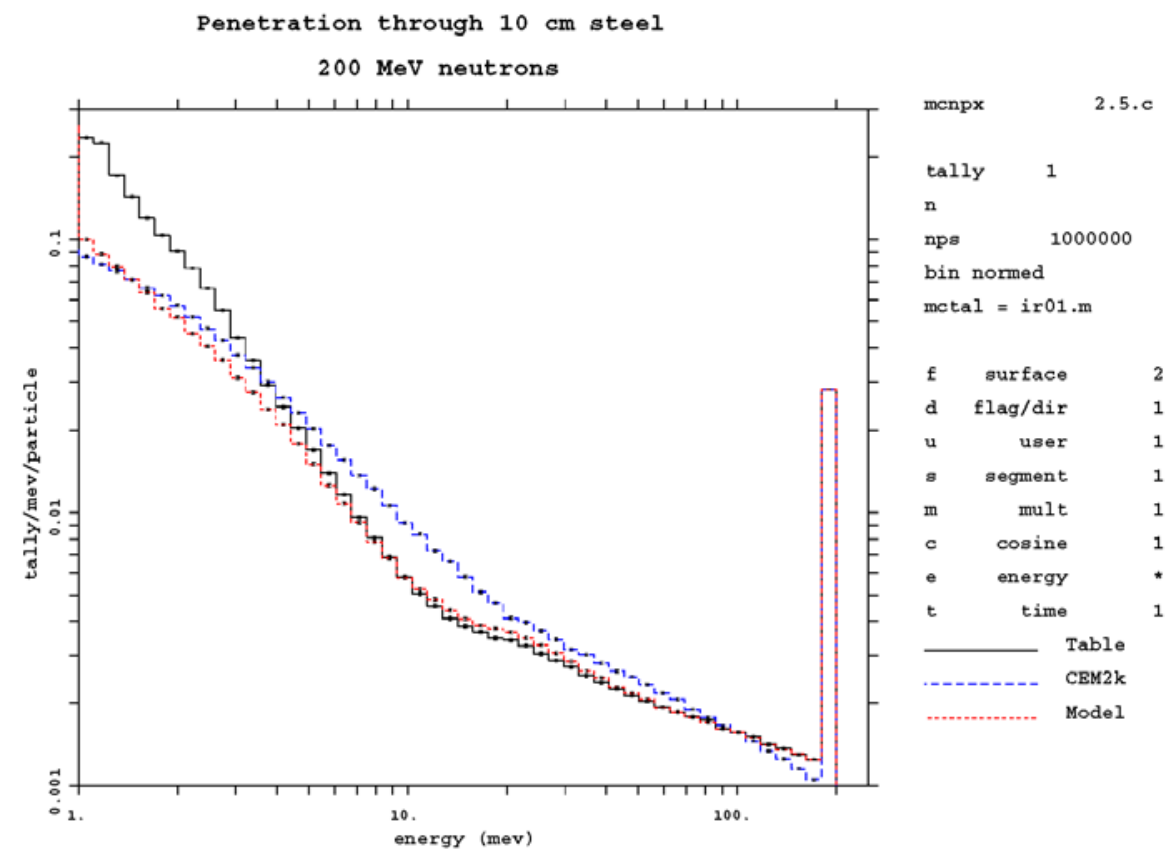

Fig. 26. The 200-MeV neutron steel penetration, table vs model.

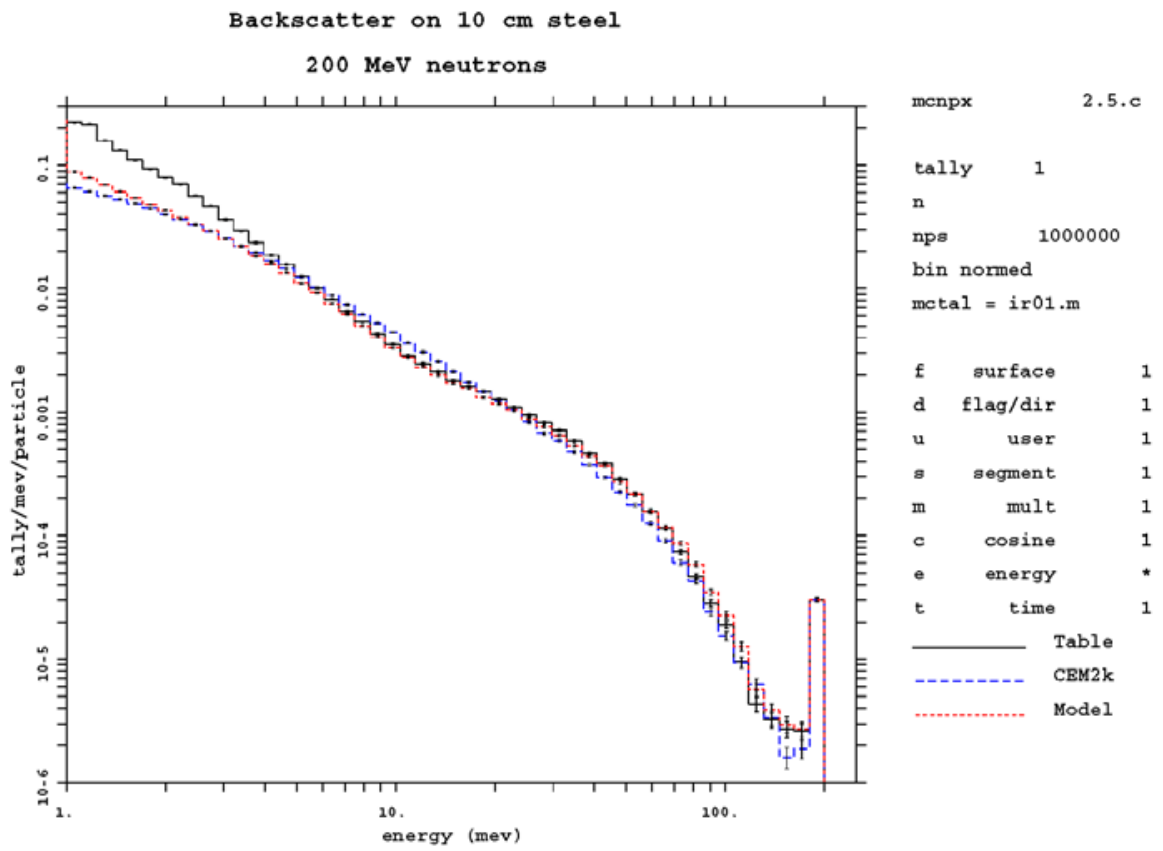

Fig. 27. The 200-MeV neutron steel backscatter, table vs model. 


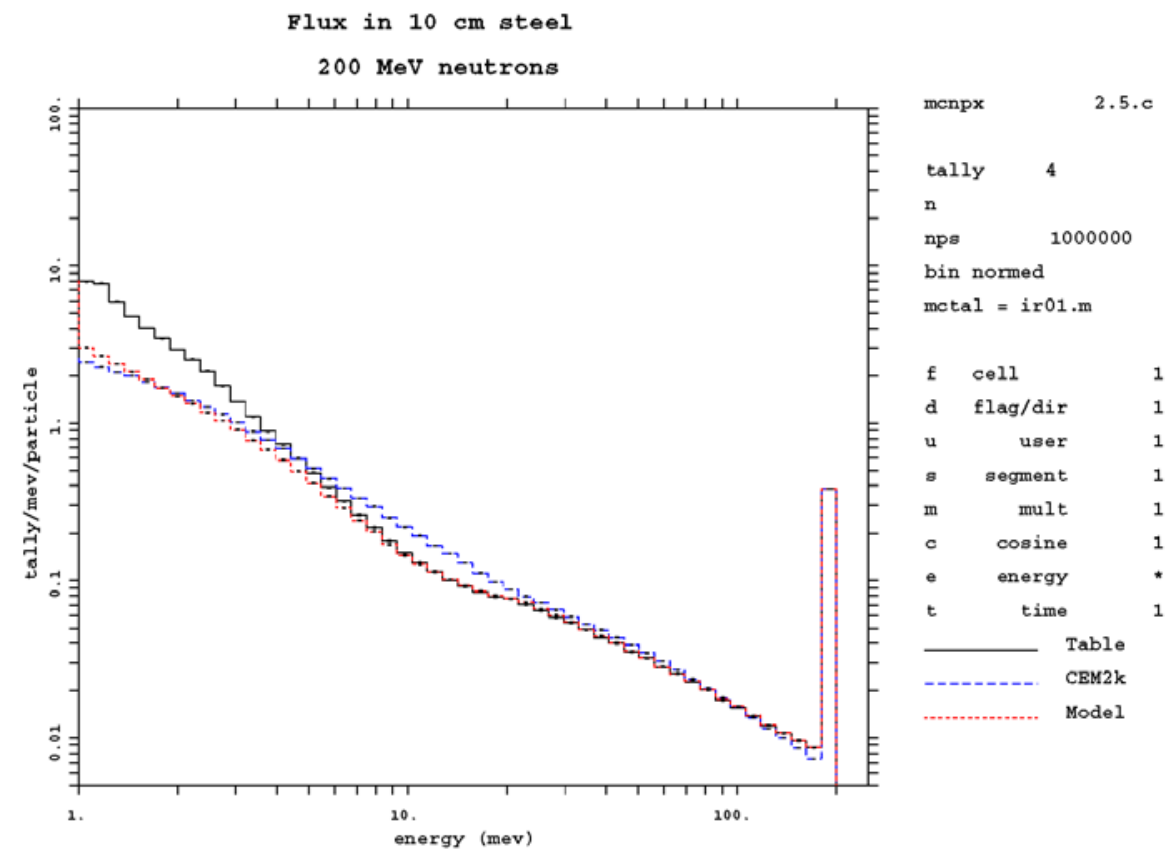

Fig. 28. The 200-MeV neutron steel flux, table vs model.

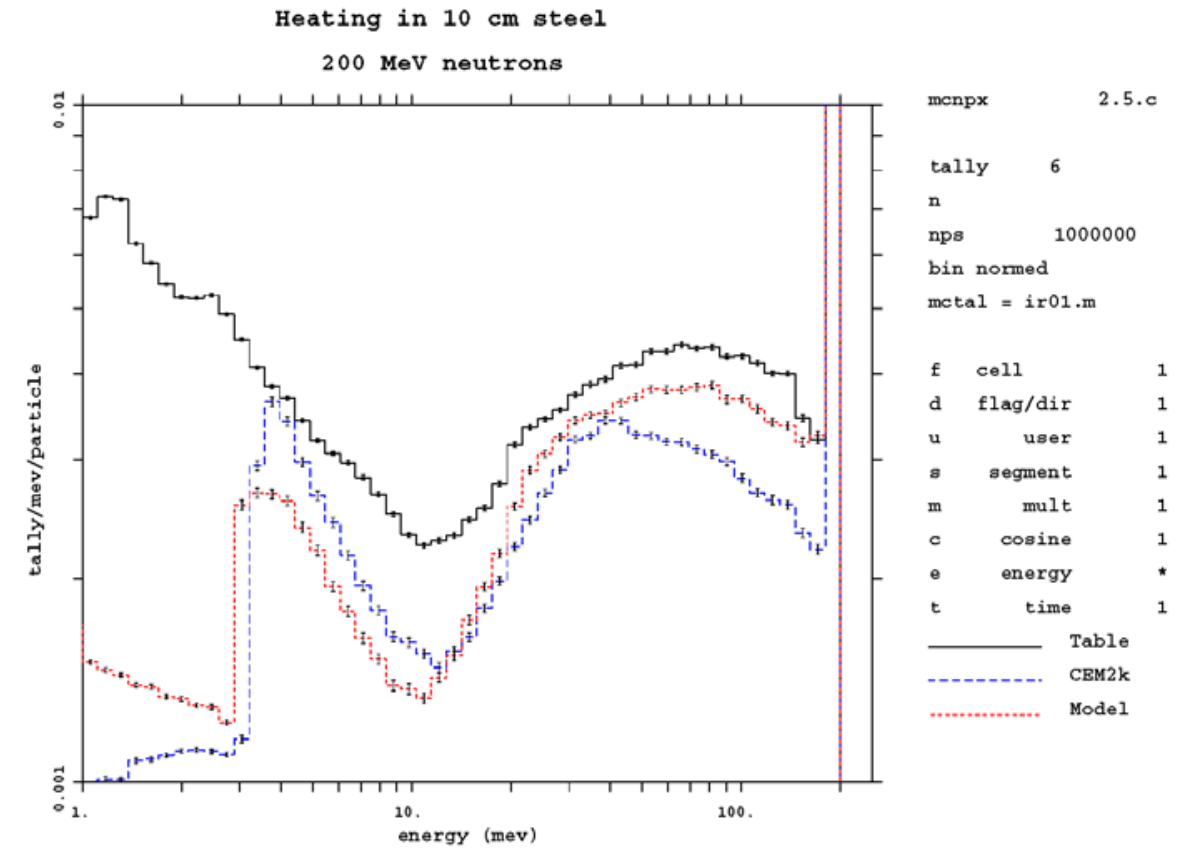

Fig. 29. The 200-MeV neutron steel heating, table vs model. 
Table 5

200-MeV Neutrons Impinging on 10-cm-Thick Stainless-Steel Slab: 0 to $200 \mathrm{MeV}$

\begin{tabular}{lccc}
\multicolumn{1}{c}{ Quantity } & Data Table & CEM2k & Model \\
Neutron Penetration & $1.5595 \mathrm{E}+00$ & $1.2567 \mathrm{E}+00$ & $1.5664 \mathrm{E}+00$ \\
Neutron Backscatter & $6.5962 \mathrm{E}-01$ & $2.7833 \mathrm{E}-01$ & $6.5341 \mathrm{E}-01$ \\
Neutron Flux & $3.5544 \mathrm{E}+01$ & $2.1934 \mathrm{E}+01$ & $3.3541 \mathrm{E}+01$ \\
Neutron Heating & $4.0758 \mathrm{E}+00$ & $3.3203 \mathrm{E}+00$ & $3.9753 \mathrm{E}+00$
\end{tabular}

Table 6

200-MeV Neutrons Impinging on 10-cm-Thick Stainless-Steel Slab: 0 to $200 \mathrm{MeV}$

Quantity

Neutron Penetration

Neutron Backscatter

Neutron Flux

Neutron Heating

Total Heating
Data Table

$1.5595 \mathrm{E}+00$

$6.5962 \mathrm{E}-01$

$3.5544 \mathrm{E}+01$

$4.0758 \mathrm{E}+00$

$4.0758 \mathrm{E}+00$
CEM2k+zoo

$1.2650 \mathrm{E}+00$

2.8266E-01

$2.2095 \mathrm{E}+01$

1.9220E-01

$4.0309 \mathrm{E}+00$
Model+zoo

$1.5875 \mathrm{E}+00$

6.6924E-01

$3.4103 \mathrm{E}+01$

1.4086E-01

$4.2283 \mathrm{E}+00$

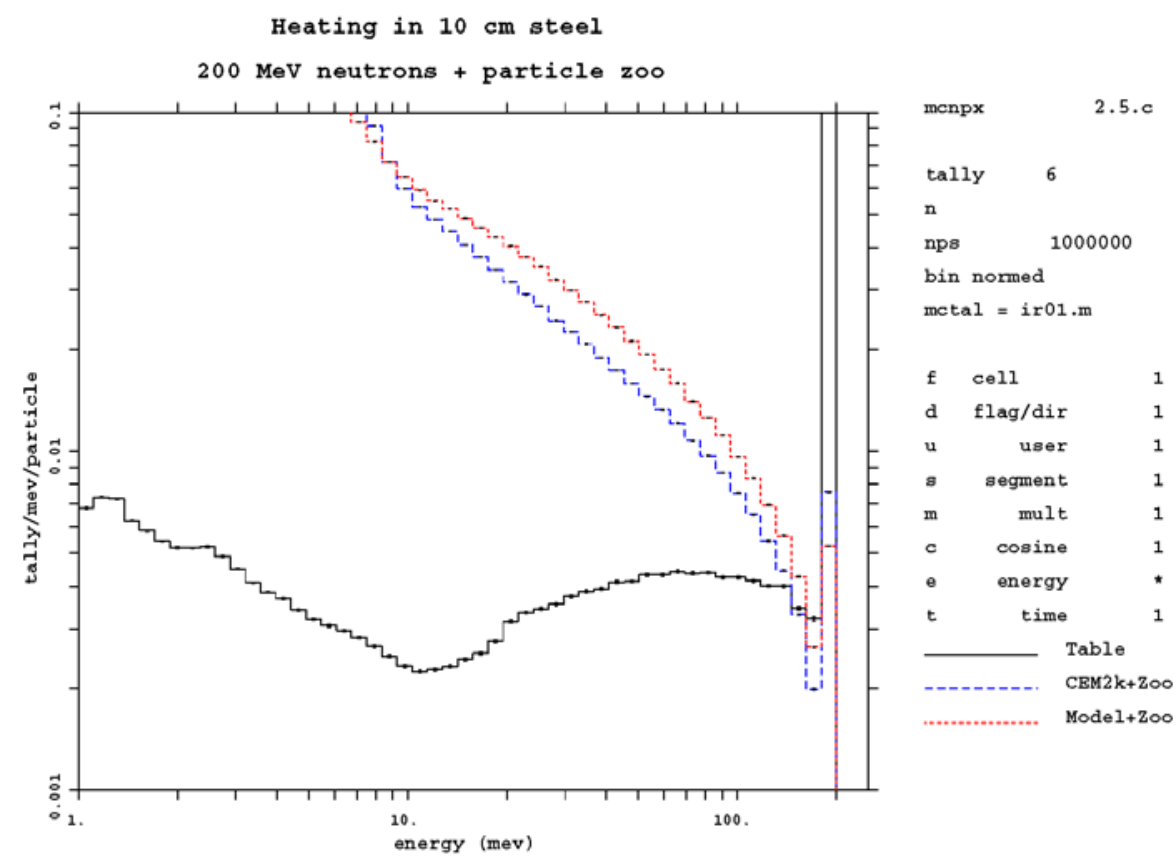

Fig. 30. The 200-MeV neutron steel heating, table vs model, zoo. 
A closer examination of the low-energy results indicates that the physics models are really quite good until the neutrons fall below $1 \mathrm{MeV}$. Figures 31 through 34 refer to a $20-\mathrm{MeV}$ monodirectional source normal to a $1-\mathrm{cm}$-thick stainless-steel infinite slab.

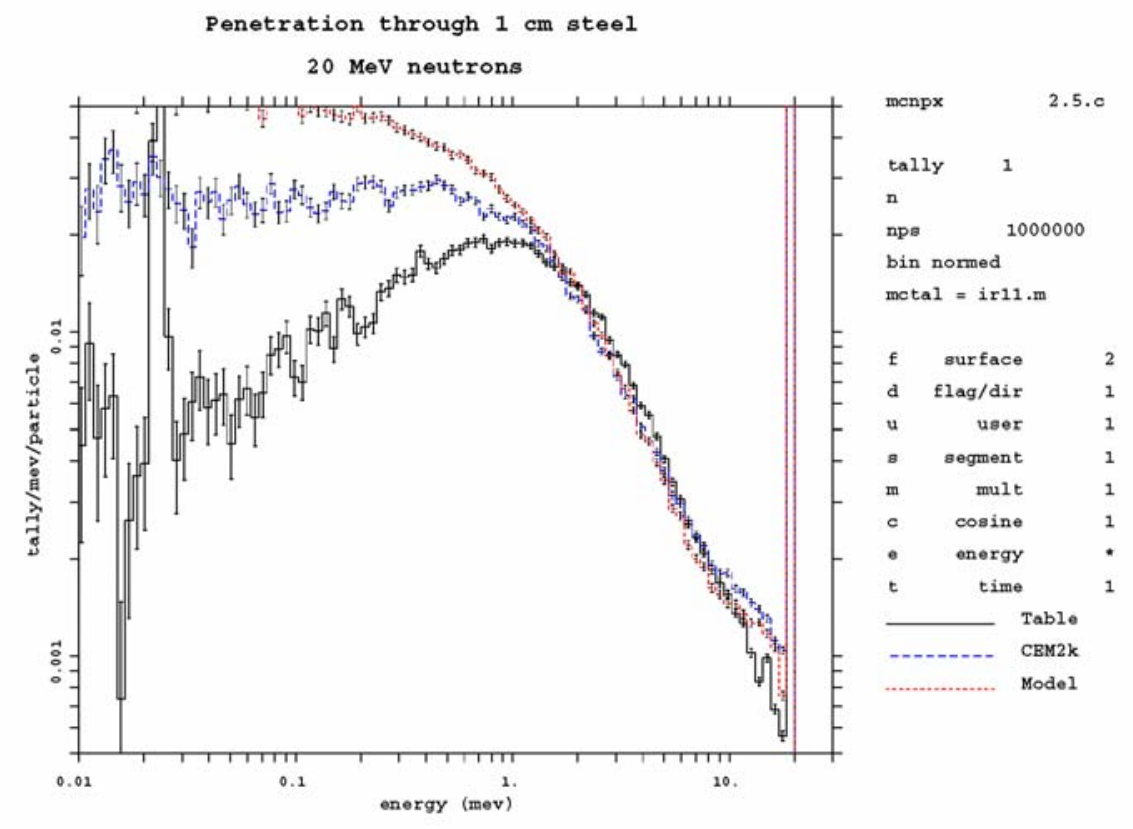

Fig. 31. The $20-\mathrm{MeV}$ neutron steel penetration, table vs model.

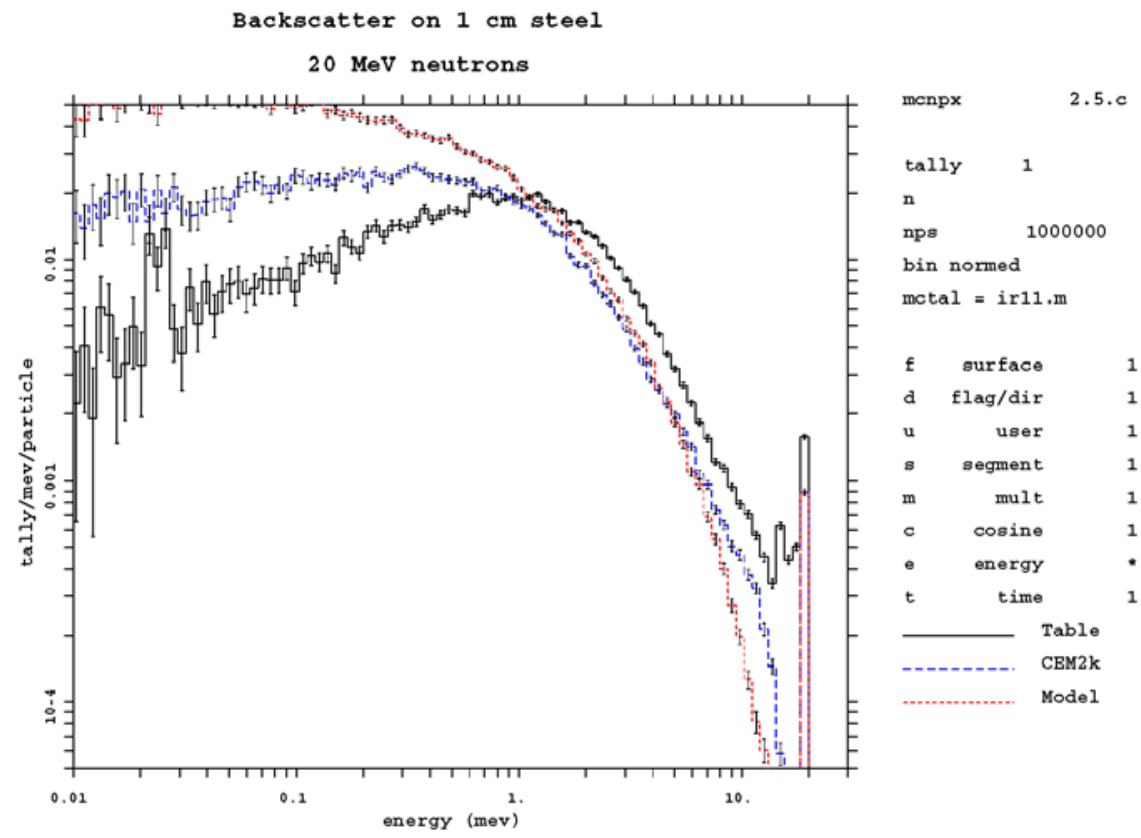

Fig. 32. The $20-\mathrm{MeV}$ neutron steel backscatter, table vs model. 


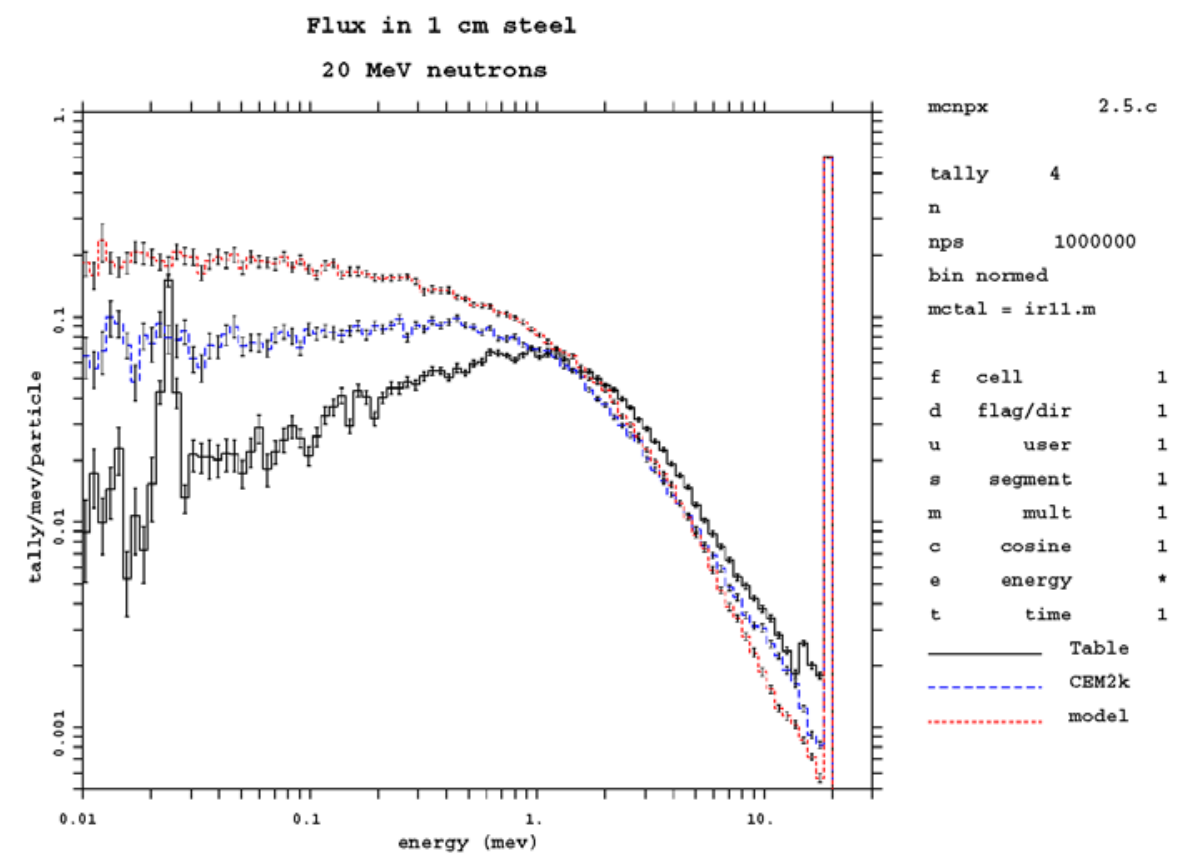

Fig. 33. The 20-MeV neutron steel flux, table vs model.

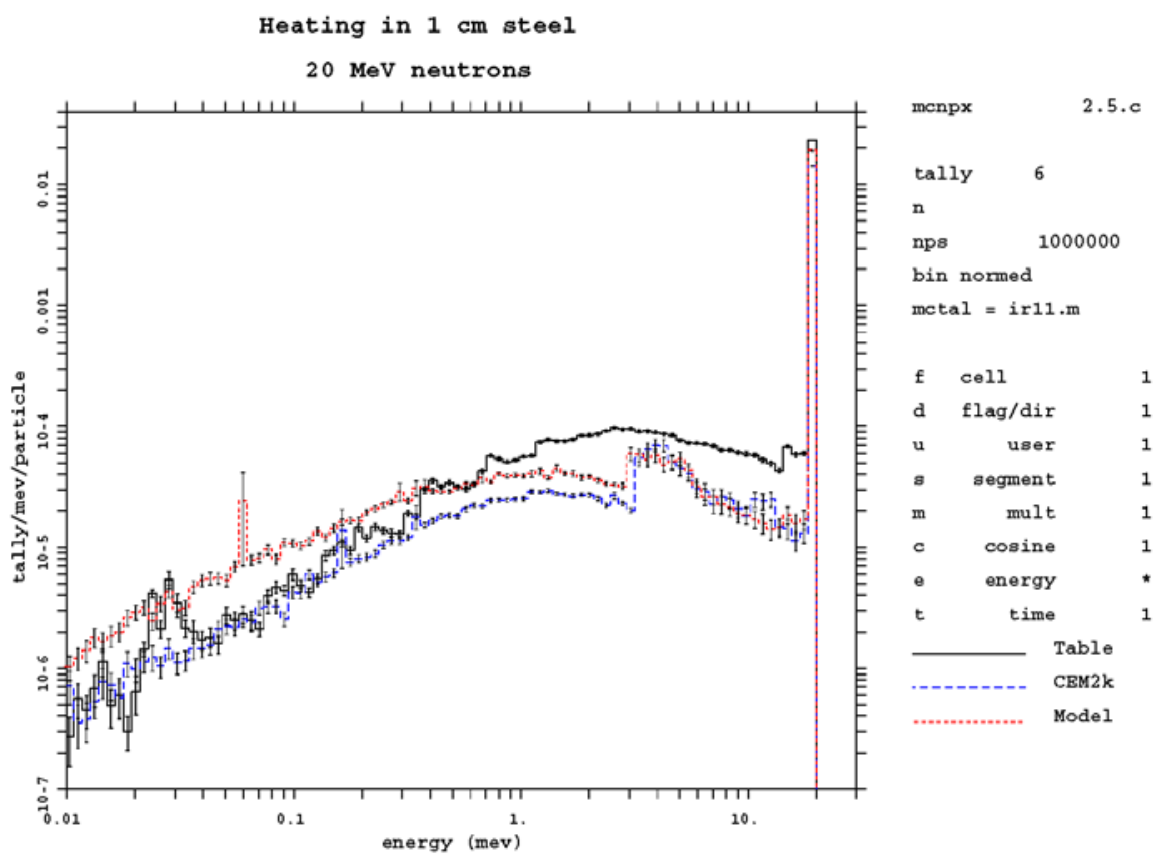

Fig. 34. The 20-MeV neutron steel heating, table vs model. 
The integral results are presented in Table 7.

The integral results from 0 to $20 \mathrm{MeV}$ show good agreement between the data table and the physics model calculations. Although the neutron penetration looks similar, the attenuations (fraction of source particles not penetrating the thin slab) for the data table and the default-model physics calculations are significantly different. The fluxes are in excellent agreement. Note that when only neutrons are run, the heating from all particles is put into the neutron heating. When the zoo of particles is run, the neutron heating is small and the total heating now compares to the total neutron heating ( $20 \%$ difference). Note further that the neutron heating number does not include photons or electrons; these are included only by using all the particles in the zoo (electron heating is included in the photon heating of the zoo); thus, the zoo heating is higher than the neutron heating in the mode $\mathrm{N}$ problems.

Figure 35 compares the total heating from the data table calculation and the model + zoo calculation. Note the constant heating for the model + zoo below $1 \mathrm{MeV}$ because the heating data run out at $1 \mathrm{MeV}$; however, in this problem the default energy cutoff for model particles was dropped from the default $1 \mathrm{MeV}$ to the lowest allowed, $1 \mathrm{keV}$.

The stainless-steel slab results show that the mix-and-match capability enables the use of data tables up to their maximum table energies before switching over to models. It is very advantageous not to have a global cutoff of, for example, $20 \mathrm{MeV}$, below which all particles in the problem use data tables and above which all particles in the problem use physics models.

Second, the stainless-steel problems demonstrate that for higher $\mathrm{Z}$ materials, neutron models can be used when no tables are available. The physics models do not really fail until the energies fall below $\sim 1 \mathrm{MeV}$.

Table 7

20-MeV Neutrons Impinging on 1-cm-Thick Stainless-Steel Slab: 0 to $20 \mathrm{MeV}$

\begin{tabular}{lcccc}
\multicolumn{1}{c}{ Quantity } & Data Table & CEM2k & Model & Model+zoo \\
Neutron Penetration & $9.6976 \mathrm{E}-01$ & $9.7752 \mathrm{E}-01$ & $9.8769 \mathrm{E}-01$ & $9.8783 \mathrm{E}-01$ \\
Neutron Backscatter & $6.8292 \mathrm{E}-02$ & $5.4757 \mathrm{E}-02$ & $7.0302 \mathrm{E}-02$ & $7.0162 \mathrm{E}-02$ \\
Neutron Flux & $1.2093 \mathrm{E}+00$ & $1.1852 \mathrm{E}+00$ & $1.2327 \mathrm{E}+00$ & $1.2323 \mathrm{E}+00$ \\
Neutron Heating & $3.8544 \mathrm{E}-02$ & $2.3226 \mathrm{E}-02$ & $3.1178 \mathrm{E}-02$ & $6.1903 \mathrm{E}-03$ \\
Total Heating & $3.8544 \mathrm{E}-02$ & $2.3226 \mathrm{E}-02$ & $3.1178 \mathrm{E}-02$ & $4.6914 \mathrm{E}-02$
\end{tabular}




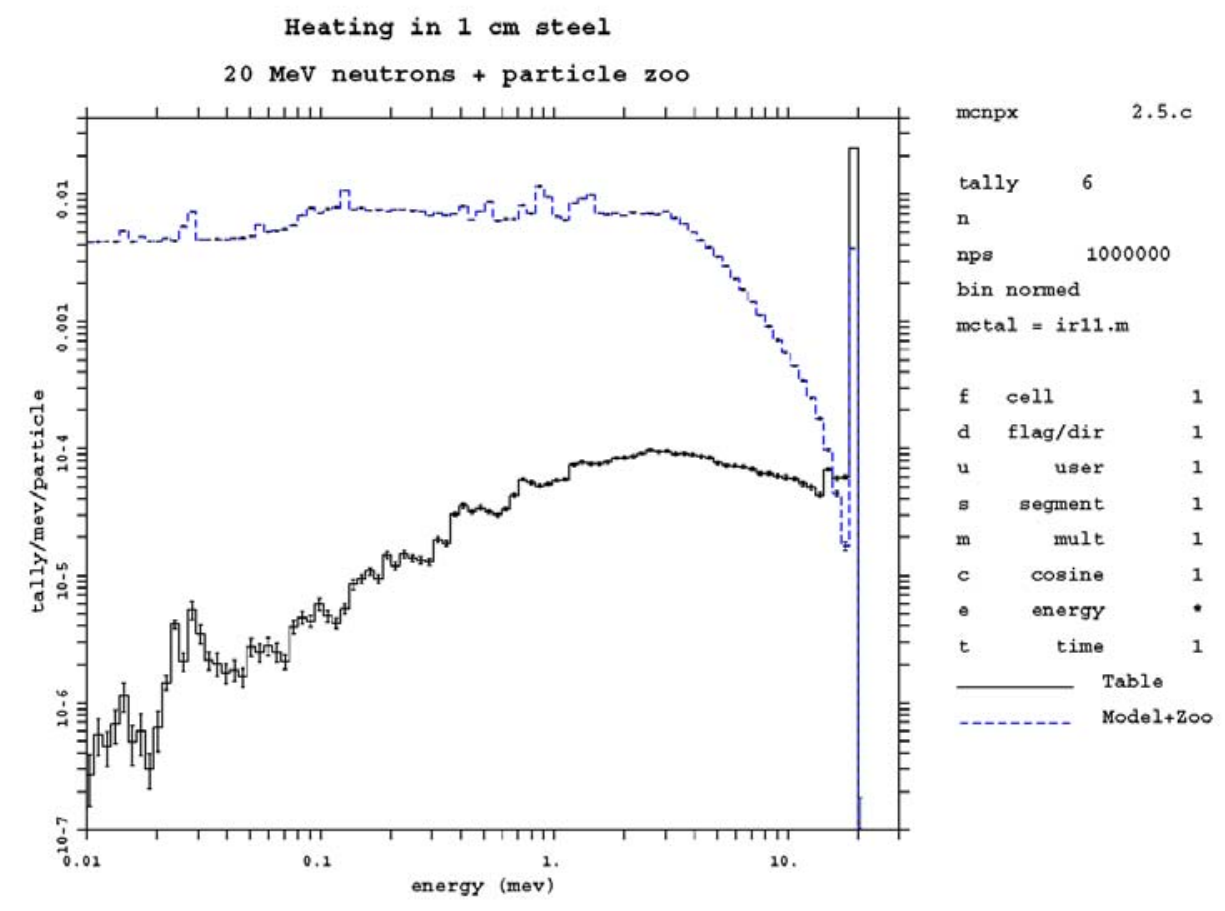

Fig. 35. The 20-MeV neutron steel heating, table vs model + zoo.

\section{TUNGSTEN COMPARISON}

Tungsten is an important proton target for neutron conversion. The tungsten comparison is for a 20-cm-high can having a radius of $5 \mathrm{~cm}$ and a density of $19.3 \mathrm{~g} / \mathrm{cm}^{3}$. The $200-\mathrm{MeV}$ monodirectional protons start at the base center, and the penetration, backscatter, flux, and heating of protons and neutrons are calculated. Comparisons are between

- tungsten using $150-\mathrm{MeV}$ data tables and neutron and proton models for ${ }^{180} \mathrm{~W}$;

- tungsten using $150-\mathrm{MeV}$ data tables with ${ }^{180} \mathrm{~W}$ lumped into ${ }^{182} \mathrm{~W}$ so that no models are used (this was the best capability before mix and match);

- tungsten with CEM2k neutron and proton models; and

- $\quad$ tungsten with the default models.

The default models are used above $150 \mathrm{MeV}$ except for the CEM2k calculation, where the CEM2k models are used from 0 to $200 \mathrm{MeV}$. The lower-energy cutoff is set to zero so that the default model cutoff of $1 \mathrm{MeV}$ is overridden; the lowest model energy then is 
$1 \mathrm{keV}$. The results of these calculations are compared in Figs. 36 to 43 . Note that proton backscatter is omitted because it was small and statistically noisy.

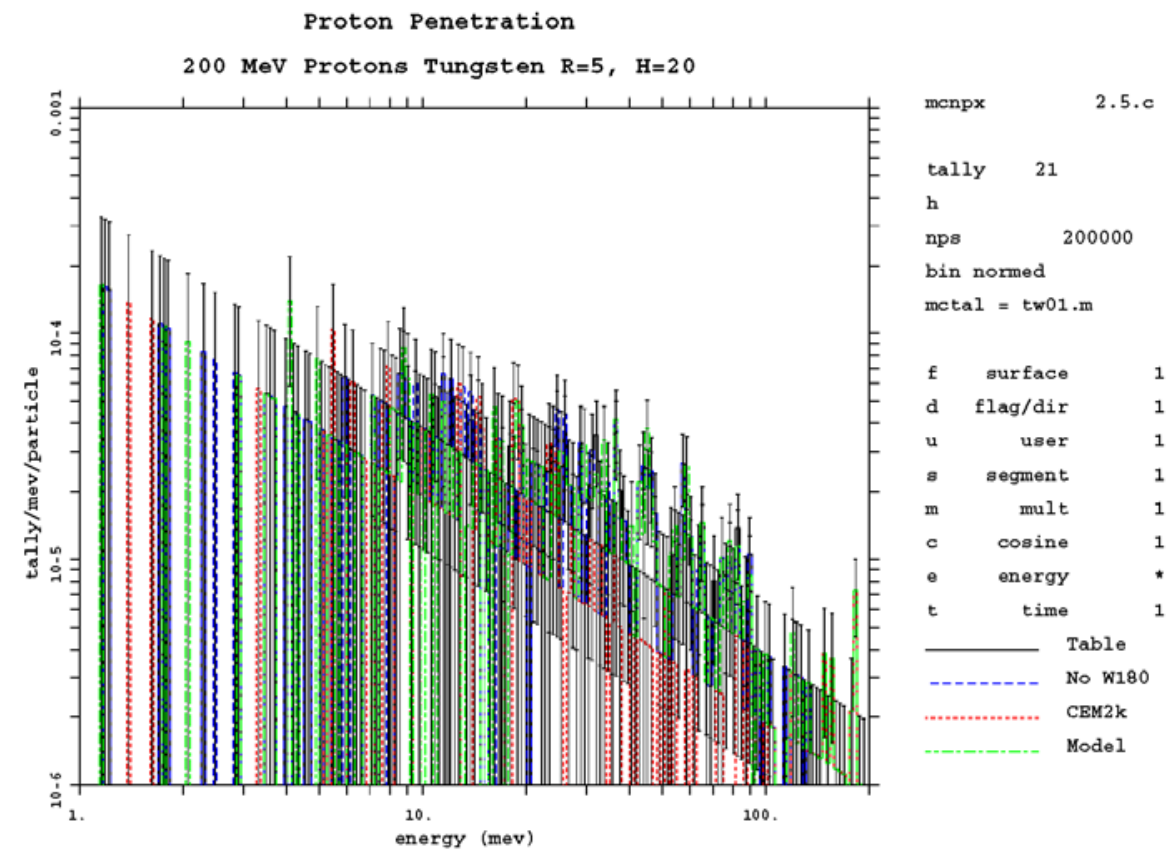

Fig. 36. The 200-MeV proton tungsten penetration, table vs model.

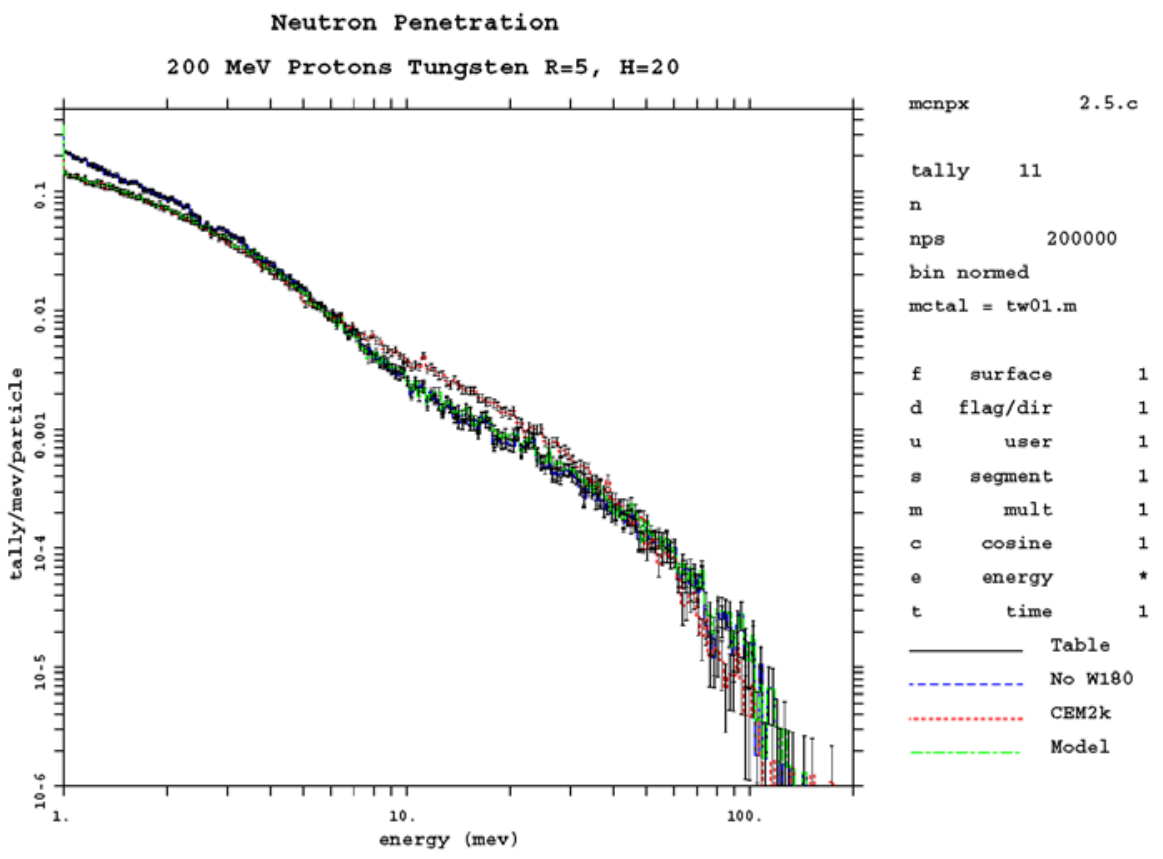

Fig. 37. Tungsten neutron penetration from $200-\mathrm{MeV}$ protons, table vs model. 


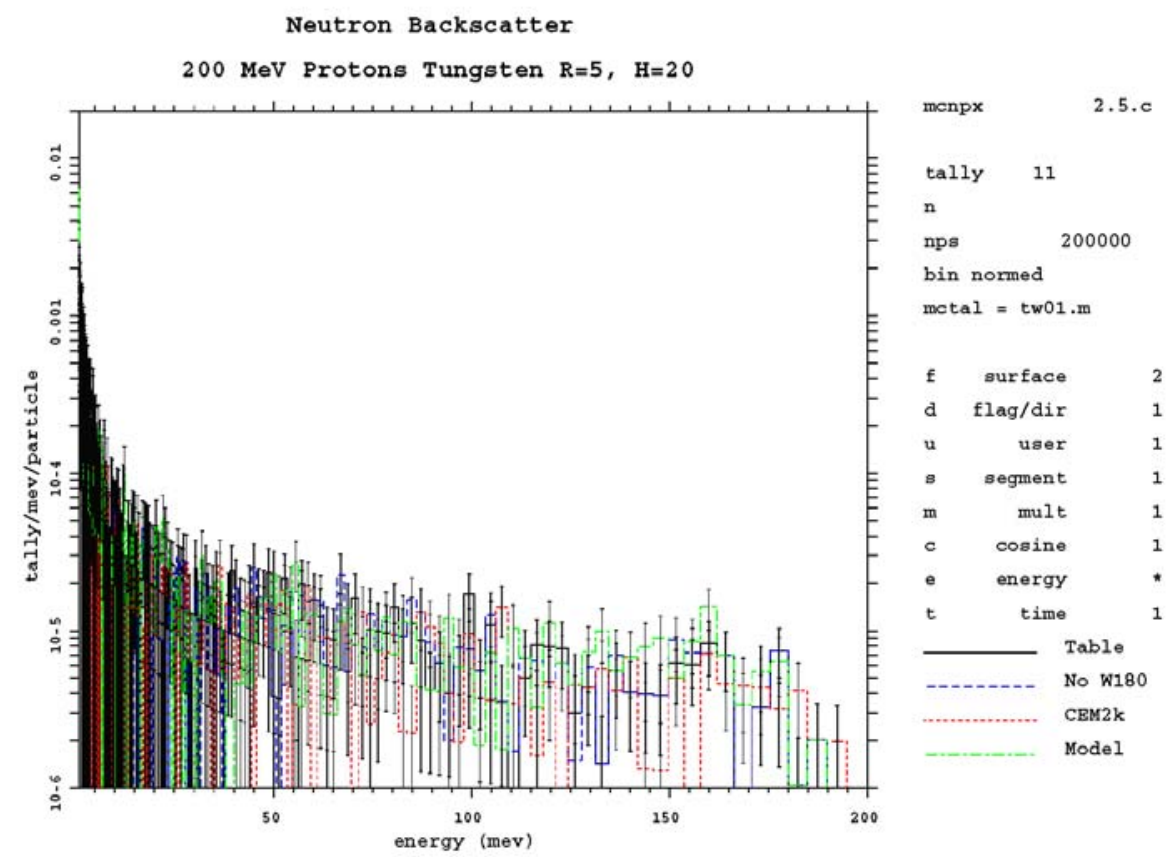

Fig. 38. Tungsten neutron backscatter from 200-MeV protons, table vs model.

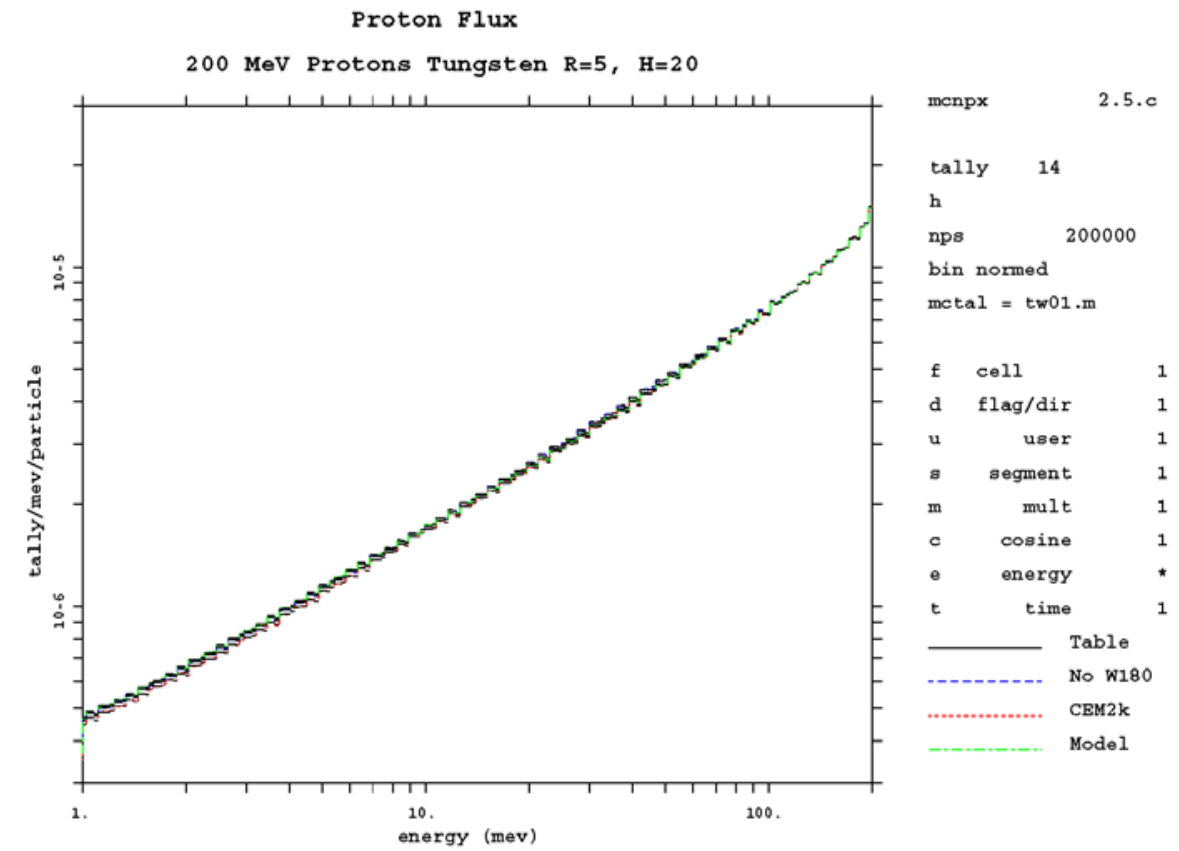

Fig. 39. The 200-MeV proton tungsten flux, table vs model. 


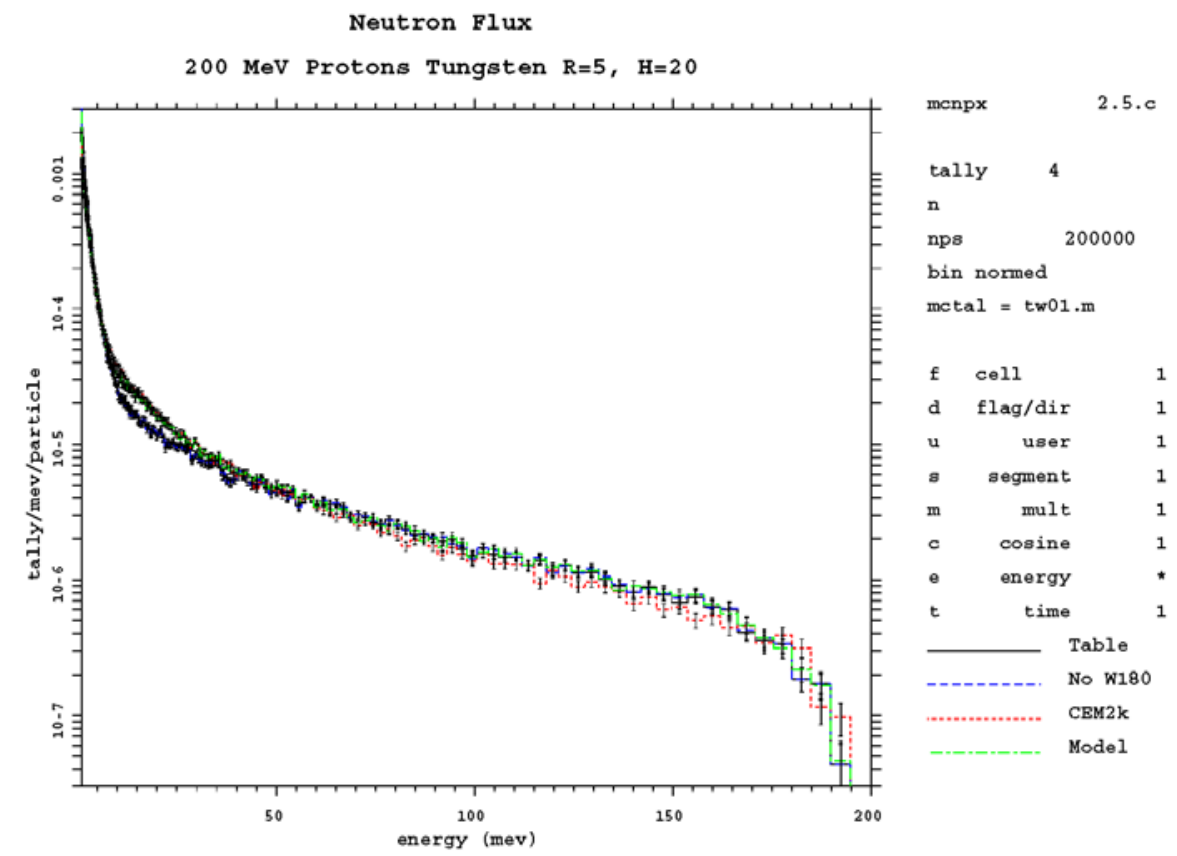

Fig. 40. Tungsten neutron flux from $200-\mathrm{MeV}$ protons, table vs model.

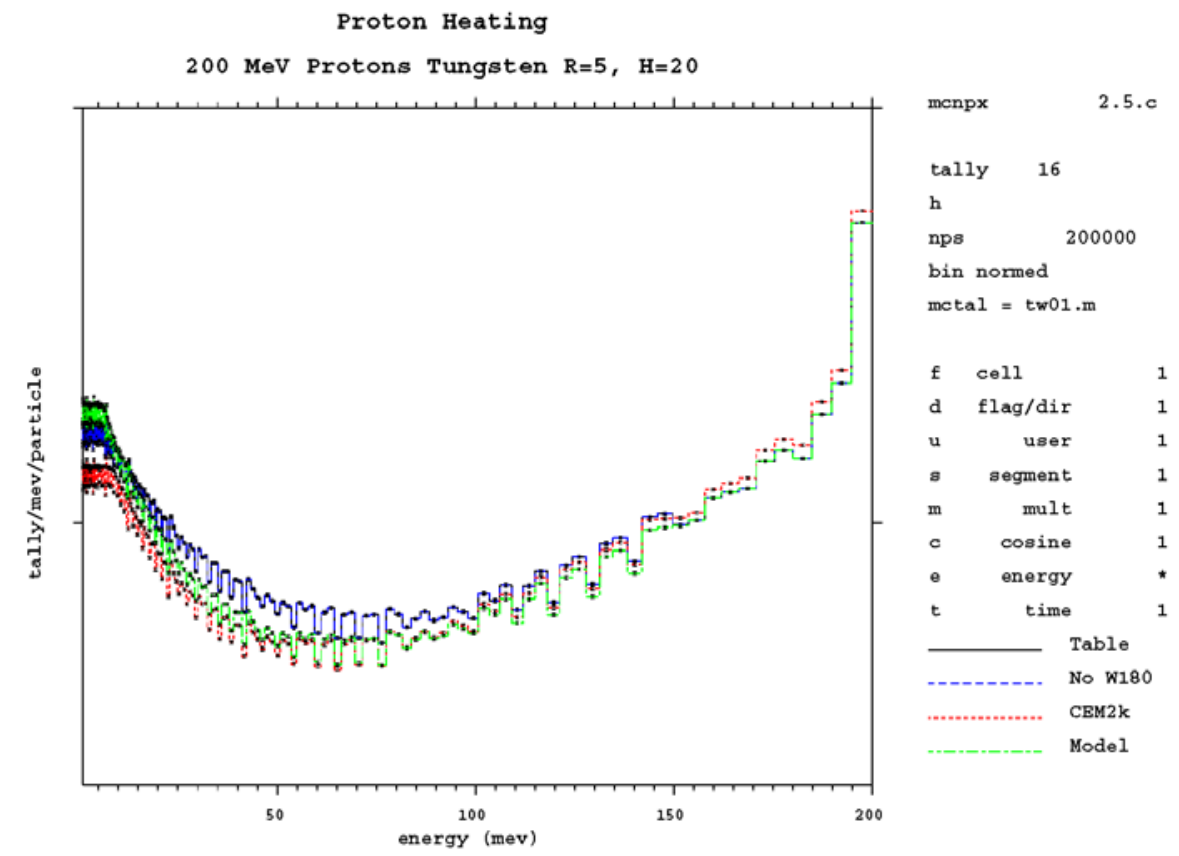

Fig. 41. The 200-MeV proton tungsten heating, table vs model. 


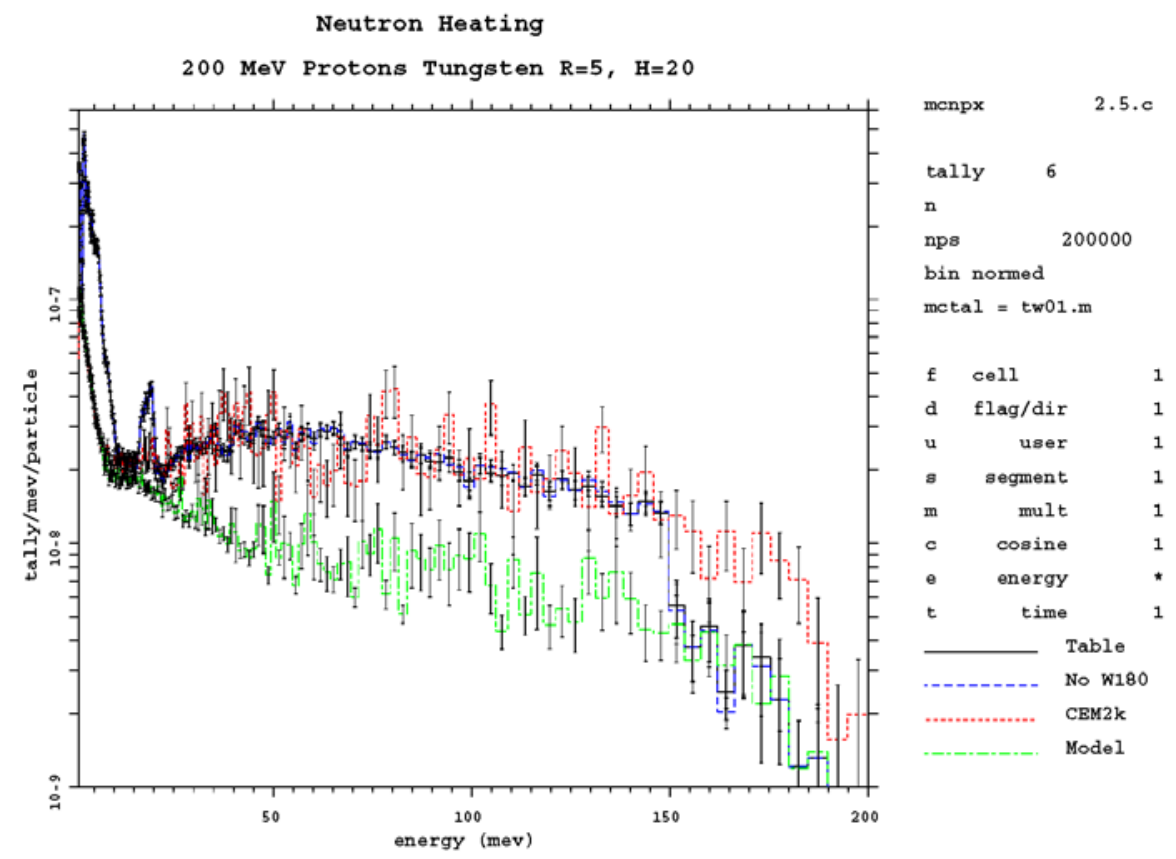

Fig. 42. Tungsten neutron heating from $200-\mathrm{MeV}$ protons, table vs model.

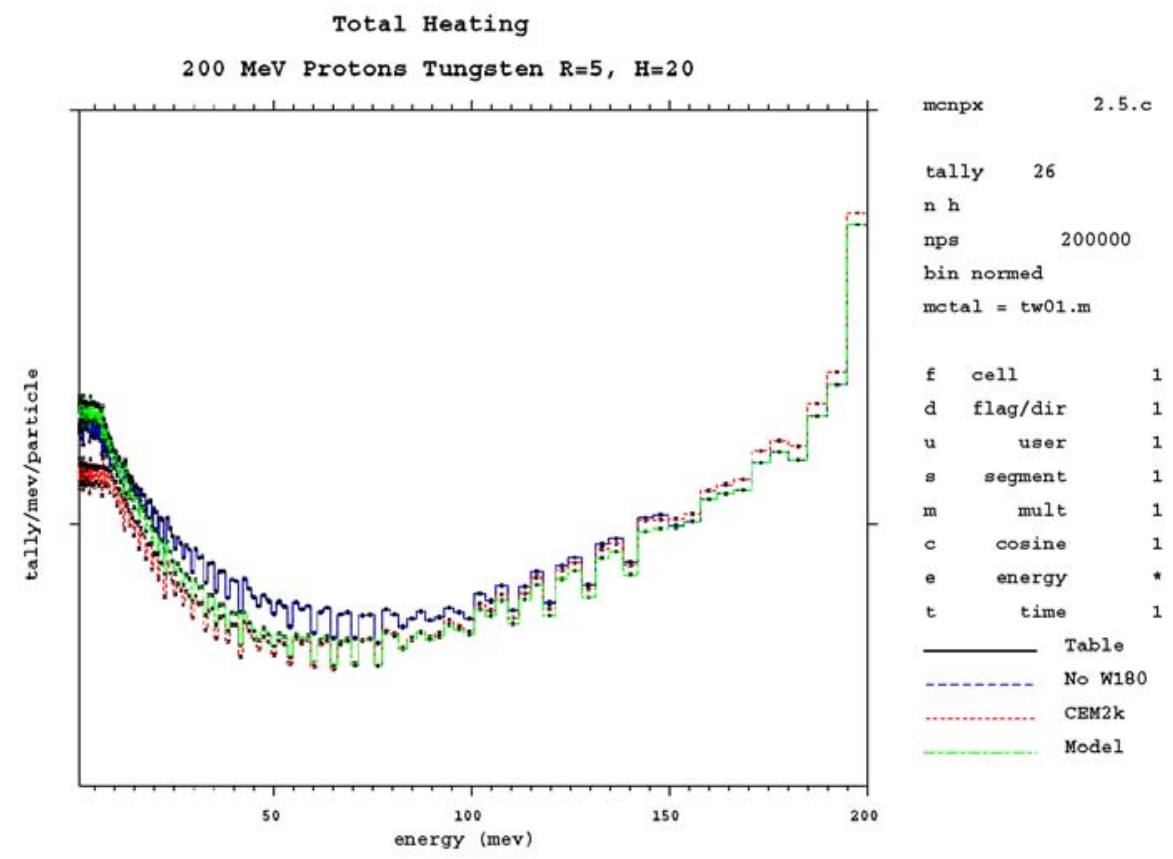

Fig. 43. Tungsten total heating from 200-MeV protons, table vs model. 
The proton penetration is not plotted because it was not converged.

Table 8 presents the integral results from 0 to $200 \mathrm{MeV}$ and from 1 to $200 \mathrm{MeV}$. Proton penetration and CEM $2 \mathrm{k}$ proton backscatter were not converged. Neutron heating had a relative error of $3 \%$, and proton backscatter had a relative error of $6 \%$. All other quantities were converged to relative errors $<1 \%$.

The tungsten calculations demonstrate that the proton physics models have excellent agreement with the proton data tables. Further, a proton physics model for the trace isotope, ${ }^{180} \mathrm{~W}$, may be mixed with the proton data tables for the other isotopes of tungsten. Also, the approximation of lumping the trace isotope ${ }^{180} \mathrm{~W}$ into ${ }^{182} \mathrm{~W}$ is excellent.

Table 8

200-MeV Protons Impinging on Tungsten Can

0 to $200 \mathrm{MeV}$

Quantity

Proton Penetration

Proton Backscatter

Neutron Penetration

Neutron Backscatter

Proton Flux

Neutron Flux

Proton Heating

Neutron Heating

Total Heating

1 to $200 \mathrm{MeV}$

Quantity

Proton Penetration

Proton Backscatter

Neutron Penetration

Neutron Backscatter

Proton Flux

Neutron Flux

Proton Heating

Neutron Heating

Total Heating

*Unconverged.

$\begin{array}{cccc}\text { Data Table } & \text { NoW180 } & \text { CEM2k } & \text { Model } \\ 1.5000 \mathrm{E}-05^{*} & 1.5000 \mathrm{E}-05^{*} & 1.0000 \mathrm{E}-05^{*} & 1.0000 \mathrm{E}-05^{*} \\ 1.5400 \mathrm{E}-03 & 1.5500 \mathrm{E}-03 & 7.9400 \mathrm{E}-04^{*} & 1.5300 \mathrm{E}-03 \\ 6.7376 \mathrm{E}-03 & 6.5435 \mathrm{E}-03 & 4.2100 \mathrm{E}-03 & 9.8350 \mathrm{E}-03 \\ 6.4091 \mathrm{E}-01 & 6.4052 \mathrm{E}-01 & 4.6088 \mathrm{E}-01 & 6.5053 \mathrm{E}-01 \\ 1.5120 \mathrm{E}-03 & 1.5120 \mathrm{E}-03 & 1.5022 \mathrm{E}-03 & 1.5054 \mathrm{E}-03 \\ 7.3386 \mathrm{E}-03 & 7.3245 \mathrm{E}-03 & 4.4633 \mathrm{E}-03 & 7.5520 \mathrm{E}-03 \\ 5.9487 \mathrm{E}-03 & 5.9484 \mathrm{E}-03 & 5.8872 \mathrm{E}-03 & 5.8968 \mathrm{E}-03 \\ 4.9915 \mathrm{E}-06 & 5.0039 \mathrm{E}-06 & 4.0502 \mathrm{E}-06 & 1.9285 \mathrm{E}-06 \\ 5.9536 \mathrm{E}-03 & 5.9534 \mathrm{E}-03 & 5.8912 \mathrm{E}-03 & 5.8988 \mathrm{E}-03\end{array}$

Data Table

NoW180

CEM2k

Model

0.0000E-00* 5.0000E-06*

$5.0000 \mathrm{E}-06^{*}$

$1.5000 \mathrm{E}-05^{*}$

$1.5100 \mathrm{E}-03$

$1.5050 \mathrm{E}-03$

$8.1000 \mathrm{E}-04 *$

$1.5050 \mathrm{E}-03$

3.3498E-03

$3.2566 \mathrm{E}-03$

$2.6600 \mathrm{E}-03$

3.9250E-03

3.0590E-01

3.0604E-01

2.7196E-01

2.6414E-01

$1.5116 \mathrm{E}-03$

$1.5117 \mathrm{E}-03$

1.5019E-03

$1.5050 \mathrm{E}-03$

3.0868E-03

3.0876E-03

2.6837E-03

2.7537E-03

5.9487E-03

5.9167E-03

5.8871E-03

5.8963E-03

4.7211E-06

4.7211E-06

4.1821E-06

1.9255E-06

5.9534E-03

5.9214E-03

5.8982E-03 
Below $1 \mathrm{MeV}$, the neutron physics model results are unreliable and disagree with the neutron data table results. Comparing the 0 - to $200-\mathrm{MeV}$ results to the $1-$ to $200-\mathrm{MeV}$ results shows that half of the neutron penetration, neutron backscatter, and neutron flux is $<1 \mathrm{MeV}$. Consequently, the neutron physics models disagree with the data table results by as much as a factor of 3 over the $0-$ to $1-\mathrm{MeV}$ energy range. Above $1 \mathrm{MeV}$, the agreement between physics models and data tables is much better, to within $\sim 10 \%$ for penetration, backscatter, and flux. One reason why the neutron physics model results do not agree better with the neutron data table results is that the small differences between the proton physics models and data tables can result in differences in the neutron production, thus degrading the comparison of neutron physics models and data tables. The default physics model neutron heating is significantly lower than the neutron data table heating because the data table heating numbers include all of the progeny particle heating and the model neutron heating does not.

\section{CARBON COMPARISON}

Carbon is an important material for proton beamstops and other applications.

Comparisons are made for neutrons and protons for a $200-\mathrm{MeV}$ monodirectional source impinges on a 100-cm-thick slab of $2.267 \mathrm{~g} / \mathrm{cm}^{3}$ carbon (graphite). Neutron and proton penetration, backscatter, flux, and heating are compared. The calculations are the following:

- Data tables for $150 \mathrm{MeV}$ are used for mixing natural carbon for neutrons and ${ }^{12} \mathrm{C}$ for protons.

- Data tables use the ENDF/B-V ${ }^{12} \mathrm{C}$ for neutrons and LA150 ${ }^{12} \mathrm{C}$ for protons. Before mix and match, natural carbon could not be mixed with isotopic ${ }^{12} \mathrm{C}$. The only available $150-\mathrm{MeV}$ libraries, the LA150 libraries, ${ }^{18}$ have ENDF/ $\mathrm{B}-\mathrm{VI}$ natural carbon for neutrons and isotopic carbon for protons. To have isotopic carbon for neutrons, the old ENDF/B-V evaluation must be used, which goes up to only $20 \mathrm{MeV}$.

- CEM2k physics models are used for neutrons and photons.

- Default physics models are used for neutrons and photons.

The results are displayed in Figs. 44 to 51 . 


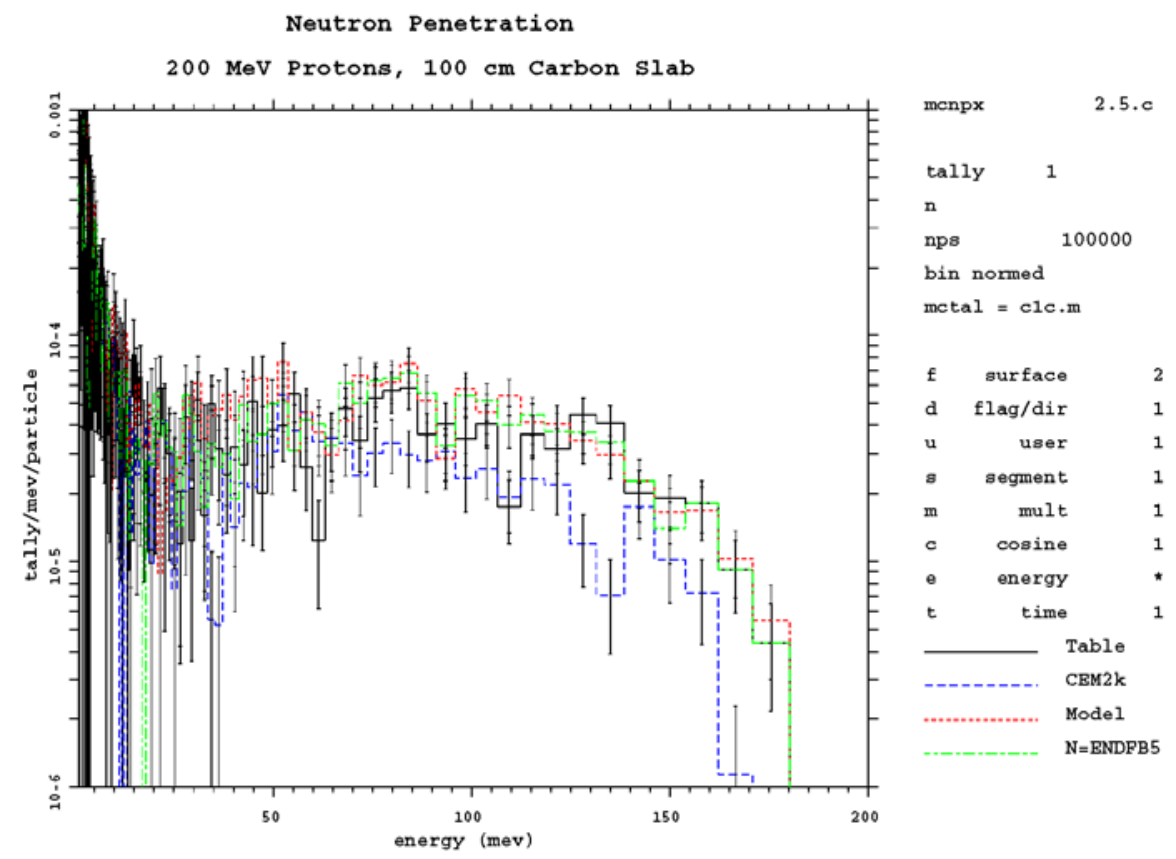

Fig. 44. Carbon neutron penetration from 200-MeV protons, table vs model.

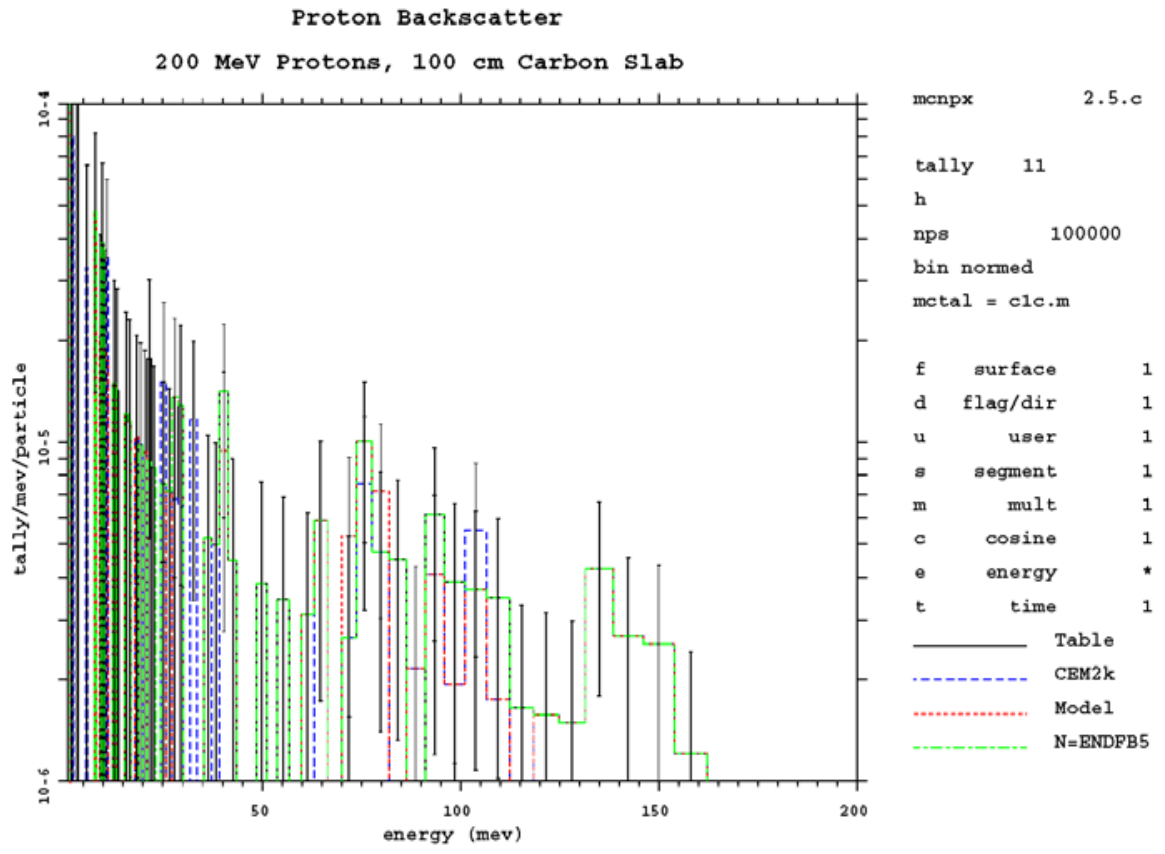

Fig. 45. Carbon proton backscatter from 200-MeV protons, table vs model. 


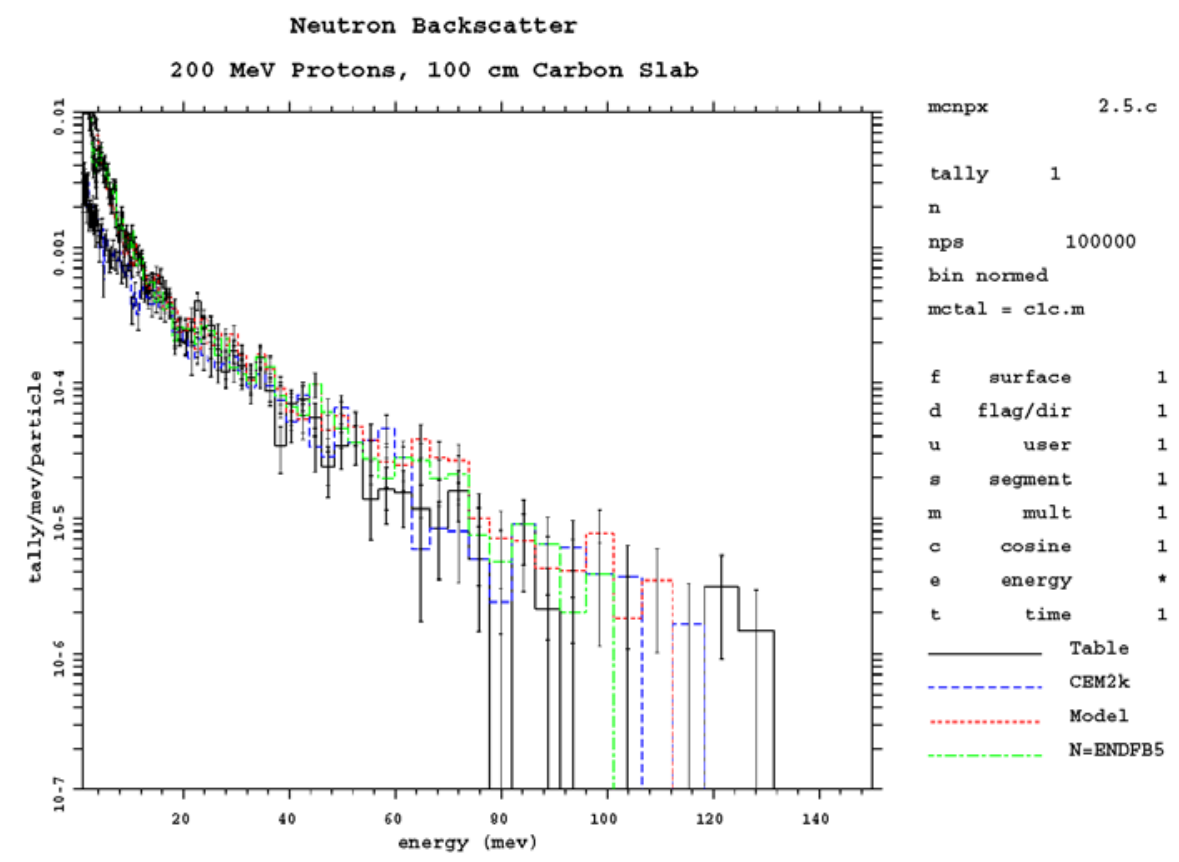

Fig. 46. Carbon neutron backscatter from 200-MeV protons, table vs model.

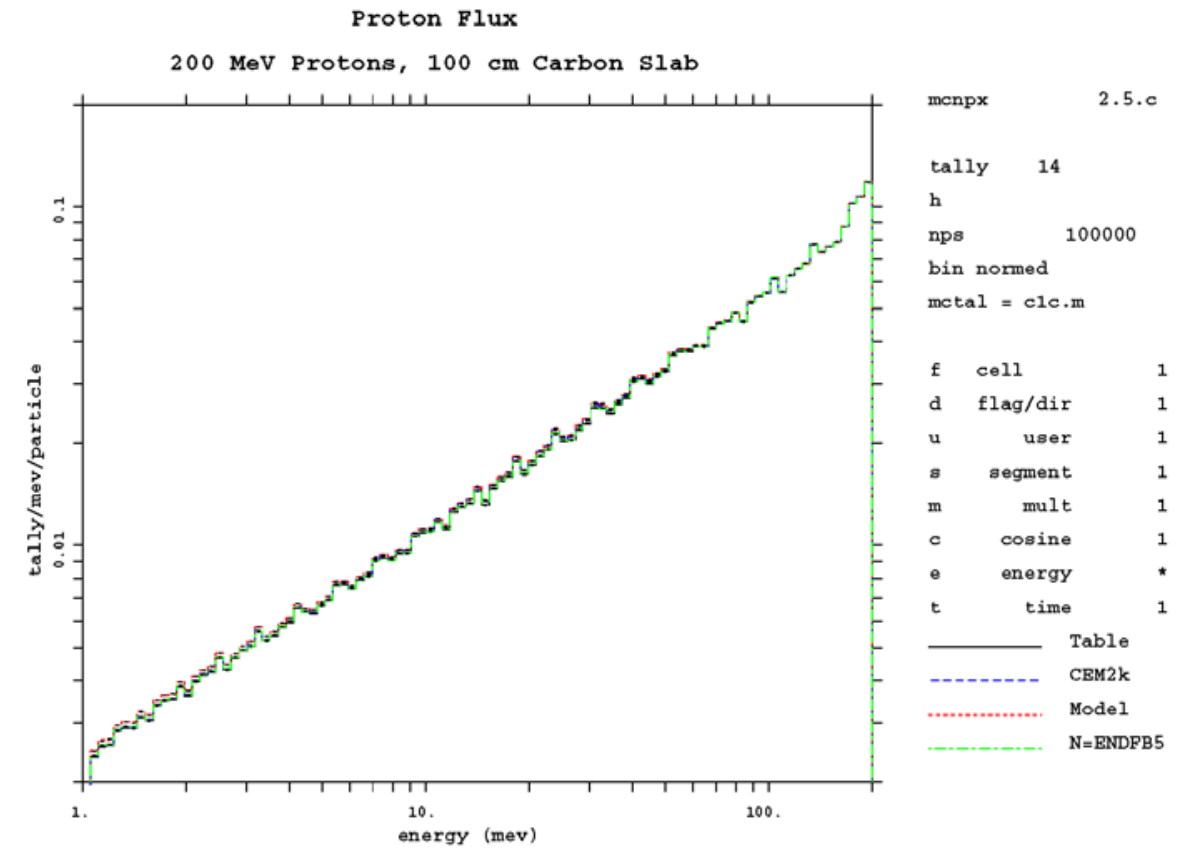

Fig. 47. Carbon proton flux from 200-MeV protons, table vs model. 


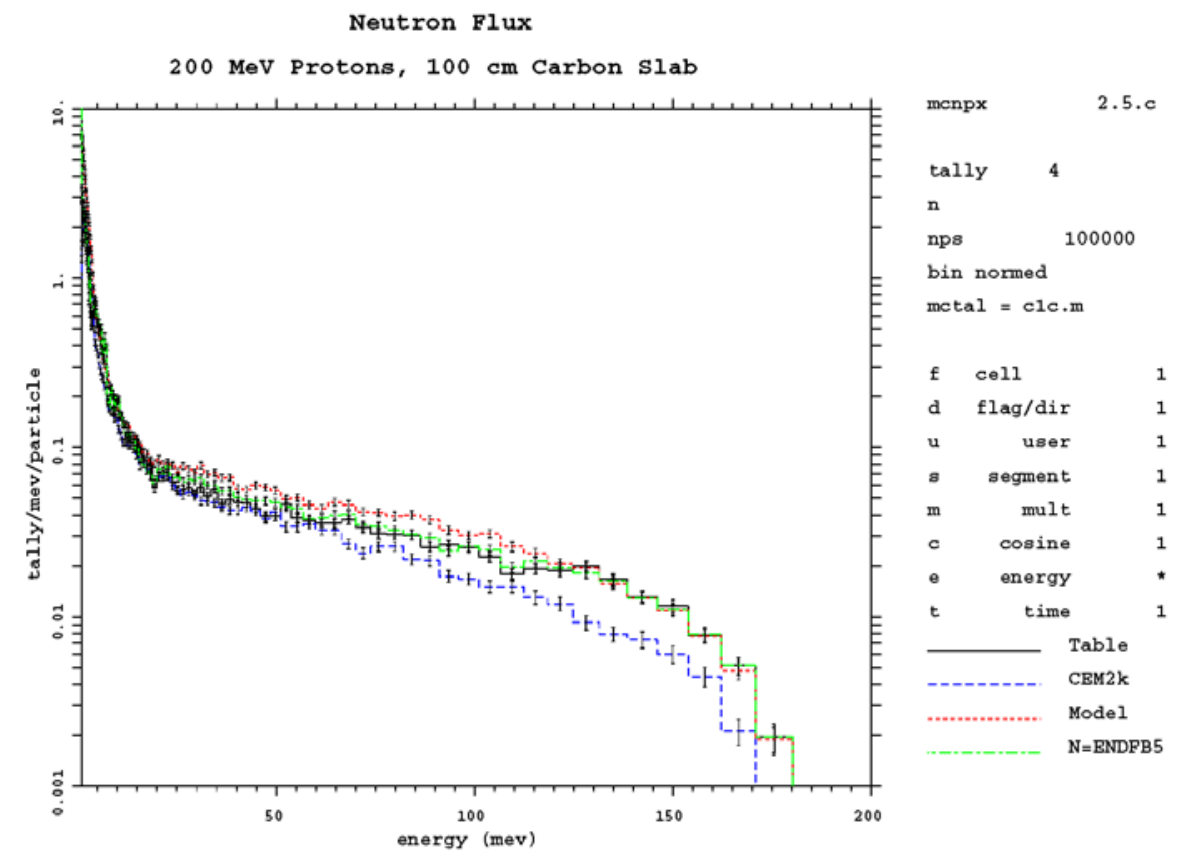

Fig. 48. Carbon neutron flux from 200-MeV protons, table vs model.

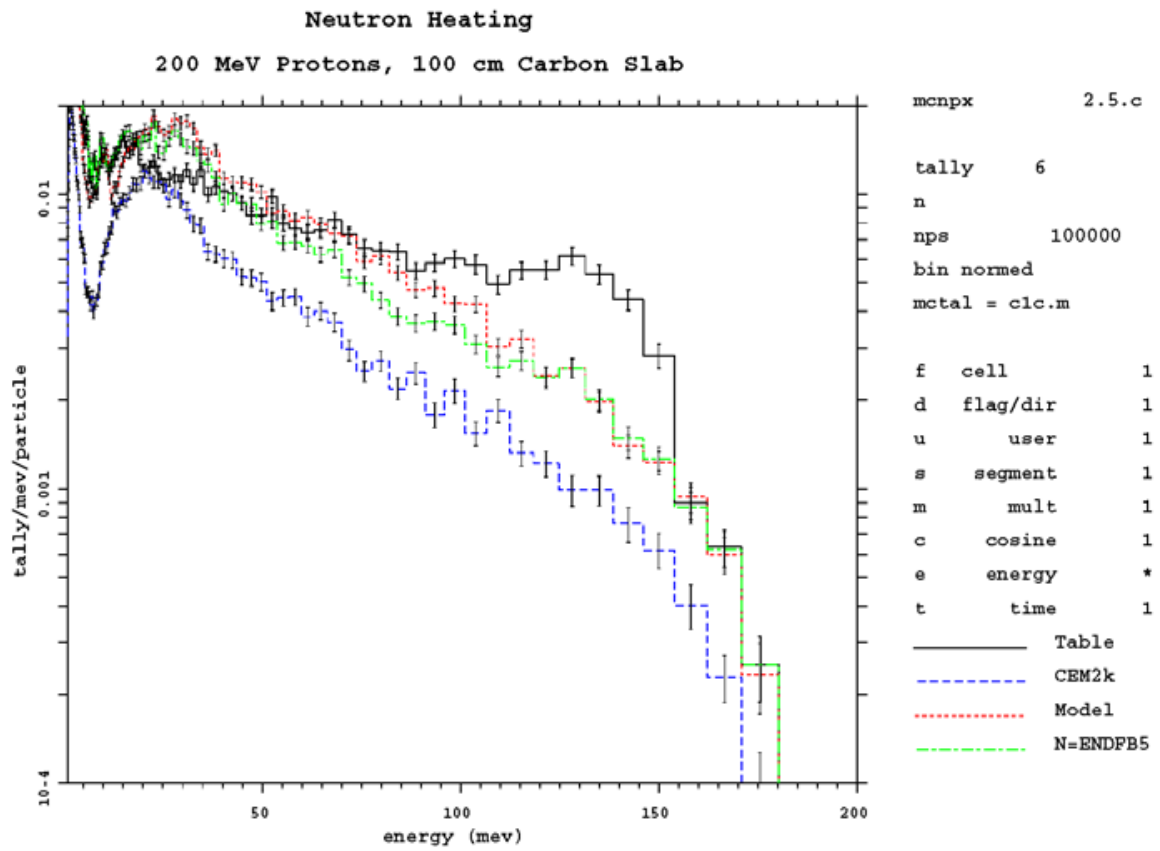

Fig. 49. Carbon neutron heating from 200-MeV protons, table vs model. 


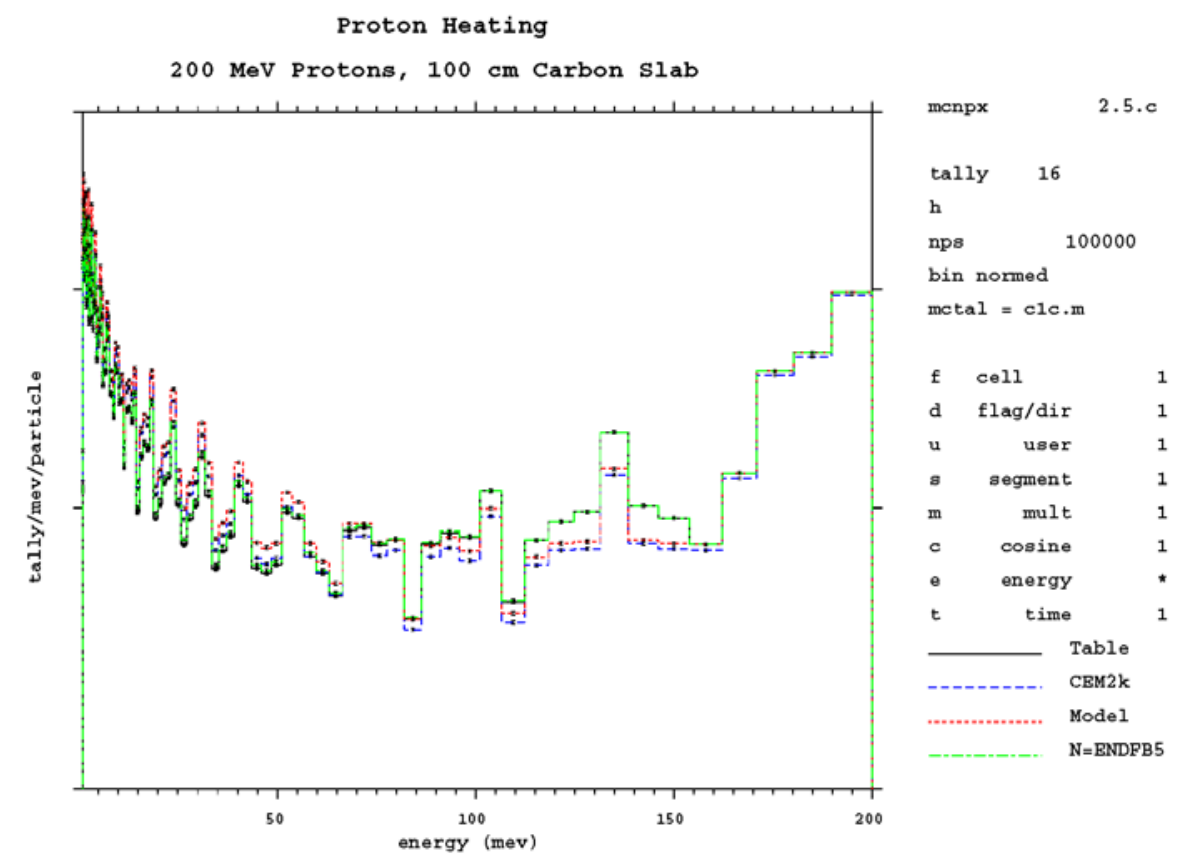

Fig. 50. Carbon proton heating from 200-MeV protons, table vs model.

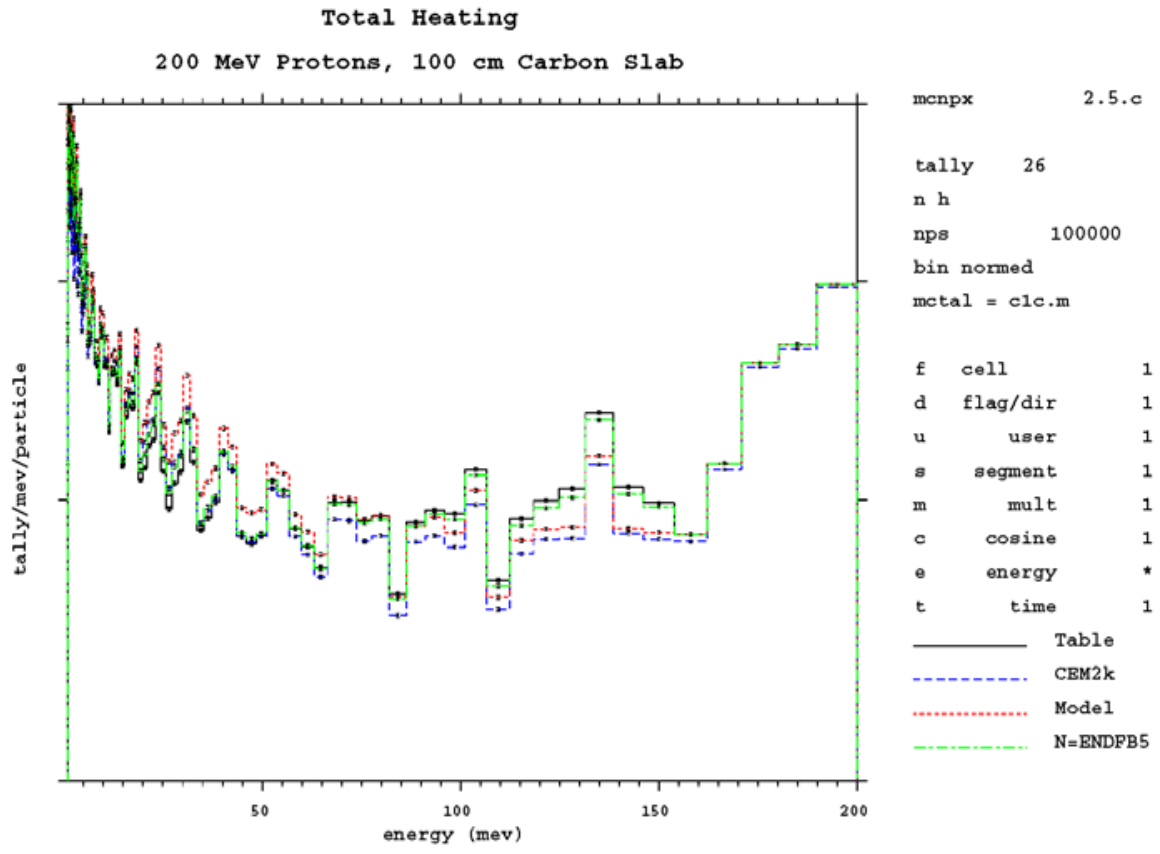

Fig. 51. Carbon total heating from 200-MeV protons, table vs model. 
The integral tabular results from 0 to $200 \mathrm{MeV}$ are presented in Table 9. All results are converged to $<1 \%$ relative error, except for the proton penetration and backscatter, which are not converged because carbon absorbs protons very well.

The carbon slab comparisons illustrate the ability to mix different nuclides, specifically natural carbon for neutrons and ${ }^{12} \mathrm{C}$ for protons, so that $150-\mathrm{MeV}$ libraries can be used for both neutrons and protons.

Proton models agree excellently with the proton tabulated data in the LA150 library, even for this low-Z material. Proton models may be used with confidence for nuclides where data tables are unavailable.

The total heating is essentially the proton heating. In the neutron heating plot, Fig. 49, the "ENDFB5" results agree with the "Model" results better than with the "Table" results. This is because in the 20 - to $150-\mathrm{MeV}$ range, the neutron default physics model is used for both "ENDFB5" and "Model" and only "Table" uses neutron data tables. In other plots, the "ENDFB5" results agree better with the "Table" results in the 20- to $150-\mathrm{MeV}$ range because both use data tables for protons in this range.

The differences in the neutron penetration, backscatter, flux, and heating in Table 9 occur for several reasons. The proton transport is somewhat different for the data table and physics model calculations, and the subsequent differences in neutron production can make the neutron calculations different. Most of the neutron penetration, backscatter, and flux are from neutrons below $1 \mathrm{MeV}$, where the models are known to be unreliable. Table 10 shows the results for $20-\mathrm{MeV}$ neutrons impinging on a $10-\mathrm{cm}$-thick carbon slab with a $1-\mathrm{MeV}$ energy cutoff. The neutron default physics model agrees with the data table penetration and backscatter to within $30 \%$, and the flux and heating agree within $15 \%$.

Table 9

200-MeV Protons Impinging on 100-cm-Thick Carbon Slab: 0 to $200 \mathrm{MeV}$

\begin{tabular}{lcccc}
\multicolumn{1}{c}{ Quantity } & Data Table & N=ENDF5 & CEM2k & Model \\
Proton Penetration & $2.9994 \mathrm{E}-05^{*}$ & $6.0000 \mathrm{E}-05^{*}$ & $4.0000 \mathrm{E}-05^{*}$ & $7.0000 \mathrm{E}-05^{*}$ \\
Proton Backscatter & $5.9000 \mathrm{E}-04$ & $5.9000 \mathrm{E}-04$ & $3.9000 \mathrm{E}-04 *$ & $5.4000 \mathrm{E}-04$ \\
Neutron Penetration & $3.0052 \mathrm{E}-02$ & $3.6079 \mathrm{E}-02$ & $9.0900 \mathrm{E}-03$ & $3.5150 \mathrm{E}-02$ \\
Neutron Backscatter & $1.4915 \mathrm{E}-01$ & $1.6572 \mathrm{E}-01$ & $2.1520 \mathrm{E}-02$ & $1.5253 \mathrm{E}-01$ \\
Proton Flux & $1.1516 \mathrm{E}+01$ & $1.1525 \mathrm{E}+01$ & $1.1532 \mathrm{E}+01$ & $1.1564 \mathrm{E}+01$ \\
Neutron Flux & $1.4309 \mathrm{E}+02$ & $1.6859 \mathrm{E}+02$ & $1.1397 \mathrm{E}+01$ & $5.8180 \mathrm{E}+01$ \\
Proton Heating & $8.1770 \mathrm{E}+01$ & $8.1902 \mathrm{E}+01$ & $8.1747 \mathrm{E}+01$ & $8.2505 \mathrm{E}+01$ \\
Neutron Heating & $1.3508 \mathrm{E}+00$ & $1.2148 \mathrm{E}+00$ & $6.2820 \mathrm{E}-01$ & $1.2773 \mathrm{E}+00$ \\
Total Heating & $8.3121 \mathrm{E}+01$ & $8.3116 \mathrm{E}+01$ & $8.2375 \mathrm{E}+01$ & $8.3782 \mathrm{E}+01$ \\
*Unconverged. & & & &
\end{tabular}


Table 10

20-MeV Neutrons Impinging on 10-cm-Thick Carbon Slab: 1 to $20 \mathrm{MeV}$

\begin{tabular}{lccc}
\multicolumn{1}{c}{ Quantity } & Data Table & CEM2k & Model \\
Neutron Penetration & $6.2304 \mathrm{E}-01$ & $7.6540 \mathrm{E}-01$ & $7.4447 \mathrm{E}-01$ \\
Neutron Backscatter & $1.2405 \mathrm{E}-01$ & $4.4490 \mathrm{E}-02$ & $1.6191 \mathrm{E}-01$ \\
Neutron Flux & $1.2499 \mathrm{E}+01$ & $1.1424 \mathrm{E}+01$ & $1.3988 \mathrm{E}+01$ \\
Neutron Heating & $2.0572 \mathrm{E}+00$ & $1.4415 \mathrm{E}+00$ & $1.7758 \mathrm{E}+00$
\end{tabular}

Table 11 shows the results for $20-\mathrm{MeV}$ neutrons impinging on a 10 -cm-thick carbon slab with an $8-\mathrm{MeV}$ energy cutoff. Other than backscatter, the default physics model results are within $2 \%$ to $12 \%$ of the data table results and the CEM $2 \mathrm{k}$ results are $4 \%$ to $25 \%$.

\section{SUMMARY}

The MCNPX mix-and-match capability makes it possible to substitute physics models for data tables at will. The ability to intermingle data tables and models is especially valuable for proton and photonuclear physics, where the models are best. Previously, either all physics models or all data tables for proton and photonuclear physics had to be used. Now data tables can be used whenever they are available. Further, if elements are required for one particle type, such as $6000.24 \mathrm{c}$ for neutrons, isotopic data may be used for another data type, such as $6012.24 \mathrm{~h}$, by nuclide substitution. Previously, 6000.24c and $6012.24 \mathrm{~h}$ could not be used in the same calculation; frequently, the best choice was to totally ignore the proton table data and use proton physics models exclusively. For photonuclear calculations, only a limited set of nuclides was available previously and models could not be used at all.

The ability to intermingle data tables and models for neutrons enables the use of models for nuclides where no data tables are available. The neutron models are not as good as the neutron data tables, particularly at low energies and for low- $Z$ materials. Below $1 \mathrm{MeV}$, they are unreliable. From 1 to $8 \mathrm{MeV}$, the CEM2k model is known to be unreliable and the default model is poor. Integral results from 1 to $20 \mathrm{MeV}$ and from 8 to $20 \mathrm{MeV}$ show the disagreement between physics models and data tables to be $\sim 10 \%$ to $20 \%$, and plots show differences of a factor of 2 to 10 at specific energies. Above $20 \mathrm{MeV}$, the physics models are good, although data tables should be used whenever available.

The mix-and-match capability also enables full utilization of neutron data tables with different upper-energy bounds. (Currently, all photonuclear and proton data libraries have the same 150-MeV upper-energy bound.) The matching of energies eliminates the need to ignore table data above $20 \mathrm{MeV}$ in some problems and to extrapolate the $20-\mathrm{MeV}$ data all the way up to $150 \mathrm{MeV}$ in other problems.

The MCNPX mix-and-match capability is clearly a significant step forward for a wide variety of important applications. 
Table 11

20-MeV Neutrons Impinging on 10-cm-Thick Carbon Slab: 8 to $20 \mathrm{MeV}$

\begin{tabular}{lccc}
\multicolumn{1}{c}{ Quantity } & Data Table & CEM2k & Model \\
Neutron Penetration & $5.2888 \mathrm{E}-01$ & $5.6228 \mathrm{E}-01$ & $5.6530 \mathrm{E}-01$ \\
Neutron Backscatter & $3.5856 \mathrm{E}-02$ & $1.6740 \mathrm{E}-02$ & $2.1660 \mathrm{E}-02$ \\
Neutron Flux & $9.3482 \mathrm{E}+00$ & $9.0042 \mathrm{E}+00$ & $9.1407 \mathrm{E}+00$ \\
Neutron Heating & $1.9541 \mathrm{E}+00$ & $1.4201 \mathrm{E}+00$ & $1.7056 \mathrm{E}+00$
\end{tabular}




\section{APPENDIX \\ MCNPX Input Files}

\section{BGO Crystal Response}

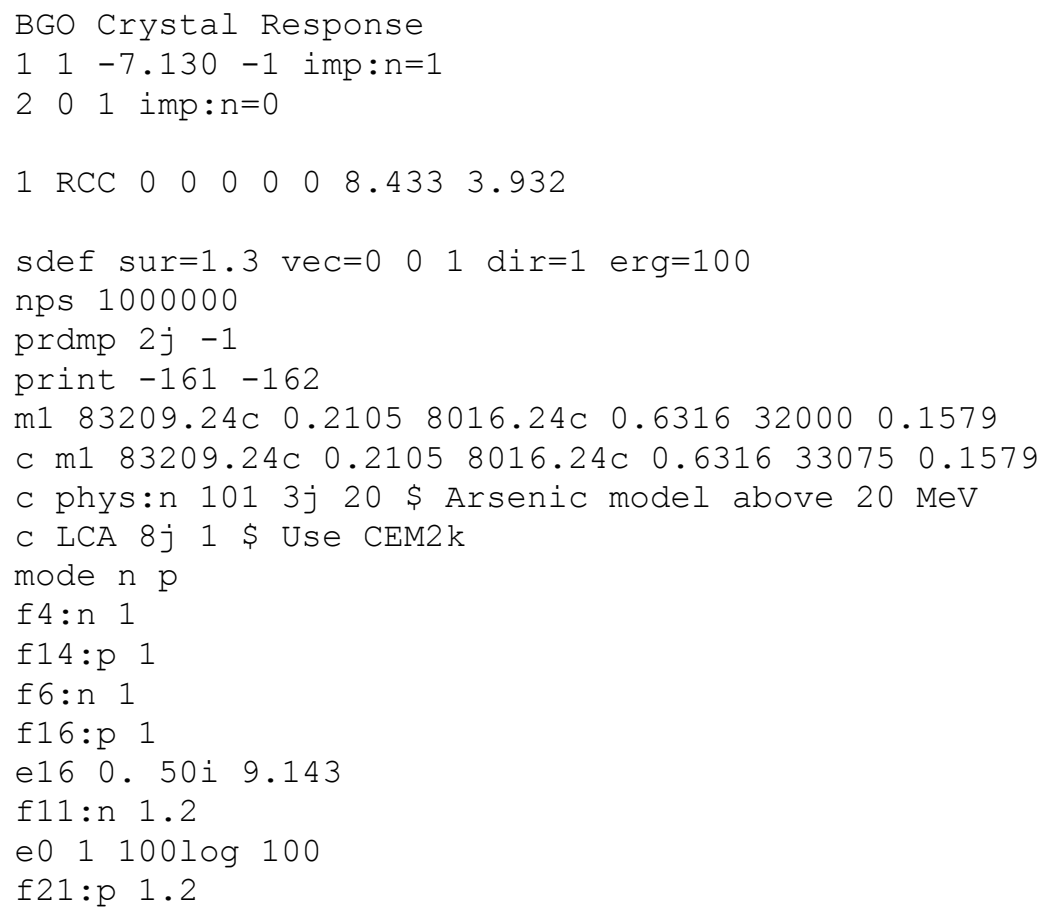

\section{Arsenic Crystal: Data Table vs Models}

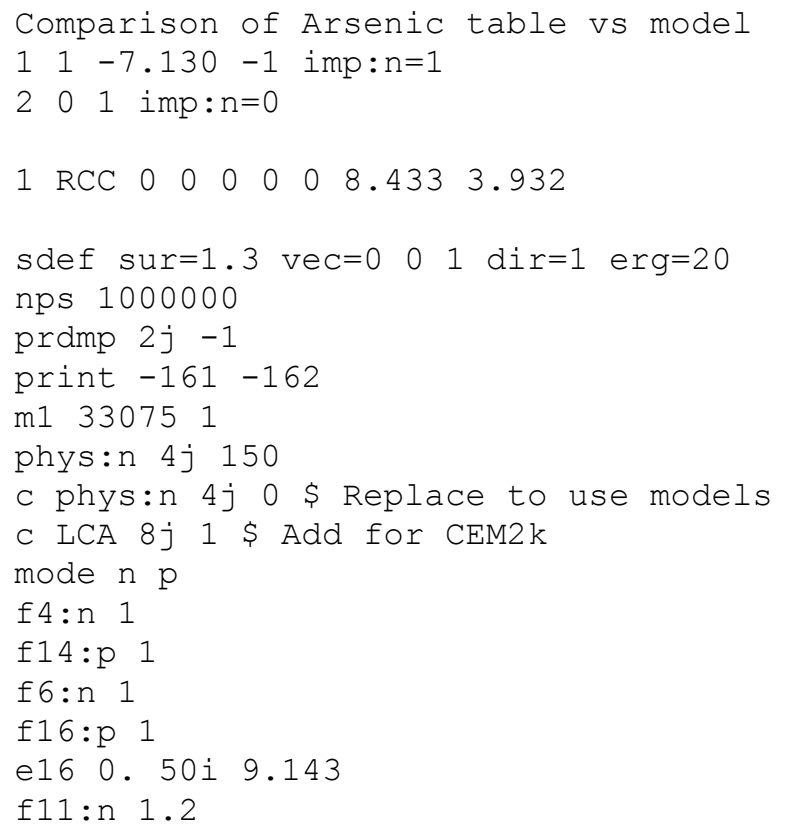


e0 $1100 \log 100$

f21:p 1.2

\section{Water Sphere}

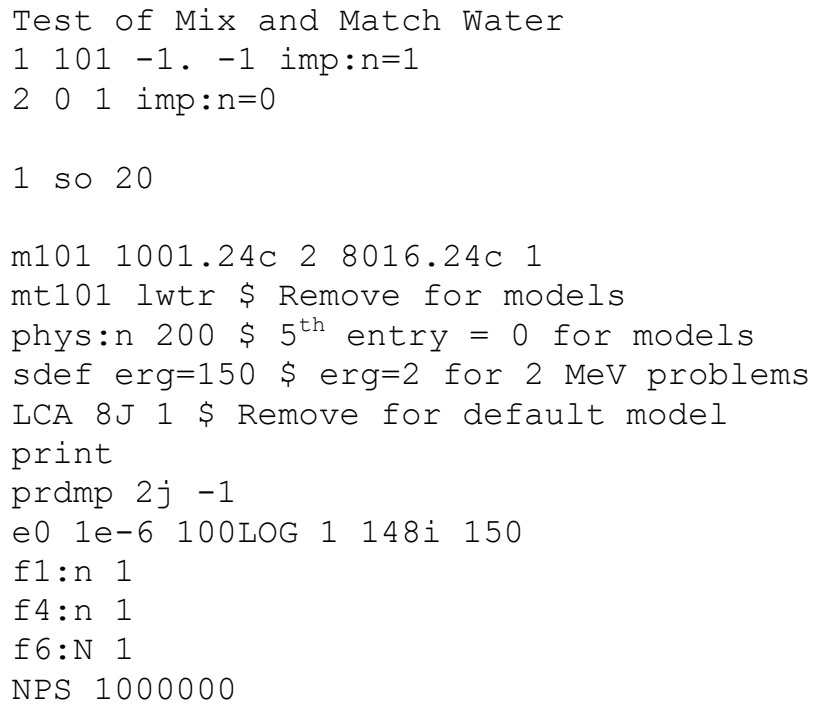

\section{Stainless-Steel Slab}

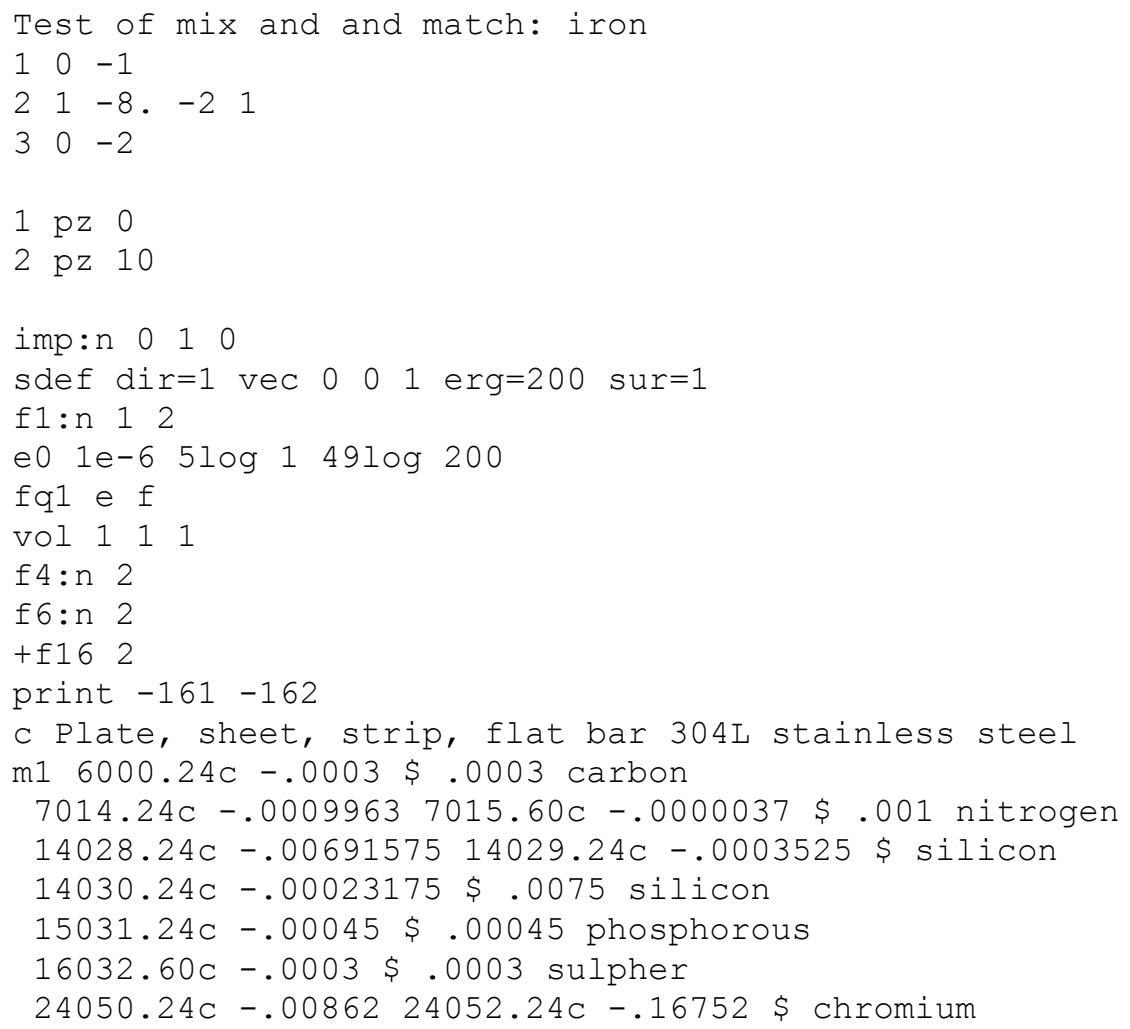




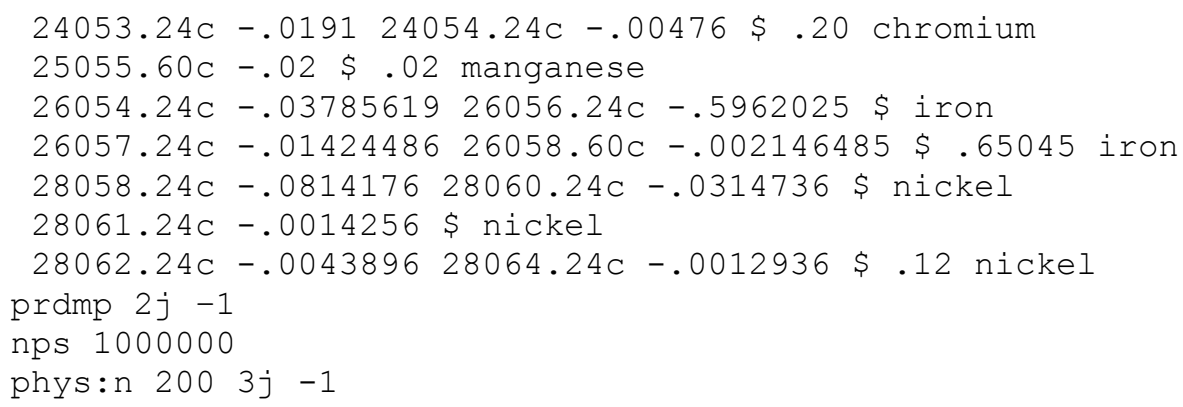

\section{Tungsten Can}

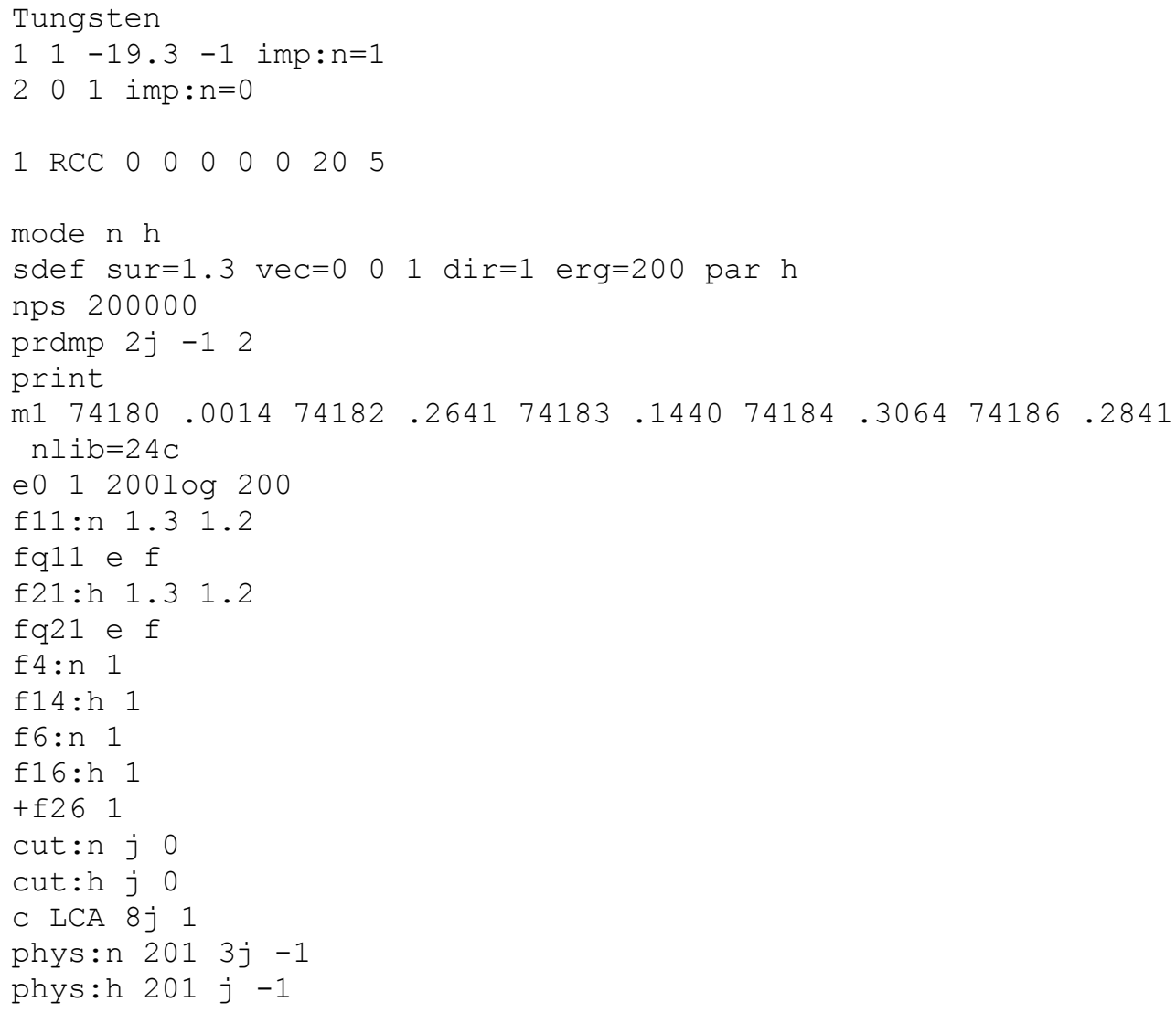

\section{0-cm-Thick Carbon Slab}

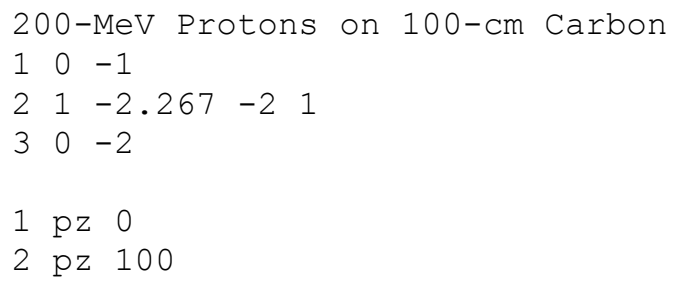




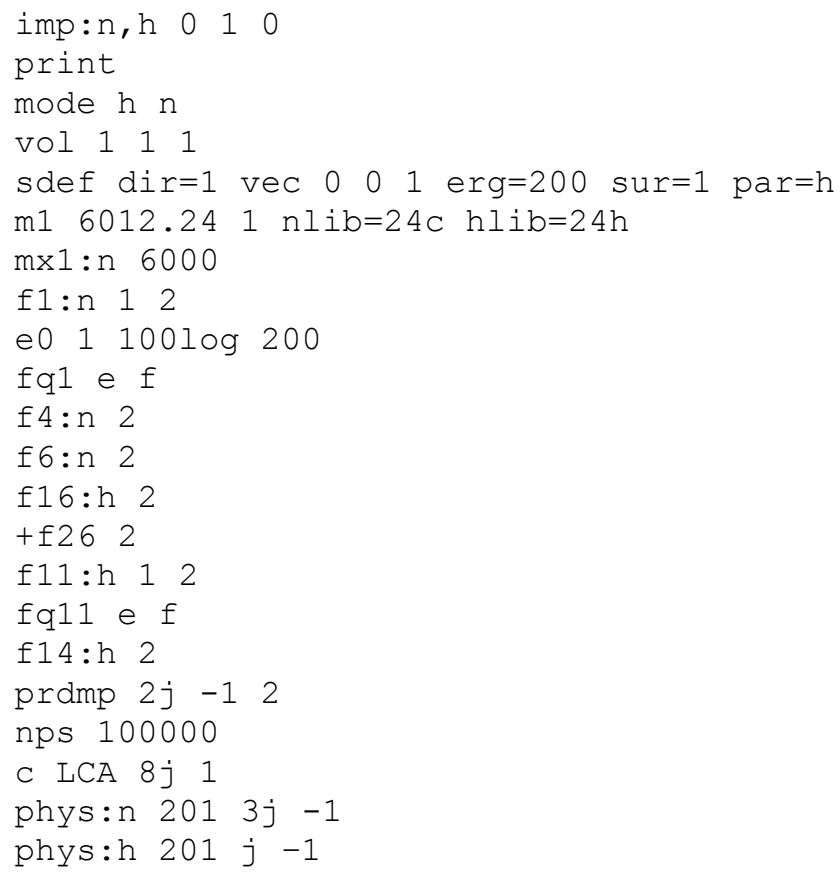

\section{0-cm-Thick Carbon Slab}

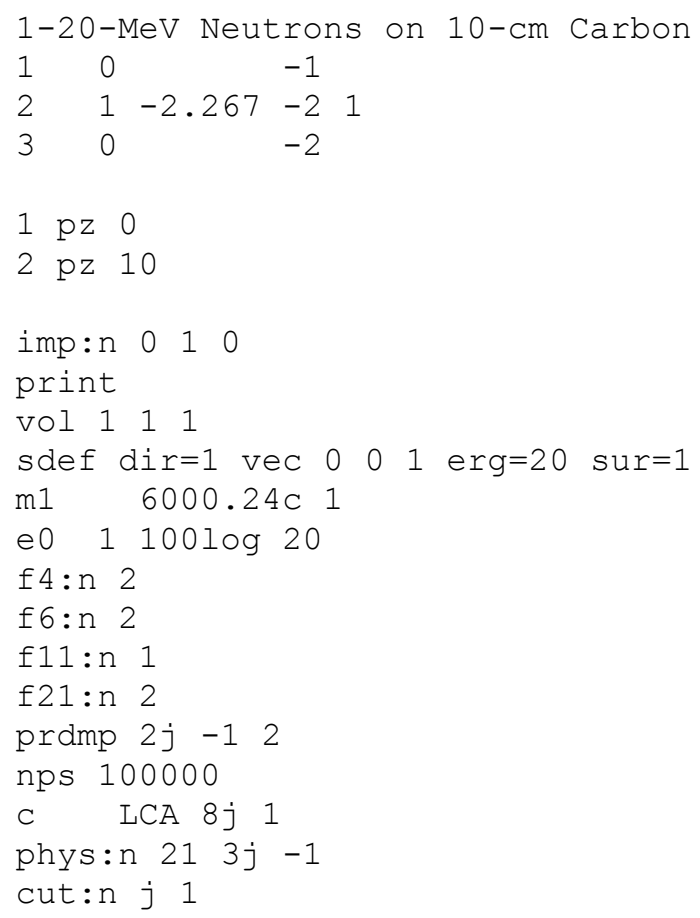




\section{REFERENCES}

1. MCNPX home page: http://menpx.lanl.gov.

2. J. F. Briesmeister, ed., "MCNP-A General Monte Carlo N-Particle Transport Code-Version 4C," Los Alamos National Laboratory report LA-13709-M (March 2000).

3. Laurie S. Waters, ed., "MCNPX User's Manual, Version 2.3.0," Los Alamos National Laboratory report LA-UR-02-2607 (April 2002).

4. Radiation Safety Information Computational Center, http://www-rsicc.ornl.gov/ rsicc. html.

5. Morgan C. White, "Development and Implementation of Photonuclear CrossSection Data for Mutually Coupled Neutron-Photon Transport Calculations in the Monte Carlo N-Particle (MCNP) Radiation Transport Code," Los Alamos National Laboratory report LA-13744-T (July 2000).

6. J. F. Briesmeister, ed., "MCNP-A General Monte Carlo N-Particle Transport Code-Version 4B," Los Alamos National Laboratory report LA-12625-M (March 1997).

7. J. F. Briesmeister, ed., "MCNP-A General Monte Carlo N-Particle Transport Code-Version 4C," Los Alamos National Laboratory report LA-13709-M (April 2000).

8. J. S. Hendricks, "Advances in MCNP4C," Los Alamos National Laboratory report LA-UR-00-2643 (2000).

9. John S. Hendricks, "MCNP4C2," Los Alamos National Laboratory report LA-UR01-858 (January 30, 2001).

10. John S. Hendricks, "MCNP4C3," Los Alamos National Laboratory report LA-UR01-2244 (April 13, 2001).

11. J. A. Halbleib, R. P. Kensek, T. A. Mehlhorn, G. D. Valdez, S. M. Seltzer, and M. J. Berger, "ITS Version 3.0: The Integrated TIGER Series of Coupled Electron/Photon Monte Carlo Transport Codes," Sandia National Laboratories report SAND91-1634 (March 1992).

12. J. S. Hendricks, G. W. McKinney, L. S. Waters, H. G. Hughes, E. C. Snow, "New MCNPX Developments," Los Alamos National Laboratory report LA-UR-02-2181 (2002). 
13. Laurie S. Waters, ed., "MCNPX User's Manual Version 2.4.0," Los Alamos National Laboratory report LA-CP-02-408 (September 2002).

14. MCNPX Team, "MCNPX, Version 2.4.0 Features Summary," Los Alamos National Laboratory report LA-UR-02-5253 (August 2002).

15. John S. Hendricks and the MCNPX Team, "MCNPX, Version 2.5.b," Los Alamos National Laboratory report LA-UR-02-7086 (November 2002).

16. Stepan G. Mashnik and Arnold J. Sierk, "Improved Cascade Exciton Model of Nuclear Reactions," Proceedings of the Fourth Workshop on Simulating Accelerator Radiation Environments (SARE4), Knoxville, TN, September 14-16, 1998, T. A. Gabriel, ed., Oak Ridge National Laboratory, pp. 29-51 (1999).

17. Stepan G. Mashnik and Arnold J. Sierk, "Recent Developments of the CascadeExciton Model of Nuclear Reactions," Los Alamos National Laboratory report LAUR-01-5390 (2001).

18. M. B. Chadwick, P. G. Young, S. Chiba, S. C. Frankle, G. M. Hale, H. G. Hughes, A. J. Koning, R. C. Little, R. E. MacFarlane, R. E. Prael, and L. S. Waters, "Cross Section Evaluations to $150 \mathrm{MeV}$ for Accelerator-Driven Systems and Implementation in MCNPX," Los Alamos National Laboratory report LA-UR-981825 (1998). 
This report has been reproduced directly from the best available copy. It is available electronically on the Web (http://www.doe.gov/bridge).

Copies are available for sale to U.S. Department of Energy employees and contractors from:

Office of Scientific and Technical Information P.O. Box 62

Oak Ridge, TN 37831

(865) 576-8401

Copies are available for sale to the public from: National Technical Information Service

U.S. Department of Commerce

5285 Port Royal Road

Springfield, VA 22616

(800) 553-6847 
